\title{
Metodologia para a Análise de Impacto em Sistemas Elásticos usando-se o Método dos Elementos Finitos e a Integração Explícita no Tempo
}

Alexandre Tácito Malavolta

Dissertação apresentada à Escola de Engenharia de São Carlos da Universidade de São Paulo, como parte dos requisitos para obtenção do título de Mestre em Engenharia Mecânica

Orientador: Prof. Dr. João Lirani 
Aos meus pais, Américo e Irene e à minha irmã, Marília. 
Agradeço:

Ao Professor João Lirani, pela dedicação, orientação e amizade.

Ao Prof. Hazin, Prof. Daros e aos amigos Giovanni, Mariano e Toddy pelas discussões e sugestões.

Aos demais colegas do Laboratório de Compósitos e Laboratório de Dinâmica.

À todos meus amigos: Cotonete, Darta, Fidélis, Frank, Gaúcho, Gordo, Mocinha, Nalha, Sam, Tio, TG, Véio entre tantos outros, pela eterna amizade.

Às secretárias Ana Paula e Merilin pelo auxílio nas questões burocráticas.

Ao CNPq, Conselho Nacional de Desenvolvimento Científico e Tecnológico, pela bolsa de estudo sem a qual seria impossível a realização deste trabalho.

À minha futura esposa Fernanda e ao meu futuro filho Gabriel. 


\section{Sumário}

Lista de Figuras $\quad$ v

Lista de Tabelas $\quad$ x

Lista de Abreviaturas e Siglas xi

Lista de Símbolos xii

Resumo xiv

$\begin{array}{ll}\text { Abstract } & \text { Xv }\end{array}$

1 Introdução 1

1.1 Escopo do estudo . . . . . . . . . . . . . . . . . . 1

1.2 Conteúdo da dissertação . . . . . . . . . . . . . . . . . . 4

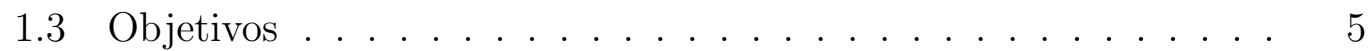

2 Propagação de Ondas $\quad 6$

2.1 Introdução . . . . . . . . . . . . . . . . . 6

2.2 Propagação de Ondas Elásticas em Meios Sólidos Infinitos . . . . 7

2.2.1 Ondas de Dilatação e Ondas de Distorção . . . . . . . . . 9

2.2.2 Ondas Planas . . . . . . . . . . . . . . . . . . 11

2.2.3 Ondas de Superfície . . . . . . . . . . . . . . 12

2.3 Propagação de Ondas Elásticas em Meios Sólidos Finitos . . . . . 13

3 Impacto $\quad 27$

3.1 Introdução . . . . . . . . . . . . . . . . . . . . . . . . . . 27

3.2 Impacto Longitudinal em Vigas . . . . . . . . . . . . . . . . . 28

3.2.1 Método da energia para o impacto longitudinal em vigas . 28 
3.2.2 Método da propagação de ondas para o impacto longitudinal em vigas . . . . . . . . . . . . . . . . . . . 29

3.3 Impacto Flexional em Vigas . . . . . . . . . . . . . . . . . . 31

3.3.1 Método da energia para o impacto flexional em vigas . . . 31

3.3.2 Método da propagação de ondas para o impacto flexional em vigas . . . . . . . . . . . . . . . 33

3.4 Impacto Torcional em Vigas . . . . . . . . . . . . . . . . . . 37

3.4.1 Método da energia para o impacto torcional em vigas . . 37

3.4.2 Método da propagação de ondas para o impacto torcional em vigas . . . . . . . . . . . . . . . . . 38

$4 \quad$ MEF aplicado à Dinâmica não-Linear 39

4.1 Introdução . . . . . . . . . . . . . . . . . . . . . . . . . 39

4.2 Análise Dinâmica de Sistemas Lineares: integração no tempo . . 41

4.2.1 Método da Integração Implícita no Tempo . . . . . . . . . 42

4.2 .2 Método da Integração Explícita no Tempo . . . . . . . . . 43

4.3 Análise Dinâmica de Sistemas não-Lineares . . . . . . . . . . . 45

4.3 .1 Contato . . . . . . . . . . . . . . . . . 46

4.3.2 Solução de Problemas não-lineares . . . . . . . . . . . . 52

5 Modelagem de Impacto em Vigas 56

5.1 Introdução . . . . . . . . . . . . . . . . 56

5.2 Detalhes das modelagens de impacto em vigas . . . . . . . . . 56

5.3 Modelagem de Impacto Longitudinal . . . . . . . . . . . . . . 60

5.4 Modelagem de Impacto Transversal . . . . . . . . . . . . . . 66

5.5 Modelagem de Impacto Torcional . . . . . . . . . . . . . . . . 72

6 Metodologia para Análise de Impacto 78

6.1 Introdução . . . . . . . . . . . . . . . . . 78

6.2 Metodologia . . . . . . . . . . . . . . . . . . . 79

6.3 Exemplo de Aplicação (1): Suporte . . . . . . . . . . . . . . . . 81

6.4 Exemplo de Aplicação (2): Eixo chavetado . . . . . . . . . . . . . 91

$\begin{array}{lll}7 & \text { Conclusões } & 103\end{array}$

8 Referências Bibliográficas 105 


\section{Lista de Figuras}

FIGURA 1.1 Modelagem da queda de um container, APARICIO SAN-

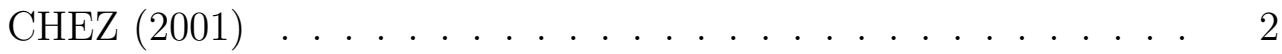

FIGURA 2.1 Coordenadas cartesianas $\ldots \ldots \ldots \ldots \ldots$

FIGURA 2.2 Coordenadas cilíndricas $\ldots \ldots \ldots \ldots \ldots$

FIGURA 2.3 Direção do movimento das partículas para onda dilatacional (a) e transversal (b) (GRAFF (1975)) . . . . . . . . . 12

FIGURA 2.4 Coordenadas para o cilíndro sólido . . . . . . . . . . 14

FIGURA 2.5 Curva de dispersão longitudinal, GRAFF (1975) $\ldots . \quad 19$

FIGURA 2.6 Tensão atuando sobre um elemento GOLDSMITH (1960) 20

FIGURA 2.7 Curva de dispersão flexional, GRAFF (1975) $\ldots \ldots$. . 23

FIGURA 2.8 Curva de dispersão torcional, GRAFF (1975) $\ldots \ldots$. . 24

FIGURA 2.9 Pulso torcional JOHNSON (1972) $\ldots \ldots \ldots \ldots$

FIGURA 3.1 Impacto longitudinal sobre uma viga, GOLDSMITH (1960) 28

FIGURA 3.2 Tensão na extremidade livre, TIMOSHENKO \& GOO-

DIER $(1980) \ldots \ldots \ldots \ldots \ldots \ldots$

FIGURA 3.3 Impacto transversal viga bi-apoiada $\ldots \ldots \ldots \ldots . . . .31$

FIGURA 3.4 Impacto transversal viga engastada . . . . . . . . . . 32

FIGURA 3.5 Deslocamento $u_{y}$ para viga engastada quando $\alpha=1 \quad \ldots \quad 35$ 
FIGURA 3.6 Tensão normal $\sigma_{x}$ para viga engastada quando $\alpha=1 . .36$

FIGURA 3.7 Viga submetida à um impacto torcional . . . . . . . . . 37

FIGURA 4.1 Processo de análise por elementos finitos BATHE (1996) 40

FIGURA 4.2 Corpos em contato, BATHE (1996) . . . . . . . . . 47

FIGURA 4.3 Método das aproximações sucessivas, OWEN \& HIN-

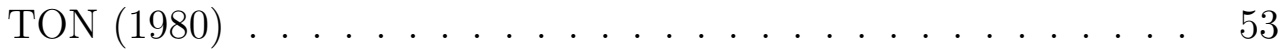

FIGURA 4.4 Método de Newton-Raphson, OWEN \& HINTON (1980) 54

FIGURA 5.1 Modelagens de impacto, TEIXEIRA (2002) . . . . . . 58

FIGURA 5.2 Modelagem do impacto axial . . . . . . . . . . . 60

FIGURA 5.3 Distribuição de tensão decorridos $3.3 \cdot 10^{-5}[\mathrm{~s}]$. . . . . . 61

FIGURA 5.4 Localização dos pontos estudados na interface de contato 61

FIGURA 5.5 Distribuição de tensão da interface de contato no instante de máximo. ........................ 62

FIGURA 5.6 Distribuição de tensão ao longo da linha diagonal. . . . 62

FIGURA 5.7 Variação da tensão equivalente para os pontos $A$ e $B$ em função do tempo . . . . . . . . . . . . . . . . 63

FIGURA 5.8 Superfície de tensão máxima para o impacto longitudinal 65

FIGURA 5.9 Modelagem do impacto flexional . . . . . . . . . . 66

FIGURA 5.10 Propagação do pulso flexional decorridos $1.3925 \cdot 10^{-4}[\mathrm{~s}] \quad 67$

FIGURA 5.11 Deslocamento vertical $u_{y}$ do ponto central na extremidade livre . . . . . . . . . . . . . . . . . . . . . 67

FIGURA 5.12 FFT do deslocamento $u_{y} \ldots \ldots$. . . . . . . . . 67

FIGURA 5.13 Distribuição no engaste da tensão equivalente de Von Mises no instante de máximo . . . . . . . . . . . . . . . . 68

FIGURA 5.14 Linha de nós do plano do engaste . . . . . . . . . . 68 
FIGURA 5.15 Variação da tensão equivalente ao longo da linha vertical do engaste no instante de máximo . . . . . . . . . . . . . . . 69

FIGURA 5.16 Variação da tensão normal ao longo da linha vertical do engaste no instante de máximo . . . . . . . . . . . . . . 69

FIGURA 5.17 Tensão na direção $z$ em função do tempo . . . . . . . . 69

FIGURA 5.18 FFT do sinal de tensão . . . . . . . . . . . . . . . . . . 70

FIGURA 5.19 FFT do sinal mostrando a frequência de maior amplitude 70

FIGURA 5.20 Superfície de tensão máxima para o impacto flexional 72

FIGURA 5.21 Modelagem do impacto torcional . . . . . . . . . . . . . 72

FIGURA 5.22 Localização dos pontos estudados . . . . . . . . . . . . . 73

FIGURA 5.23 Propagação da onda torcional . . . . . . . . . . . . . 73

FIGURA 5.24 Variação do ângulo $\theta$ do ponto $A$ ao longo do tempo . . 74

FIGURA 5.25 FFT do ângulo $\theta \ldots \ldots$. . . . . . . . . . . 74

FIGURA 5.26 Variação do tensão equivalentenos pontos $B$ e $C$. . . . 74

FIGURA 5.27 Distribuição da tensão equivalente no plano central . . . 75

FIGURA 5.28 Superfície de tensão máxima para o impacto torcional 76

FIGURA 6.1 Esquema do suporte . . . . . . . . . . . . . . 81

FIGURA 6.2 Dimensões do suporte e região de interesse $\quad$. . . . . . . 82

FIGURA 6.3 Detalhe da malha na região de interesse . . . . . . . . . 82

FIGURA 6.4 Distribuição de tensão decorridos $0.998 \cdot 10^{-4}[\mathrm{~s}] \quad$. . . . 83

FIGURA 6.5 Distribuição de tensão decorridos 0.017 [s] . . . . . . . . 84

FIGURA 6.6 Deslocamento vertical do ponto 1 da estrutura ao longo do tempo. ........................ 85

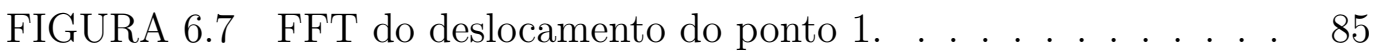


FIGURA 6.8 Tensão normal do ponto 2 da estrutura em função do

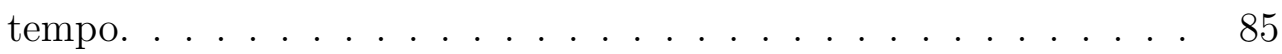

FIGURA 6.9 FFT da tensão do ponto 2. . . . . . . . . . . . . . 85

FIGURA 6.10 Distribuição da tensão equivalente de Von Mises para h $=20[\mathrm{~mm}] \ldots \ldots \ldots \ldots$. . . . . . . . . . . . . 86

FIGURA 6.11 Distribuição da tensão equivalente de Von Mises para h $=30[\mathrm{~mm}] \ldots \ldots \ldots \ldots \ldots$

FIGURA 6.12 Distribuição da tensão equivalente de Von Mises para h $=40[\mathrm{~mm}] \ldots \ldots \ldots \ldots \ldots \ldots$

FIGURA 6.13 Distribuição da tensão equivalente de Von Mises para h $=50[\mathrm{~mm}] \ldots \ldots \ldots \ldots \ldots \ldots$

FIGURA 6.14 Curva aproximada pela regressão linear $\quad \ldots$. . . . . . . 89

FIGURA 6.15 Distribuição da tensão equivalente de Von Mises para

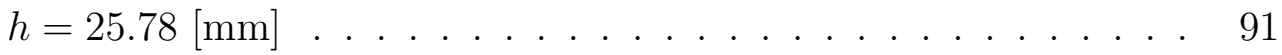

FIGURA 6.16 Esquema do eixo especificando as regiões de interesse e de travamento . . . . . . . . . . . . . . . . . . 92

FIGURA 6.17 Esquema do redutor de velocidades . . . . . . . . . . . . 92

FIGURA 6.18 Detalhe da malha na região do rasgo. . . . . . . . . . . 94

FIGURA 6.19 Condições de contorno aplicadas. . . . . . . . . . . . . . 94

FIGURA 6.20 Propagação da onda decorridos $3.386 \cdot 10^{-5}[\mathrm{~s}] \quad$. . . . . 95

FIGURA 6.21 Localização do ponto A na região de interesse. . . . . . 96

FIGURA 6.22 Deslocamento do ponto A na direção $x$. . . . . . . . . 96

FIGURA 6.23 FFT do deslocamento. . . . . . . . . . . . . . 96

FIGURA 6.24 Linha de nós para o estudo da concentração de tensão 97

FIGURA 6.25 Distribuição de tensão na região de interesse - $\phi_{2}=50$ $[\mathrm{mm}] \ldots \ldots \ldots \ldots$ 
FIGURA 6.26 Variação da tensão ao longo da linha de nós . . . . . . . 98

FIGURA 6.27 Distribuição de tensão na região de interesse - $\phi_{2}=60$ $[\mathrm{mm}] \ldots \ldots \ldots \ldots$

FIGURA 6.28 Variação da tensão ao longo da linha de nós . . . . . . . 98

FIGURA 6.29 Distribuição de tensão na região de interesse - $\phi_{2}=70$ $[\mathrm{mm}] \ldots \ldots \ldots \ldots \ldots$

FIGURA 6.30 Variação da tensão ao longo da linha de nós . . . . . . . 99

FIGURA 6.31 Distribuição de tensão na região de interesse - $\phi_{2}=80$ $[\mathrm{mm}] \ldots \ldots \ldots \ldots \ldots$

FIGURA 6.32 Variação da tensão ao longo da linha de nós . . . . . . . 99

FIGURA 6.33 Distribuição de tensão na região de interesse - $\phi_{2}=100$ $[\mathrm{mm}] \ldots \ldots \ldots \ldots \ldots$

FIGURA 6.34 Variação da tensão ao longo da linha de nós . . . . . . . 100

FIGURA 6.35 Curva ajustada pela regressão linear . . . . . . . . . . . 101

FIGURA 6.36 Distribuição de tensão na região de interesse - $\phi_{2}=58$ $[\mathrm{mm}] \ldots \ldots \ldots \ldots 2 \ldots \ldots \ldots$

FIGURA 6.37 Variação da tensão ao longo da linha de nós . . . . . . . 102 


\section{Lista de Tabelas}

TABELA 2.1 Algumas relações fundamentais da elasticidade $\ldots \ldots$

TABELA 3.1 Valores de $\phi$ para diferentes relações de massa $\alpha=m_{1} / m_{2} 34$

TABELA 4.1 Tipos de contato, HALLQUIST (1993) $\ldots \ldots \ldots$

TABELA 5.1 Equação da superfície de tensão máxima para cada caso 59

TABELA 5.2 Faixa de velocidade e massa do impactador adotada nas modelagens . . . . . . . . . . . . . . . . . 59

TABELA 5.3 Valores da tensão máxima para diferentes abordagens 64

TABELA 5.4 Valores do deslocamento e da tensão máxima para diferentes abordagens . . . . . . . . . . . . . . 71

TABELA 5.5 Valores da tensão máxima para diferentes abordagens . 76

TABELA 6.1 Frequências naturais do primeiro modo de flexão $\ldots$. . . 86

TABELA 6.2 Tensão máxima de impacto em função da aresta $h \ldots 88$

TABELA 6.3 Coeficiente $c$ em função da aresta $h \ldots \ldots$. . . . 89

TABELA 6.4 Coeficientes de segurança sugeridos para choques . . . . 90

TABELA 6.5 Frequências naturais do primeiro modo de flexão $\ldots$. . 97

TABELA 6.6 Tensão máxima de impacto em função do diâmetro $\phi_{2}$ • 100

TABELA 6.7 Coeficiente $c$ em função do diâmetro $\phi_{2} \ldots \ldots \ldots$ 


\title{
Lista de Abreviaturas e Siglas
}

\author{
CAD Computer aided design \\ CAM Computer aided manufacturing \\ MEF Método dos elementos finitos \\ FFT Fast fourrier transform
}




\section{Lista de Símbolos}

A Área da secção transversal, $\left[\mathrm{m}^{2}\right]$

c Velocidade de propagação da onda, $[\mathrm{m} / \mathrm{s}]$

$c_{1} \quad$ Velocidade de propagação da onda de dilatação, $[\mathrm{m} / \mathrm{s}]$

$c_{2}$ Velocidade de propagação da onda de distorção, $[\mathrm{m} / \mathrm{s}]$

$c_{R} \quad$ Velocidade de propagação das ondas de Rayleigh, $[\mathrm{m} / \mathrm{s}]$

$C S$ Coeficiente de segurança

E Módulo de Young, $\left[\mathrm{N} / \mathrm{m}^{2}\right]$

$g$ Aceleração da gravidade, $\left[\mathrm{m} / \mathrm{s}^{2}\right]$

I Momento de inércia, $\left[\mathrm{m}^{4}\right]$

$i$ Relação de transmissão

$J_{t} \quad$ Momento polar de inércia, $\left[\mathrm{m}^{4}\right]$

$k \quad$ Rigidez da viga, $[\mathrm{N} / \mathrm{m}]$

$K \quad$ Raio de giração

$L \quad$ Comprimento da viga, $[\mathrm{m}]$

$m_{1} \quad$ Massa da viga, $[\mathrm{Kg}]$

$m_{2}$ Massa do impactador, $[\mathrm{Kg}]$

$M_{t} \quad$ Momento de torção, [N.m]

$n$ Rotação, [rpm]

$r$ Raio, $[\mathrm{m}]$

$R$ Raio externo, [m]

$t \quad$ Tempo, [s]

$T$ Período de oscilação, [s]

TP Tensão perigosa, $[\mathrm{Pa}]$ 


\begin{tabular}{|c|c|}
\hline$v_{0}$ & Velocidade inicial, $[\mathrm{m} / \mathrm{s}]$ \\
\hline$W_{f}$ & Módulo de resistência a flexão, $\left[\mathrm{m}^{3}\right]$ \\
\hline$W_{t}$ & Módulo de resistência a torção, $\left[\mathrm{m}^{3}\right]$ \\
\hline$\alpha$ & Relação de massas \\
\hline$\gamma$ & Distorção \\
\hline$\Delta t$ & Incremento de tempo, $[\mathrm{s}]$ \\
\hline$\Delta$ & Dilatação volumétrica \\
\hline$\epsilon$ & Deformação \\
\hline$\theta$ & Ângulo de rotação, [rad] \\
\hline$\lambda$ & Constante de Lamé \\
\hline$\Lambda$ & Comprimento de onda \\
\hline$\mu$ & Módulo de elasticidade transversal, $\left[\mathrm{N} / \mathrm{m}^{2}\right]$ \\
\hline$\nu$ & Coeficiente de Poisson \\
\hline$\xi$ & Número de onda \\
\hline$\rho$ & Densidade, $\left[\mathrm{Kg} / \mathrm{m}^{3}\right]$ \\
\hline$\sigma$ & Tensão normal, $[\mathrm{Pa}]$ \\
\hline$\sigma_{e}$ & Tensão de escoamento, $[\mathrm{Pa}]$ \\
\hline$\sigma_{\max }$ & Tensão máxima de Von Mises devido ao impacto, $[\mathrm{Pa}]$ \\
\hline$\sigma_{\text {adm }}$ & Tensão admissível, $[\mathrm{Pa}]$ \\
\hline$\tau$ & Tensão de cisalhamento, $[\mathrm{Pa}]$ \\
\hline$\omega$ & Frequência angular, [rad/s] \\
\hline $\bar{\omega}$ & Giros \\
\hline$[K]$ & Matriz de rigidez \\
\hline$[\bar{K}]$ & Matriz de rigidez efetiva \\
\hline$[\ltimes \bar{K} \backslash]$ & Matriz de rigidez efetiva diagonal \\
\hline$[C]$ & Matriz de amortecimento \\
\hline$[M]$ & Matriz de massa \\
\hline$\{F\}$ & Vetor de forças externas \\
\hline$\{\ddot{u}\}$ & Vetor de acelerações nodais \\
\hline$\{\dot{u}\}$ & Vetor de velocidades nodais \\
\hline$\{u\}$ & Vetor de deslocamentos nodais \\
\hline
\end{tabular}




\section{Resumo}

MALAVOLTA, A. T. (2003). Metodologia para a Análise de Impacto em Sistemas Elásticos usando-se o Método dos Elementos Finitos e a Integração Explícita no Tempo. São Carlos, 2003. 108p. Dissertação (Mestrado) - Escola de Engenharia de São Carlos, Universidade de São Paulo.

O fenômeno de impacto mecânico entre corpos sólidos está presente em diversas áreas da engenharia. Exemplos atuais deste tipo de problema podem ser encontrados no projeto de elementos de máquinas, sistemas de transporte como containers com material nuclear, tubulações em indústrias químicas, autoveículos e várias outras estruturas que devem obedecer à códigos de segurança estabelecidos por legislações governamentais. Na maioria destes casos, o conhecimento das tensões oriundas do impacto entre os corpos é fundamental para evitarem-se falhas nas estruturas projetadas, predizer danos indesejáveis, diminuir coeficientes de segurança, etc. Neste contexto, é proposta neste trabalho uma metodologia de projeto contra impacto em sistemas mecânicos elásticos baseada nas equações de superfície de tensão máxima, que representam diferentes situações de impacto em uma determinada geometria. O Método dos Elementos Finitos com a integração explícita no tempo é aplicado para resolver o problema dinâmico associado ao impacto. Como exemplos de aplicação são estudados um suporte e um eixo chavetado.

Palavras-Chave: Impacto, Método dos Elementos Finitos, Integração explícita no tempo. 


\section{Abstract}

MALAVOLTA, A. T. (2003). Impact Analysis Methodology for Elastic Systems using the Finite Element Method and Explicit Time Integration. São Carlos, 2003. 108p. Dissertação (Mestrado) - Escola de Engenharia de São Carlos, Universidade de São Paulo.

Impact between solid bodies is present in many areas of engineering. Relevant examples of this sort of problem can be found in machine element design, transport systems such as containers for nuclear material, pipes in chemical plants, vehicles and many others structures that should comply with safety codes issued by govern agencies. In the majority of these cases, the knowledge of the stresses due to the impact between the bodies is fundamental to avoid failures on the designed structures, to predict undesired damages, and to decrease safety factors. Therefore, in this work a design methodology for linear mechanical systems submitted to impact is proposed. It is based on the surface of maximum stress which represents different crash situations for a given elastic model. The Finite Element Method with the explicit time integration algorithm is used to solve the associated dynamic problem. Examples are presented such as a bracket and a shaft.

Keywords: Impact, Finite Element Method, Explicit Time Integration. 


\section{Capítulo 1}

\section{Introdução}

\section{$1.1 \quad$ Escopo do estudo}

O fenômeno de impacto entre corpos sólidos tem despertado um crescente interesse de pesquisadores e projetistas no decorrer das últimas décadas devido às suas aplicações em diferentes áreas da engenharia. Como exemplos podem-se citar o projeto de meios de transporte onde os componentes mecânicos devem absorver boa parte da energia gerada por um eventual impacto para que a segurança dos passageiros seja mantida. Ainda na construção de tubulações, oleodutos e containers nucleares também é importante o conhecimento do fenômeno para evitarem-se desastres ecológicos ou outros danos devido ao rompimento da estrutura. Seu estudo também está relacionado com o desenvolvimento de equipamentos de segurança como capacetes, armaduras, etc. Na maioria destes casos é interessante estimar a magnitude das ondas de tensão geradas pelo impacto para que as estruturas projetadas não sofram falhas ou que falhem dentro de condições conhecidas, permitindo a minimização dos coeficientes de segurança, implicando na redução de material, potência instalada e outros recursos utilizados.

Grande parte dos estudos sobre impacto hoje, envolvem o fenômeno de falha e plastificação. Em APARICIO SANCHEZ (2001) é estudado, utilizando o Método dos Elementos Finitos (MEF), o comportamento de um container para transpor- 
te de material radioativo quando o mesmo sofre uma queda sobre uma superfície rígida. MACDONALD (2002) também aplica o MEF no estudo do impacto de projéteis de titânio com alta velocidade sobre placas de alumínio aplicadas na indútria aeroespacial e valida os resultados obtidos por meio de experimentos. Estudos do impacto em vigas, placas, tubos e cascas que envolvam grandes deformações são apresentados em JONES (1998). Em KARAGIOZOVA et al. (2000) é aplicado o MEF para estudar os efeitos de buckling em tubos de parede fina submetidos ao impacto axial. No caso de materiais compósitos, TITA (2001) apresenta um estudo do impacto de esferas sobre placas do material e ABRATE (1998) desenvolve diferentes modelos para prever falhas no material.

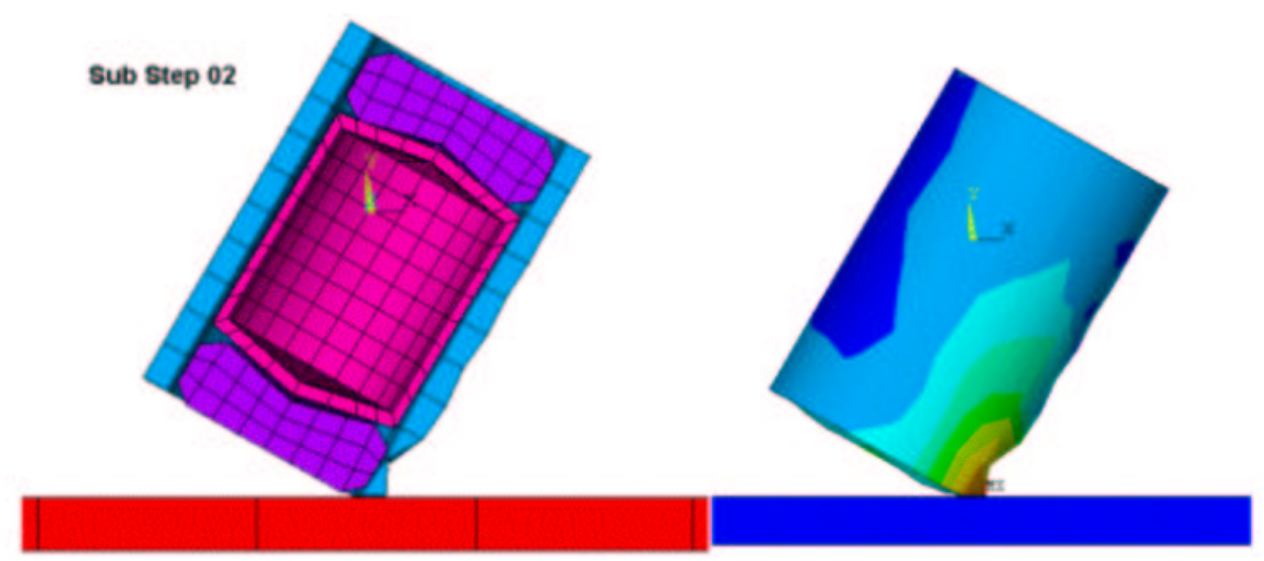

Figura 1.1: Modelagem da queda de um container, APARICIO SANCHEZ (2001)

Nos casos em que o impacto entre corpos sólidos não apresente falha nem plastificação, ou seja, permaneçam no regime elástico, ocorrerá a propagação de ondas de tensão elásticas na medida em que o distúrbio gerado na região de contato se reflete nas superfícies de contornos, produzindo vibrações. Como a determinação das deformações produzidas na região de contato que satisfaçam as equações do movimento e que sejam geometricamente compatíveis são extremamente difíceis de serem obtidas, diferentes aproximações analíticas foram desenvolvidas para a análise do fenômeno de impacto. Uma classificação geral é dividir o fenômeno em duas grandes classes: 
- Impacto de corpos rígidos

- Impacto de corpos elásticos

No impacto entre corpos rígidos é assumido que todos os pontos do corpo sofram instantaneamente a mesma mudança de velocidade como consequência do impacto. Esta aproximação despreza os efeitos de inércia do corpo e poderá levar a resultados errôneos quando uma porcentagem significativa da energia total é convertida em vibrações. Em geral, quando o tempo de duração do impacto é maior que o período da menor frequência natural excitada no corpo, a aproximação é satisfatória pois neste caso várias reflexões de ondas terão ocorrido durante o tempo de contato e o corpo pode ser considerado em equilíbrio quase estático. Quando os aspectos vibracionais são relevantes, o tratamento de corpo rígido torna-se inadequado e uma abordagem baseada na teoria de propagação de ondas é recomendada.

Expressões para a determinação das tensões em vigas submetidas ao impacto de uma massa rígida, baseadas na teoria de propagação de ondas elásticas, podem ser encontradas em GOLDSMITH (1960), JOHNSON (1972), GRAFF (1975), STRONGE (2000) entre outros. No caso de geometrias mais complexas o equacionamento do problema torna-se extremamente complicado e com isso, o uso de ferramentas computacionais como o Método dos Elementos Finitos tornase bastante útil para análise do fenômeno devido a sua versatilidade de inserir condições de contorno em geometrias complexas, com diferentes modelos de materiais. Apesar de fornecer uma solução aproximada, em muitos casos, esta é a única maneira de se encontrar uma resposta para o problema.

Utilizando-se do MEF, TEIXEIRA (2002) apresenta um estudo de impacto de massas rígidas sobre sistemas elásticos. Variando-se a massa e a velocidade do impactador foram desenvolvidas expressões que relacionam essas grandezas com a máxima tensão de impacto e as curvas geradas foram denominadas de superfícies de tensão máxima. No presente trabalho, estas curvas serão discutidas e aplicadas para o desenvolvimento de uma metodologia de estudo de impacto em sistemas elásticos. 


\subsection{Conteúdo da dissertação}

O trabalho foi dividido em sete capítulos estruturados conforme abaixo:

- Capítulo 1: Introdução sobre o fenômeno de impacto e objetivos do trabalho.

- Capítulo 2: Apresenta uma breve revisão sobre o problema de propagação de ondas elásticas em meios sólidos.

- Capítulo 3: Apresenta alguns métodos de obtenção de tensões oriundas do impacto longitudinal, transversal e torcional em vigas, dando especial atenção aos métodos de energia e de propagação de ondas.

- Capítulo 4: Apresenta o Método dos Elementos Finitos discutindo sobre a formulação implícita - explícita e a solução de problemas não lineares em análise dinâmica.

- Capítulo 5: Contém as modelagens de impacto em vigas comparando-se os resultados do impacto longitudinal, tranversal e torcional com os métodos de obtenção da tensão máxima discutidos no capítulo 3, além de apresentar as superfícies de tensão máxima para cada caso.

- Capítulo 6: Apresenta uma metodologia de projeto quanto à impacto baseada nas equações da superfície de tensão máxima e como exemplos de aplicação são modelados um suporte e um eixo chavetado.

- Capítulo 7: Contém as conclusões do trabalho desenvolvido. 


\subsection{Objetivos}

O trabalho apresentado teve como objetivos:

1. Estudo da teoria de propagação de ondas em meios sólidos visando sua aplicação na obtenção das tensões oriundas do impacto.

2. Estudo de impacto em vigas e de suas principais abordagens para a determinação das tensões (método da energia e o método de propagação de ondas) possibitando a comparação desses dois enfoques com o Método dos Elementos Fintitos.

3. Estudo da análise dinâmica não linear e do método da integração explícita no tempo na solução do problema dinâmico associado ao impacto.

4. Proposta de uma metodologia para a análise de impacto em sistemas elásticos, baseada nas superfícies de tensão máxima, usando-se o Método dos Elementos Finitos e a integração explícita no tempo. 


\section{Capítulo 2}

\section{Propagação de Ondas}

\subsection{Introdução}

A teoria de propagação de ondas elásticas em meios sólidos começou a ser desenvolvida no século 19 com Stokes, Poisson, Rayleigh e Kelvin, entre outros, a partir da teoria da elasticidade, condições de compatibilidade e equações do movimento. O crescente interesse pelo seu estudo deve-se às suas aplicações em diferentes áreas como em acústica, sismologia e ensaios não destrutivos como no uso de ultrasom. Em mecânica estrutural, particularmente, a determinação da resposta de sistemas mecânicos submetidos à cargas de impacto pode ser obtida por meio da teoria de propagação de ondas. Conforme GRAFF (1975) o fenômeno basicamente pode ser dividido em três categorias:

- Ondas elásticas : quandos as tensões no material estão no regime elástico.

- Ondas visco-elásticas : quando os efeitos visco-elásticos estão presentes.

- Ondas plásticas : quando o limite de escoamento do material é ultrapassado.

A seguir serão discutidos alguns aspectos básicos da teoria de propagação de ondas elásticas em meios sólidos, visando um melhor entendimento do fenômeno e de suas simplificações para a obtenção de expressões que determinam as tensões geradas no impacto, objeto principal deste trabalho. 


\subsection{Propagação de Ondas Elásticas em Meios Sólidos Infinitos}

Considere as tensões atuantes nos elementos das figuras 2.1 e 2.2. Os subíndices das componentes de cisalhamento representam, o primeiro, o plano em que ela está atuando e o segundo a sua direção. As componentes de tensão das outras faces dos elementos foram omitidas por simplificação.

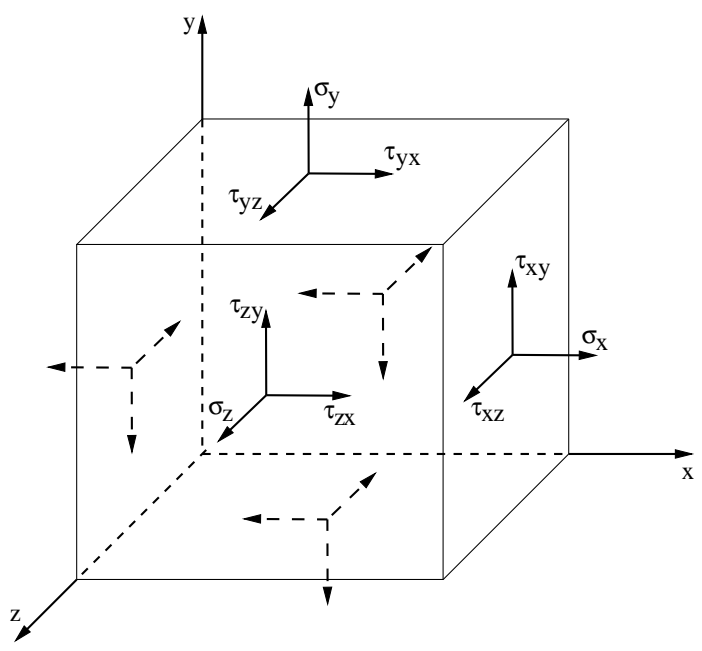

Figura 2.1: Coordenadas cartesianas

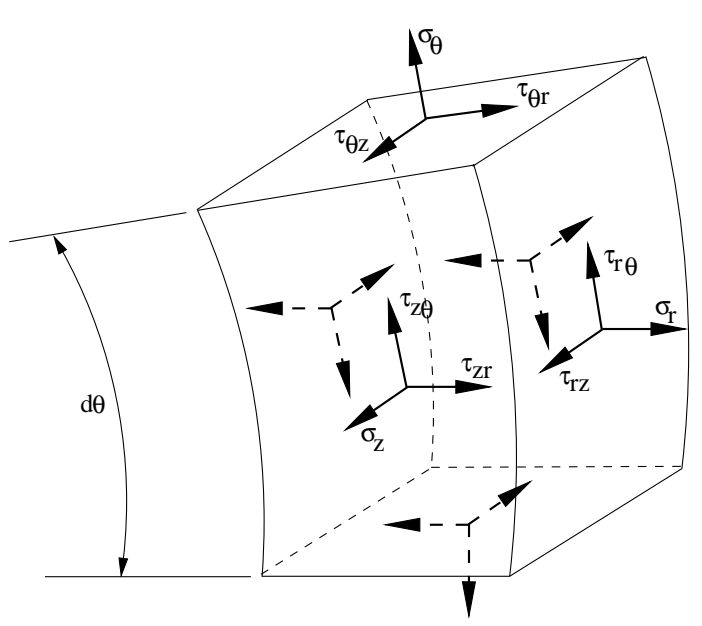

Figura 2.2: Coordenadas cilíndricas

Na ausência de forças de campo o balanço de forças fornece, em coordenadas cartesianas:

$$
\begin{aligned}
\rho \frac{\partial^{2} u_{x}}{\partial t^{2}} & =\frac{\partial \sigma_{x}}{\partial x}+\frac{\partial \tau_{x y}}{\partial y}+\frac{\partial \tau_{x z}}{\partial z} \\
\rho \frac{\partial^{2} u_{y}}{\partial t^{2}} & =\frac{\partial \tau_{y x}}{\partial x}+\frac{\partial \sigma_{y}}{\partial y}+\frac{\partial \tau_{y z}}{\partial z} \\
\rho \frac{\partial^{2} u_{z}}{\partial t^{2}} & =\frac{\partial \tau_{z x}}{\partial x}+\frac{\partial \tau_{z y}}{\partial y}+\frac{\partial \sigma_{z}}{\partial z}
\end{aligned}
$$


E em coordenadas cilíndricas:

$$
\begin{aligned}
\rho \frac{\partial^{2} u_{r}}{\partial t^{2}} & =\frac{\partial \sigma_{r}}{\partial r}+\frac{1}{r} \frac{\partial \tau_{r \theta}}{\partial \theta}+\frac{\partial \tau_{r z}}{\partial z}+\frac{\sigma_{r}-\sigma_{\theta}}{r} \\
\rho \frac{\partial^{2} u_{\theta}}{\partial t^{2}} & =\frac{\partial \tau_{r \theta}}{\partial r}+\frac{1}{r} \frac{\partial \sigma_{\theta}}{\partial \theta}+\frac{\partial \tau_{\theta z}}{\partial z}+\frac{2 \tau_{r \theta}}{r} \\
\rho \frac{\partial^{2} u_{z}}{\partial t^{2}} & =\frac{\partial \tau_{r z}}{\partial r}+\frac{1}{r} \frac{\partial \tau_{\theta z}}{\partial \theta}+\frac{\partial \sigma_{z}}{\partial z}+\frac{\tau_{r z}}{r}
\end{aligned}
$$

A tabela abaixo ilustra, no sistema de coordenadas cartesiano e cilíndrico, algumas relações fundamentais da teoria da elasticidade:

Tabela 2.1: Algumas relações fundamentais da elasticidade

\begin{tabular}{|ll|}
\hline Sistema $x, y, z$ & Sistema $r, \theta, z$ \\
\hline \hline$\epsilon_{x}=\frac{\partial u_{x}}{\partial x}$ & $\epsilon_{r}=\frac{\partial u_{r}}{\partial r}$ \\
$\epsilon_{y}=\frac{\partial u_{y}}{\partial y}$ & $\epsilon_{\theta}=\frac{u_{r}}{r}+\frac{1}{r} \frac{\partial \theta}{\partial \theta}$ \\
$\epsilon_{z}=\frac{\partial u_{z}}{\partial z}$ & $\epsilon_{z}=\frac{\partial u_{z}}{\partial z}$ \\
\hline \hline$\gamma_{x y}=\frac{\partial u_{y}}{\partial x}+\frac{\partial u_{x}}{\partial y}$ & $\gamma_{\theta z}=\frac{1}{r} \frac{\partial u_{z}}{\partial \theta}+\frac{\partial u_{\theta}}{\partial z}$ \\
$\gamma_{y z}=\frac{\partial u_{z}}{\partial y}+\frac{\partial u_{y}}{\partial z}$ & $\gamma_{z r}=\frac{\partial u_{r}}{\partial z}+\frac{\partial u_{z}}{\partial r}$ \\
$\gamma_{z x}=\frac{\partial u_{x}}{\partial z}+\frac{\partial u_{z}}{\partial x}$ & $\gamma_{r \theta}=\frac{\partial u_{\theta}}{\partial r}-\frac{u_{\theta}}{r}+\frac{1}{r} \frac{\partial u_{r}}{\partial \theta}$ \\
\hline \hline$\Delta=\frac{\partial u_{x}}{\partial x}+\frac{\partial u_{y}}{\partial y}+\frac{\partial u_{z}}{\partial z}$ & $\Delta=\frac{\partial u_{r}}{\partial r}+\frac{u_{r}}{r}+\frac{1}{r} \frac{\partial u_{\theta}}{\partial \theta}+\frac{\partial u_{z}}{\partial z}$ \\
\hline \hline $2 \bar{\omega}_{x}=\frac{\partial u_{z}}{\partial y}-\frac{\partial u_{y}}{\partial z}$ & $2 \bar{\omega}_{r}=\frac{1}{r} \frac{\partial u_{z}}{\partial \theta}-\frac{\partial u_{\theta}}{\partial z}$ \\
$2 \bar{\omega}_{y}=\frac{\partial u_{x}}{\partial z}-\frac{\partial u_{z}}{\partial x}$ & $2 \bar{\omega}_{\theta}=\frac{\partial u_{r}}{\partial z}+\frac{\partial u_{z}}{\partial r}$ \\
$2 \bar{\omega}_{z}=\frac{\partial u_{y}}{\partial x}-\frac{\partial u_{x}}{\partial y}$ & $2 \bar{\omega}_{z}=\frac{1}{r}\left[\frac{\partial}{\partial r}\left(r u_{\theta}\right)-\frac{\partial u_{r}}{\partial \theta}\right]$ \\
\hline \hline$\sigma_{i}=\lambda \Delta+2 \mu \epsilon_{i}$ & $\sigma_{i}=\lambda \Delta+2 \mu \epsilon_{i}$ \\
$\tau_{i j}=\tau_{j i}=\mu \gamma_{i j}=\mu \gamma_{j i}$ & $\tau_{i j}=\tau_{j i}=\mu \gamma_{i j}=\mu \gamma_{j i}$ \\
\hline
\end{tabular}

Substituindo-se essas expressões, em coordenadas cartesianas, nas equações (2.1) à (2.3), é possível obter-se:

$$
\begin{aligned}
\rho \frac{\partial^{2} u_{x}}{\partial t^{2}} & =(\lambda+\mu) \frac{\partial \Delta}{\partial x}+\mu \nabla^{2} u_{x} \\
\rho \frac{\partial^{2} u_{y}}{\partial t^{2}} & =(\lambda+\mu) \frac{\partial \Delta}{\partial y}+\mu \nabla^{2} u_{y} \\
\rho \frac{\partial^{2} u_{z}}{\partial t^{2}} & =(\lambda+\mu) \frac{\partial \Delta}{\partial z}+\mu \nabla^{2} u_{z}
\end{aligned}
$$

onde: $\quad \nabla^{2} \equiv\left[\frac{\partial^{2}}{\partial x^{2}}+\frac{\partial^{2}}{\partial y^{2}}+\frac{\partial^{2}}{\partial z^{2}}\right] \quad$ é o operador Laplaciano. 
O mesmo para o sistema de coordenadas cilíndrico fornece:

$$
\begin{aligned}
\rho \frac{\partial^{2} u_{r}}{\partial t^{2}} & =(\lambda+2 \mu) \frac{\partial \Delta}{\partial r}-\frac{2 \mu}{r} \frac{\partial \bar{\omega}_{z}}{\partial \theta}+2 \mu \frac{\partial \bar{\omega}_{\theta}}{\partial z} \\
\rho \frac{\partial^{2} u_{\theta}}{\partial t^{2}} & =(\lambda+2 \mu) \frac{1}{r} \frac{\partial \Delta}{\partial \theta}-2 \mu \frac{\partial \bar{\omega}_{r}}{\partial z}+2 \mu \frac{\partial \bar{\omega}_{z}}{\partial r} \\
\rho \frac{\partial^{2} u_{z}}{\partial t^{2}} & =(\lambda+2 \mu) \frac{\partial \Delta}{\partial z}-\frac{2 \mu}{r} \frac{\partial}{\partial r}\left[r \bar{\omega}_{\theta}\right]+\frac{2 \mu}{r} \frac{\partial \bar{\omega}_{r}}{\partial \theta}
\end{aligned}
$$

A solução das equações (2.7) à (2.9) ou (2.10) à (2.12) para dadas condições de contorno, determina a história do distúrbio de um ponto do meio em coordenadas cartesianas ou cilíndricas respectivamente. Como esta solução é extremamente difícil de ser obtida analiticamente para geometrias complexas, o uso do Método dos Elementos Finitos torna-se uma importante ferramenta de análise para o problema e será aplicado no capítulo 5.

\subsubsection{Ondas de Dilatação e Ondas de Distorção}

A obtenção da forma padrão das equações de onda em um meio sólido tornase mais simples escrevendo-se as equações do movimento em sua forma vetorial. A equação (2.13) representa a forma vetorial em coordenadas cartesianas das expressões (2.7) à (2.9):

$$
(\lambda+\mu) \nabla \nabla \cdot \mathbf{u}+\mu \nabla^{2} \mathbf{u}=\rho \ddot{\mathbf{u}}
$$

onde: $\mathbf{u}$ é o vetor de deslocamento e $\ddot{\mathbf{u}}$ representa a derivada parcial segunda em relação ao tempo.

Conforme GRAFF (1975), aplicando-se o divergente em ambos os lados da equação $(2.13)$, lembrando-se de que $\nabla \cdot \mathbf{u}=\Delta$, obtém-se:

$$
\frac{\partial^{2} \Delta}{\partial t^{2}}=c_{1}^{2} \nabla^{2} \Delta
$$


onde a velocidade de propagação $c_{1}$ é dada por: $c_{1}=\sqrt{\frac{\lambda+2 \mu}{\rho}}$

Por outro lado aplicando-se o rotacional em ambos os lados de (2.13), lembrandose de que $\boldsymbol{\omega}=\frac{1}{2} \nabla \times \mathbf{u}$, obtém-se:

$$
\frac{\partial^{2} \boldsymbol{\omega}}{\partial t^{2}}=c_{2}^{2} \nabla^{2} \boldsymbol{\omega}
$$

onde a velocidade de propagação $c_{2}$ é dada por: $c_{2}=\sqrt{\frac{\mu}{\rho}}$

Em situações onde todas os giros $\bar{\omega}_{i}$ desaparecem, o vetor de deslocamentos u pode ser dado como o gradiente de um escalar e a equação (2.14) passa a representar a onda de dilatação:

$$
\frac{\partial^{2} \mathbf{u}}{\partial t^{2}}=c_{1}^{2} \nabla^{2} \mathbf{u}
$$

Enquanto que, no caso onde a dilatação seja nula, $\Delta=0$, a equação (2.13) torna-se representativa da onda de distorção:

$$
\frac{\partial^{2} \mathbf{u}}{\partial t^{2}}=c_{2}^{2} \nabla^{2} \mathbf{u}
$$

As equações (2.14) à (2.17) representam a forma padrão da equação de onda para um meio sólido, elástico e isotrópico onde as forças de campo estão ausentes. Elas mostram que um distúrbio pode se propagar no interior do meio com duas velocidades diferentes: a dilatação volumétrica $\Delta$ viaja com velocidade $c_{1}$ e é denominada de onda de dilatação, enquanto que os giros $\bar{\omega}_{i}(i=x, y, z)$ viajam com velocidade $c_{2}$ e são denominados ondas de distorção. Os deslocamentos das partículas no meio têm a mesma direção de propagação da onda de dilatação e são perpendiculares à esta direção no caso de ondas de distorção. 


\subsubsection{Ondas Planas}

Uma forma particular de propagação da onda ocorre quando o vetor de deslocamentos $\mathbf{u}$ é função da coordenada $x$ e do tempo $t$ da seguinte forma:

$$
\mathbf{u}=f(\mathbf{x} \cdot \mathbf{p}-c t) \mathbf{d}
$$

onde:

x : vetor posição

p : versor na direção da propagação da onda

d : versor na direção do deslocamento da partícula

c : velocidade de propagação da onda

De acordo com ACHENBACH (1975) substituindo-se o vetor de deslocamento u na equação (2.13) obtém-se:

$$
\left(\mu+\rho c^{2}\right) \mathbf{d}+(\lambda+\mu)(\mathbf{p} \cdot \mathbf{d}) \mathbf{p}=0
$$

Desde que $\mathbf{p}$ e $\mathbf{d}$ são dois versores distintos, a equação (2.19) pode ser satisfeita de apenas duas maneiras: $\mathbf{d}= \pm \mathbf{p} \quad$ ou $\quad \mathbf{p} \cdot \mathbf{d}=0$

Se $\mathbf{d}= \pm \mathbf{p}$ tem-se $\mathbf{p} \cdot \mathbf{d}= \pm 1$ e a equação (2.19) torna-se:

$$
c=c_{1}=\sqrt{\frac{\lambda+2 \mu}{\rho}}
$$

Quando $\mathbf{d} \neq \pm \mathbf{p}$ e $\mathbf{p} \cdot \mathbf{d}=0$ a equação (2.19) torna-se:

$$
c=c_{2}=\sqrt{\frac{\mu}{\rho}}
$$

No primeiro caso, a direção do movimento das partículas do meio é paralela a direção de propagação da onda enquanto que esta direção é perpendicular no segundo caso. 
A figura 2.3 ilustra este fato para o caso de uma onda harmônica com o deslocamento na direção $x$ dado por:

$$
u_{x}=A e^{i \xi(x-c t)}
$$

onde: $\xi=2 \pi / \Lambda$ é o chamado número de onda sendo inversamente proporcional ao comprimento de onda $\Lambda$.

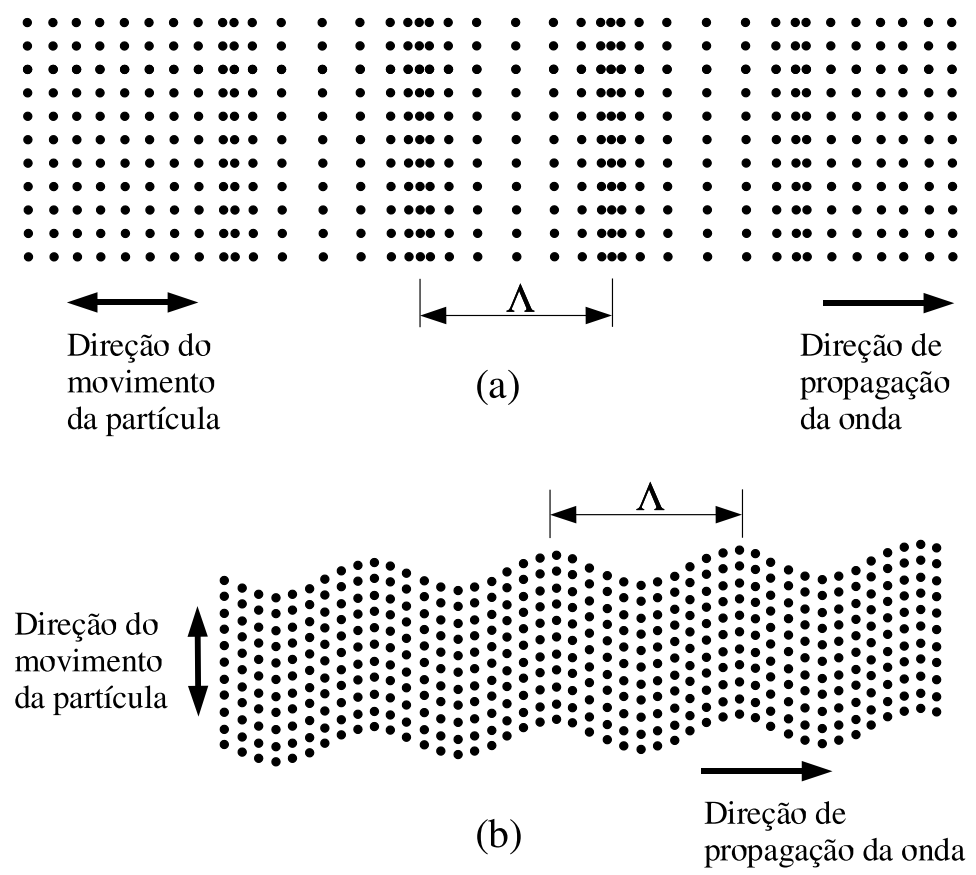

Figura 2.3: Direção do movimento das partículas para onda dilatacional (a) e transversal (b) (GRAFF (1975))

\subsubsection{Ondas de Superfície}

Em um meio semi-infinito além das ondas de dilatação e distorção, na superfície de contorno pode ocorrer ondas elásticas de superfície também conhecidas como ondas de Rayleigh. Estas ondas aparecem apenas nas superfícies dos corpos e seus efeitos decrescem rapidamente com a profundidade. Conforme KOLSKY (1963), elas viajam com velocidade $c_{R}$ correspondente à uma fração $k_{1}$ da veloci- 
dade de distorção $c_{2}$, sendo $k_{1}$ obtido a partir do seguinte polinômio:

$$
k_{1}^{6}-8 k_{1}^{4}+\left(24-16 \alpha_{1}^{2}\right) k_{1}^{2}+16 \alpha_{1}^{2}-16=0
$$

onde: $\alpha_{1}=[(1-2 \nu) /(2-2 \nu)]^{0.5}$

As ondas de Rayleigh têm velocidades de propagação menores do que os outros tipos de onda e são amplamente aplicadas em sismologia no estudo de terremotos. No presente trabalho as ondas de superfície são irrelevantes e são desconsideradas.

\subsection{Propagação de Ondas Elásticas em Meios Sólidos Finitos}

A propagação de ondas de tensão em meios sólidos limitados, como uma viga, pode ser determinada a partir das equações (2.7) à (2.12) aplicando-se condições de contorno apropriadas. No entanto, para casos com geometrias complexas, aplicar e satisfazer tais condições de contorno dificulta muito a solução dessas equações. Quando um pulso de tensão se propaga pelo meio, um infinito número de componentes de frequência podem estar presentes. Cada uma destas componentes viaja com velocidade e comprimentos de onda próprias. Essa velocidade de propagação é denominada de velocidade de fase $c$. Na maioria dos casos a propagação é um fenômeno dispersivo, ou seja, a velocidade de fase das ondas, $c$, é função de sua frequência angular $\omega$ ou do comprimento de onda $\Lambda$. A análise dos efeitos de dispersão é necessária para determinar a variação da velocidade de fase com o comprimento de onda ou com o número de onda $\xi$, e essa investigação pode ser representada na forma de curvas denominadas de curvas de dispersão. Uma aproximação para a solução do problema em vigas infinitas de secção circular uniforme, conforme GOLDSMITH (1960), foi dada por Pochhammer and Chree cujas equações consideram a propagação de um trem de infinitas ondas senoidais ao longo do eixo $z$ da viga, tal que o deslocamento de cada ponto é uma função harmônica simples da coordenada $z$ e do tempo $t$. 


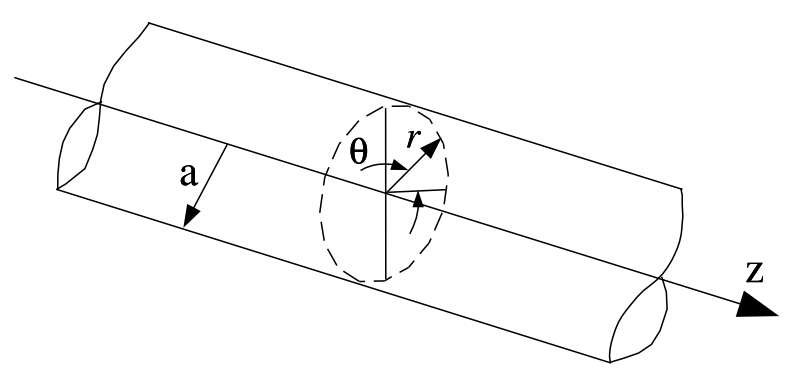

Figura 2.4: Coordenadas para o cilíndro sólido

$$
\begin{aligned}
& u_{r}=U e^{i(\xi z+\omega t)} \\
& u_{\theta}=V e^{i(\xi z+\omega t)} \\
& u_{z}=W e^{i(\xi z+\omega t)}
\end{aligned}
$$

onde: $U, V$ e $W$ são funções de $r$ e $\theta, \xi$ é o número de onda e $\omega$ a frequência angular.

Substituindo-se os deslocamentos $u_{r}, u_{\theta}$ e $u_{z}$ nas equações (2.10) à (2.12) e aplicando-se as condições de contorno na superfície da barra $r=a$ onde $\sigma_{r}=\tau_{r \theta}=\tau_{r z}=0$, expressões podem ser desenvolvidas para os deslocamentos e velocidade de fase das ondas. Três diferentes tipos de onda podem ser consideradas em vigas: ondas longitudinais, flexionais e torcionais. Para cada tipo é possível obter uma equação, denominada de equação frequencial, envolvendo os parâmetros adimensionais $c / c_{0}, r / \Lambda$ e $\nu$ em termos de funções de Bessel; onde $c_{0}=\sqrt{E / \rho}$. As raízes reais da equação frequencial podem ser determinadas numericamente e plotadas em curvas de dispersão com diferentes ramos. Cada ramo representa um um modo de propagação da onda e está associado à um modo de vibrar e sua frequência natural. Maiores detalhes da obtenção da equação frequencial e das curvas de dispersão podem ser encontrados em DAVIES (1948), KOLSKY (1963), GRAFF (1975) e ACHENBACH (1975).

No caso de vigas de secção não circular o problema torna-se mais complicado e sua solução tem sido proposta por vários autores. Em MORSE (1950) são obtidas curvas de dispersão e valores experimentais para ondas longitudinais em 
vigas retangulares com diferentes valores de coeficientes de Poisson e os valores calculados mostraram boa concordância com os valores medidos para grandes comprimentos de onda. MINDLIN \& FOX (1960) desenvolvem uma formulação a partir de soluções de propagação de ondas em placas infinitas para vigas de secção retangular. NIGRO (1966) desenvolve soluções aproximadas pelo método de Ritz para as curvas de dispersão dos modos longitudinal, flexional e torcional de vigas retangulares. AALAMI (1973) apresenta uma formulação baseada em métodos de discretização e no método da energia de Rayleigh-Ritz para a propagação de ondas em vigas ortotrópicas com secção arbitrária. FRASER (1969) aplica o métdo da colocação para obter curvas de dispersão em vigas retangulares infinitas. NAYFEH \& ABDELRAHMAN (2000) propõem um modelo aproximado para a obtenção de curvas de dispersão em vigas retangulares simplificando as condições de contorno. LIU \& LI (2000) estudam a propagação de ondas torcionais em vigas retangulares ortotrópicas aplicando o método da bicaracterística para resolver as equações diferenciais do problema.

\section{Equação frequencial para uma viga cilíndrica}

Para a determinação da equação frequencial em uma viga cilíndrica, torna-se adequado escrever o vetor de deslocamentos $\mathbf{u}$ em termos de funções potenciais $\Phi$ e $\mathbf{H}$ de forma que:

$$
\mathbf{u}=\nabla \Phi+\nabla \times \mathbf{H} \quad \nabla \cdot \mathbf{H}=F(\mathbf{r}, t)
$$

onde: $F(\mathbf{r}, t)$ é uma função arbitrária.

As componentes escalares do vetor $\mathbf{u}$ podem ser escritas, conforme GRAFF (1975), como:

$$
\begin{aligned}
& u_{r}=\frac{\partial \Phi}{\partial r}+\frac{1}{r} \frac{\partial H_{z}}{\partial \theta}-\frac{\partial H_{\theta}}{\partial z} \\
& u_{\theta}=\frac{1}{r} \frac{\partial \Phi}{\partial \theta}+\frac{\partial H_{r}}{\partial z}-\frac{\partial H_{z}}{\partial r} \\
& u_{z}=\frac{\partial \Phi}{\partial z}+\frac{1}{r} \frac{\partial}{\partial r}\left(r H_{\theta}\right)-\frac{1}{r} \frac{\partial H_{r}}{\partial \theta}
\end{aligned}
$$


Considerando-se a propagação de ondas harmônicas no cilíndro pode-se encontrar, conforme GRAFF (1975), as seguintes expressões para $\Phi, H_{r}, H_{\theta}$ e $H_{z}$ com dado $n$ inteiro:

$$
\begin{aligned}
\Phi & =f(r) \cos (n \theta) e^{i(\xi z-\omega t)} \\
H_{r} & =h_{r}(r) \operatorname{sen}(n \theta) e^{i(\xi z-\omega t)} \\
H_{\theta} & =h_{\theta}(r) \cos (n \theta) e^{i(\xi z-\omega t)} \\
H_{z} & =h_{z}(r) \operatorname{sen}(n \theta) e^{i(\xi z-\omega t)}
\end{aligned}
$$

As funções $f(r), h_{r}(r), h_{\theta}(r)$ e $h_{z}(r)$ podem ser escritas em termos de funções de Bessel como:

$$
\begin{aligned}
f(r) & =A J_{n}(\alpha r) \\
h_{r}(r) & =B_{1} J_{n-1}(\beta r)+B_{2} J_{n+1}(\beta r) \\
h_{\theta}(r) & =B_{1} J_{n-1}(\beta r)-B_{2} J_{n+1}(\beta r) \\
h_{z}(r) & =B_{3} J_{n}(\beta r)
\end{aligned}
$$

onde: $\quad \alpha^{2}=\left(\omega / c_{1}\right)^{2}-\xi^{2} \quad$ e $\quad \beta^{2}=\left(\omega / c_{2}\right)^{2}-\xi^{2}$

Substituindo-se as equações (2.28) à (2.35) nas expressões dos deslocamentos tem-se:

$$
\begin{aligned}
& u_{r}=\left[f^{\prime}+\frac{n}{r} h_{z}+\xi h_{r}\right] \cos (n \theta) e^{i(\xi z-\omega t)} \\
& u_{\theta}=\left[-\frac{n}{r} f+\xi h_{r}-h_{z}^{\prime}\right] \operatorname{sen}(n \theta) e^{i(\xi z-\omega t)} \\
& u_{z}=\left[-\xi f-h_{r}^{\prime}-(n+1) \frac{h_{r}}{r}\right] \cos (n \theta) e^{i(\xi z-\omega t)}
\end{aligned}
$$


A partir das equações (2.36) à (2.38) pode-se chegar às seguintes expressões para as tensões:

$$
\begin{aligned}
\sigma_{r} & =\left\{-\lambda\left(\alpha^{2}+\xi^{2}\right) f+2 \mu\left[f^{\prime \prime}+\frac{n}{r}\left(h_{z}^{\prime}-\frac{h_{z}}{r}\right)+\xi h_{r}^{\prime}\right]\right\} \cos (n \theta) e^{i(\xi z-\omega t)} \\
\tau_{r \theta} & =\mu\left[\frac{-2 n}{r}\left(f^{\prime}-\frac{f}{r}\right)-2 h_{z}^{\prime \prime}+\beta^{2} h_{z}-\xi\left(\frac{n+1}{r} h_{r}-h_{r}^{\prime}\right)\right] \operatorname{sen}(n \theta) e^{i(\xi z-\omega t)} \\
\tau_{r z} & =\mu\left\{-2 \xi f^{\prime}-\frac{n}{r}\left[h_{r}^{\prime}+\left(\frac{n+1}{r}-\beta^{2}+\xi^{2}\right) h_{r}\right]-\frac{n \xi}{r} h_{z}\right\} \cos (n \theta) e^{i(\xi z-\omega t)}
\end{aligned}
$$

Para obter-se a equação frequencial basta substituir os resultados de $f(r)$, $h_{r}(r), h_{\theta}(r)$ e $h_{z}(r)$ nas expressões acima com as condições de contorno $\sigma_{r}=$ $\tau_{r \theta}=\tau_{r z}=0$ quando $r=a$. Desta forma, para que exista uma solução não trivial, o determinante resultante do conjunto de equações deve ser:

$$
\left|a_{i j}\right|=0 \quad i, j=1,2,3
$$

onde:

$$
\begin{aligned}
& a_{11}=\left[\frac{\lambda\left(\alpha^{2}+\xi^{2}\right)(\alpha a)^{2}}{2 \mu \alpha^{2}}+(\alpha a)^{2}-n^{2}\right] J_{n}(\alpha a)+\alpha a J_{n}^{\prime}(\alpha a) \\
& a_{12}=\left[n^{2}-(\beta a)^{2}\right] J_{n}(\beta a)-\beta a J_{n}^{\prime}(\beta a) \\
& a_{13}=2 n\left[\beta a J_{n}^{\prime}(\beta a)-J_{n}(\beta a)\right] \\
& a_{21}=n\left[\alpha a J_{n}^{\prime}(\alpha a)-J_{n}(\alpha a)\right] \\
& a_{22}=-n\left[\beta a J_{n}^{\prime}(\beta a)-J_{n}(\beta a)\right] \\
& a_{23}=-\left[2 n^{2}-(\beta a)^{2}\right] J_{n}(\beta a)+2 \beta a J_{n}^{\prime}(\beta a) \\
& a_{31}=-\alpha a J_{n}^{\prime}(\alpha a) \\
& a_{32}=-\frac{\beta^{2}-\xi^{2}}{2 \xi^{2}} \beta a J_{n}^{\prime}(\beta a) \\
& a_{33}=n J_{n}(\beta a)
\end{aligned}
$$




\section{(a) Ondas Longitudinais}

Para ondas longitudinais em vigas cilíndricas, é considerado que o deslocamento $u_{\theta}$ é nulo. Desta forma, das equações (2.25) e (2.27), tem-se:

$$
\begin{aligned}
u_{r} & =\frac{\partial \Phi}{\partial r}-\frac{\partial H_{\theta}}{\partial z} \\
u_{z} & =\frac{\partial \Phi}{\partial z}+\frac{1}{r} \frac{\partial}{\partial r}\left(r H_{\theta}\right)
\end{aligned}
$$

A solução para $\Phi$ e $H_{\theta}$ é dada pelas equações (2.28) e (2.30) com $n=0$ :

$$
\begin{aligned}
\Phi & =A J_{0}(\alpha r) e^{i(\xi z-\omega t)} \\
H_{\theta} & =-B_{2} J_{1}(\beta r) e^{i(\xi z-\omega t)}
\end{aligned}
$$

Substituindo-se as equações acima nas expressões das tensões, quando $r=a$, chega-se a seguinte equação frequencial para o modo longitudinal:

$$
\frac{2 \alpha}{a}\left(\beta^{2}+\xi^{2}\right) J_{1}(\alpha a) J_{1}(\beta a)-\left(\beta^{2}-\xi^{2}\right)^{2} J_{0}(\alpha a) J_{1}(\beta a)-4 \xi^{2} \alpha \beta J_{1}(\alpha a) J_{0}(\beta a)=0
$$

Os deslocamentos $u_{r}$ e $u_{z}$ para este modo são dados por:

$$
\begin{aligned}
& u_{r}=B_{2}\left[-\frac{A}{B_{2}} \alpha J_{1}(\alpha r)+i \xi J_{1}(\beta r)\right] e^{i(\xi z-\omega t)} \\
& u_{z}=B_{2}\left[\frac{A}{B_{2}} i \xi J_{0}(\alpha r)-\beta J_{0}(\beta r)\right] e^{i(\xi z-\omega t)}
\end{aligned}
$$

onde:

$$
\frac{A}{B_{2}}=-\left(\frac{\beta}{\alpha}\right)^{2} \frac{\beta^{2}-\xi^{2}}{2 \xi^{2}} \frac{J_{1}(\beta a)}{J_{1}(\alpha a)}
$$


A figura 2.3 mostra os três primeiros ramos da curva de dispersão no caso longitudinal para $\nu=0.29$. Ela corresponde as raízes reais da equação frequencial e representa em termos adimensionais, a variação da velocidade de fase $\bar{c}=c / c_{0}$ em função do número de onda $\bar{\xi}=\xi a / 2 \pi$. É importante notar que cada ponto em cima de um ramo, pode representar cilíndros de raios diferentes. A curva pontilhada é devido a correção de Rayleigh para o primeiro modo quando são considerados os efeitos de inércia lateral na formulação do problema, através da expansão das funções de Bessel em séries de potência.

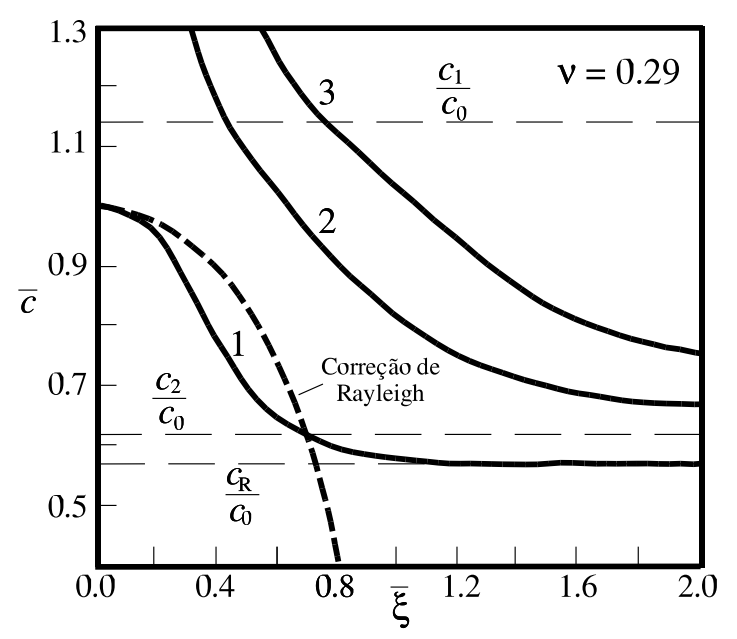

Figura 2.5: Curva de dispersão longitudinal, GRAFF (1975)

Observando-se o comportamento do primeiro modo da curva pode-se verificar, conforme GRAFF (1975), que para números de onda $\xi$ pequenos a velocidade de fase $c$ aproxima-se da velocidade clássica de propagação da onda longitudinal $c_{0}=\sqrt{E / \rho}$, caracterizando uma onda com velocidade de propagação constante ou seja, uma onda não dispersiva. Esta aproximação apresenta desvios consideráveis na medida em que ocorre o aumento de $\xi$ até que, para altos valores, $c$ se aproxima da velocidade $c_{R}$ das ondas de Rayleigh indicando que, para altas frequências o distúrbio é confinado na superfície da viga. 
A aproximação mais elementar para o caso de ondas longitudinais em vigas considera justamente que a velocidade de propagação $c$ é constante e igual a $c_{0}$. Para tanto, algumas hipóteses são assumidas como: distribuição de tensão uniforme ao longo da secção, as secções tranversais permanecem planas e os efeitos de inércia associados com o deslocamentos laterais são desprezados. Espera-se que com tais simplificações, a comparação entre os resultados de tensão obtidos pelo método de propagação de ondas com outros métodos, apresente diferenças conforme será visto no capítulo 5 .

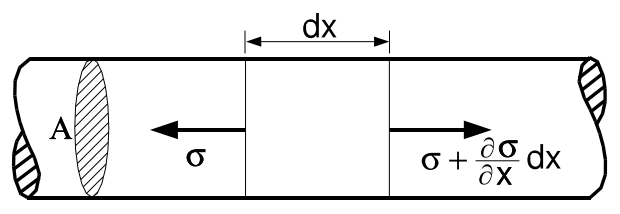

Figura 2.6: Tensão atuando sobre um elemento GOLDSMITH (1960)

Na ausência de forças de campo, aplicando-se o equilíbrio de forças para o elemento da figura 2.6, obtém-se:

$$
\begin{aligned}
\left(\sigma+\frac{\partial \sigma}{\partial x} d x\right) A-\sigma A & =m \frac{\partial^{2} u_{x}}{\partial x^{2}} \\
\frac{\partial \sigma}{\partial x} d x A & =\rho A d x \frac{\partial^{2} u_{x}}{\partial x^{2}} \\
\frac{\partial}{\partial x}\left(E \frac{\partial u_{x}}{\partial x}\right) & =\rho \frac{\partial^{2} u_{x}}{\partial x^{2}}
\end{aligned}
$$

No caso de materiais homegêneos ( $E$ e $\rho$ constantes) finalmente chega-se à equação padrão para a onda unidimensional em uma viga:

$$
\frac{\partial^{2} u_{x}}{\partial t^{2}}=c_{0}^{2} \frac{\partial^{2} u_{x}}{\partial x^{2}}
$$

onde: $c_{0}=\sqrt{E / \rho}$ 


\section{(b) Ondas Flexionais}

No caso de ondas flexionais todos os deslocamentos devem ser considerados. Isso torna a solução bastante complexa quando as equações de Pochhammer and Chree são aplicadas. Uma saída para o problema é dada por LOVE (1934) que assume os deslocamentos da forma:

$$
\begin{aligned}
& u_{r}=U^{\prime} \cos \theta e^{i(\xi z+\omega t)} \\
& u_{\theta}=V^{\prime} \operatorname{sen} \theta e^{i(\xi z+\omega t)} \\
& u_{z}=W^{\prime} \cos \theta e^{i(\xi z+\omega t)}
\end{aligned}
$$

onde: $U^{\prime}, V^{\prime}$ e $W^{\prime}$ são funções de $r$ apenas.

Novamente substituindo os deslocamentos na equação do movimento é possível escrevê-los em termos de funções de Bessel, conforme GOLDSMITH (1960):

$$
\begin{aligned}
& u_{r}=\left[B_{1} \frac{\partial}{\partial r} J_{1}(h r)+B_{2} \xi \frac{\partial}{\partial r} J_{1}\left(k^{\prime} r\right)+\frac{B_{3}}{r} J_{1}\left(k^{\prime} r\right)\right] e^{i(\xi z+\omega t)} \cos \theta \\
& u_{\theta}=-\left[\frac{B_{1}}{r} J_{1}(h r)+\frac{B_{2} \xi}{r} J_{1}\left(k^{\prime} r\right)+B_{3} \frac{\partial}{\partial r} J_{1}\left(k^{\prime} r\right)\right] e^{i(\xi z+\omega t)} \operatorname{sen} \theta \\
& u_{z}=i\left[B_{1} \xi J_{1}(h r)-B_{2} k^{\prime 2} J_{1}\left(k^{\prime} r\right)\right] e^{i(\xi z+\omega t)} \cos \theta
\end{aligned}
$$

onde: $\quad k^{\prime 2}=\frac{\omega^{2} \rho}{\mu}-\xi^{2} \quad h^{2}=\frac{\omega^{2} \rho}{\lambda+2 \mu}-\xi^{2} \quad$ e $\quad B_{1}, B_{2}$ e $B_{3}$ são constantes.

Da mesma forma que no caso longitudinal, a curva de dispersão pode ser obtida a partir da equação frequencial da viga fornecendo uma solução exata, do ponto de vista da elasticidade, para a variação da velocidade de fase $c$ em função do número de onda, $\xi$. Maiores detalhes sobre a obtenção da equação frequencial e da curva de dispersão para o caso flexional, pode ser encontrada em DAVIES (1948), KOLSKY (1963) e GRAFF (1975). 
A descrição mais elementar para as ondas flexionais em uma viga de secção constante é dada a partir da seguinte equação conhecida como equação de EulerBernouilli:

$$
E I \frac{\partial^{4} u_{y}}{\partial x^{4}}+\rho A \frac{\partial^{2} u_{y}}{\partial t^{2}}=0
$$

onde: $E$ é o módulo de elasticidade, $I$ é o momento de inércia, $A$ é a área da seç̧ão tranversal, $\rho$ é a densidade e $u_{y}$ é o deslocamento transversal da viga.

Assumindo o deslocamento transversal da forma $u_{y}=D \cos (\omega t-\xi x)$ onde $D$ é a amplitude, pode-se escrever a velocidade de fase $c$ da onda de flexão, conforme KOLSKY (1963), como:

$$
c=\frac{2 \pi c_{0} K}{\Lambda}
$$

onde: $K=\sqrt{I / A}$ é o raio de giração da secção tranversal da viga.

A equação (2.55) indica que para comprimentos de ondas infinitesimais (número de onda infinito), a velocidade de propagação da onda flexional é infinita. Para tentar minimizar esta deficiência alguns termos de correção são incorporados na equação (2.54) para considerar os efeitos de cisalhamento, rotações e contrações laterais da viga. Uma expressão bastante aplicada é a equação de Timoshenko:

$$
\frac{E I}{\rho A} \frac{\partial^{4} u_{y}}{\partial x^{4}}-\frac{I}{A}\left[1+\frac{E}{\eta^{*} \mu}\right] \frac{\partial^{4} u_{y}}{\partial x^{2} \partial t^{2}}+\frac{\partial^{2} u_{y}}{\partial t^{2}}+\frac{\rho I}{\eta^{*} A \mu} \frac{\partial^{4} u_{y}}{\partial t^{4}}=0
$$

onde: $\eta^{*}$ é um paramêtro de correção devido a distribuição não uniforme de cisalhamento na secção.

A velocidade de fase para a equação (2.56) é determinada, conforme GOLDSMITH (1960), a partir da expressão:

$$
\left(\frac{c_{0}}{c}\right)^{2}+\frac{E}{\eta^{*} \mu}\left(\frac{c}{c_{0}}\right)^{2}=1+\frac{\Lambda^{2}}{\pi^{2} R^{2}}+\frac{E}{\eta^{*} \mu}
$$


Considerando-se uma viga de secção transversal circular de raio $a$, torna-se possível comparar os resultados fornecidos pela teoria exata, com os fornecidos pelas teorias de Euler-Bernouilli e de Timoshenko. A figura 2.7 ilustra este fato quando $\nu=0.29$ plotando em termos adimensionais, a velocidade de fase $\bar{c}=c / c_{0}$ contra o número de onda $\bar{\xi}=a \xi / 2 \pi$.

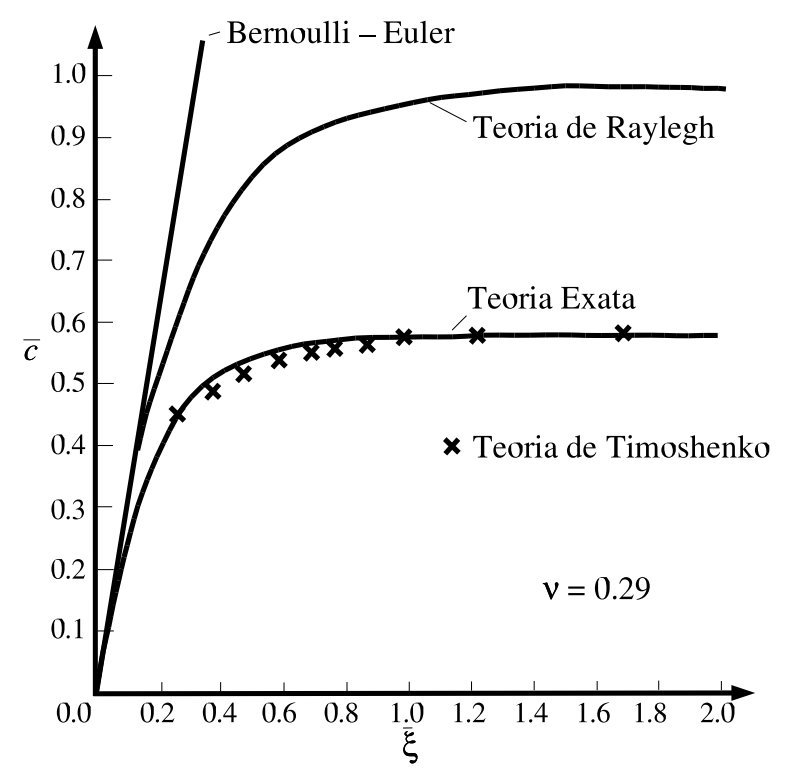

Figura 2.7: Curva de dispersão flexional, GRAFF (1975)

No caso da teoria exata, é mostrado apenas o primeiro ramo da equação frequencial que corresponde ao primeiro modo de flexão. Pode-se notar que a teoria de Timoshenko fornece uma excelente aproximação para a velocidade de fase da onda de flexão para o primeiro modo de vibrar da viga enquanto que a teoria de Euler-Bernouilli apresenta valores satisfatórios apenas para pequenos valores do número de onda. Adicionalmente também é apresentada a curva correspondente a teoria de Rayleigh quando apenas os efeitos de rotação no elemento são considerados. 


\section{(c) Ondas Torcionais}

Para ondas torcionais, é assumido que cada elemento da viga apresenta uma rotação pura em torno do eixo sem sofrer deformação. Assim $u_{r}=u_{z}=0$ e $u_{\theta}$ é função de $r$ apenas, sendo independente de $\theta$. Tal deslocamento é obtido apenas se $H_{z} \neq 0$ for assumido, resultando em:

$$
\begin{aligned}
& H_{z}=B_{3} J_{0}(\beta r) e^{i(\xi z-\omega t)} \\
& u_{\theta}=V(r) e^{i(\xi z-\omega t)}
\end{aligned}
$$

A equação frequencial para o modo torcional pode então ser deduzida, fornecendo, conforme GRAFF (1975):

$$
\beta a J_{0}(\beta a)=2 J_{1}(\beta a)
$$

A figura 2.8 mostra a curva de dispersão para o caso torcional quando $\nu=0.29$ obtida a partir da equação frequencial com os quatro primeiros modos torcionais. Ela ilustra novamente, a variação em termos adimensionais da velocidade de fase $\bar{c}=c / c_{1}$ contra o número de onda $\bar{\xi}=a \xi / 2 \pi$.

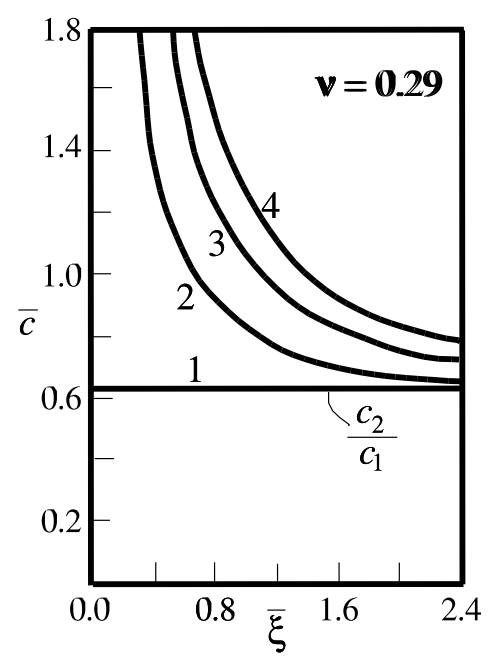

Figura 2.8: Curva de dispersão torcional, GRAFF (1975) 
Pode-se notar que o primeiro modo apresenta velocidade de fase constante e dada por $c=c_{2}=\sqrt{\mu / \rho}$ mostrando que a velocidade de propagação da onda neste caso, é não dispersiva para o primeiro modo de vibrar torcional da viga.

A aproximação mais elementar para a onda torcional é obtida, conforme JOHNSON (1972), considerando-se um pulso torcional $M_{t}$ aplicado repentinamente na extremidade da viga de raio $r$ em $t=0$. A uma distância $x$ da origem, conforme ilustrado na figura 2.9, é assumido que o plano da secção transversal gira de um ângulo $\theta$. Então um elemento da viga de comprimento $\delta x$ apresenta uma rotação em relação ao outro lado de $(\partial \theta / \partial x) \delta x$. Seja $\left(\partial M_{t} / \partial x\right)$ a taxa de mudança do torque ao longo da viga. Assim o torque resultante no elemento é de $\left(\partial M_{t} / \partial x\right) \delta x$ o que produz uma aceleração angular $\partial^{2} \theta / \partial t^{2}$, tal que:

$$
\frac{\partial M_{t}}{\partial x} \delta x=I \delta x \frac{\partial^{2} \theta}{\partial t^{2}}
$$

onde: $I \delta x$ é o momento de inércia do elemento de comprimento $\delta x$ sobre o eixo da viga.

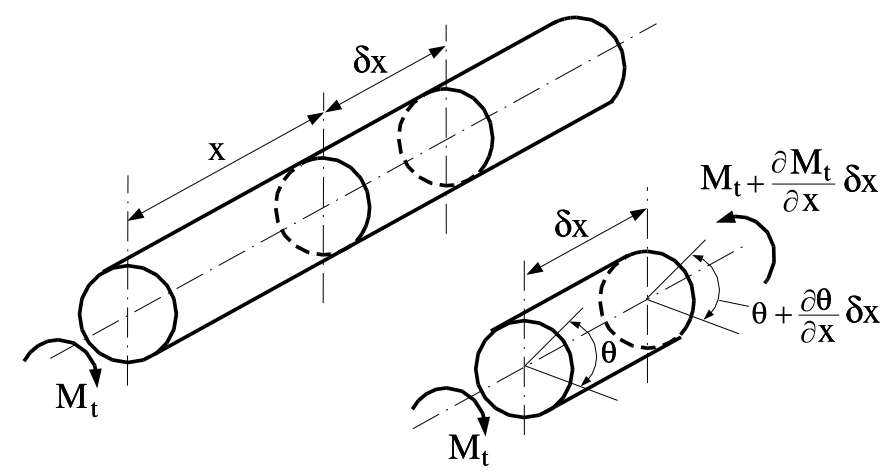

Figura 2.9: Pulso torcional JOHNSON (1972)

A partir da teoria elementar de torção tem-se que o o torque $T$ é dado por:

$$
M_{t}=\mu J_{t} \frac{\partial \theta}{\partial x}
$$

onde: $J_{t}$ é o momento polar de inércia 
É possível combinando as duas equações escrever:

$$
\frac{\partial^{2} \theta}{\partial t^{2}}=c_{t}^{2} \frac{\partial^{2} \theta}{\partial x^{2}}
$$

onde: $c_{t}=\sqrt{\frac{\mu J_{t}}{I}}$ representa a velocidade de propagação do pulso torcional ao longo da viga.

Para o caso de uma viga cilíndrica de raio $r$ tem-se que o momento de inércia por unidade de comprimento é $I=\pi r^{4} \rho / 2$ e o momento polar de inércia $J_{t}=$ $\pi r^{4} / 2$. Assim a velocidade de propagação $c_{t}$ será dada por:

$$
c_{t}=\sqrt{\frac{\mu\left(\pi r^{4}\right) / 2}{\pi r^{4} \rho / 2}} \quad \Rightarrow \quad c_{t}=c_{2}=\sqrt{\frac{\mu}{\rho}}
$$

Note que a aproximação elementar para o caso da onda torcional fornece a mesma velocidade de propagação do caso da teoria exata, demonstrando que o pulso torcional viaja com velocidade constante para o primeiro modo de vibrar da viga.

No caso de uma viga de secção transversal quadrada e de lado $2 r$ o valor da velocidade $c_{t}$ pode ser aproximada, conforme JOHNSON (1972), por:

$$
c_{t}=0.919 \sqrt{\frac{\mu}{\rho}}
$$




\section{Capítulo 3}

\section{Impacto}

\subsection{Introdução}

Nos casos em que a geometria ou as condições de contorno do problema de impacto sejam muito complexas, a solução analítica das equações (2.7) à (2.9) ou (2.10) à (2.12) torna-se de difícil obtenção e o uso do Método dos Elementos Finitos torna-se uma importante ferramenta de análise para o problema e será aplicado no capítulo 5 na determinação das tensões oriundas do impacto em vigas engastadas.

Por outro lado, em muitas situações de impacto, como o impacto longitudinal, flexional ou torcional em vigas engastadas ou bi-apoiadas, o impactador pode ser considerado como rígido, especialmente quando sua massa ou seu módulo de elasticidade é bem maior que a do sistema. Isso torna possível o desenvolvimento de alguns métodos analíticos simples para a determinação de tensões oriundas do impacto. A seguir serão desenvolvidos e discutidos alguns métodos para a obtenção destas tensões dando especial atenção aos métodos de energia e propagação de ondas. O entendimento desses sistemas simples é um pré-requisito essencial para análise de estruturas mais complexas. 


\subsection{Impacto Longitudinal em Vigas}

\subsubsection{Método da energia para o impacto longitudinal em vigas}

A figura 3.1 ilustra o impacto longitudinal de uma massa rígida $m_{2}$ colidindo com velocidade $v_{0}$ na viga de massa $m_{1}$ engastada em $x=L$. O deslocamento na direção x, o módulo de elasticidade, a densidade, a área da secção transversal e o momento de inércia são designados por: $u_{x}, E, \rho, A$ e $I$ respectivamente.

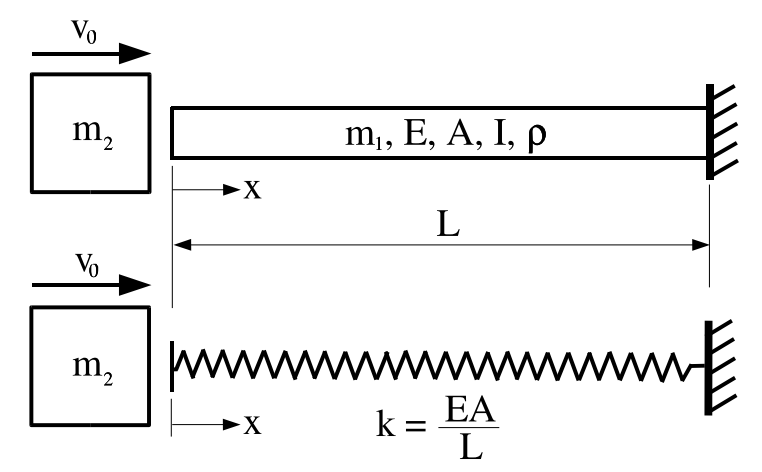

Figura 3.1: Impacto longitudinal sobre uma viga, GOLDSMITH (1960)

A aproximação mais simples para o impacto longitudinal assume a viga como uma mola de rigidez $k=E A / L$. No instante de máximo deslocamento da mola é feito o balanço de energia igualando-se a energia cinética com a potencial. Desta forma:

$$
\frac{m_{2} v_{0}^{2}}{2}=\frac{k u_{x}^{2}}{2} \quad \Rightarrow \quad \epsilon_{x}=\frac{u_{x}}{L}=v_{0} \sqrt{\frac{m_{2}}{E A L}}=\frac{v_{0}}{c_{0}} \sqrt{\frac{m_{2}}{m_{1}}}
$$

A tensão máxima será então:

$$
\sigma_{\max }=E \epsilon_{x} \Rightarrow \sigma_{\max }=\frac{E v_{0}}{c_{0}} \sqrt{\frac{m_{2}}{m_{1}}} \Rightarrow \sigma_{\max }=\sigma_{0} \sqrt{\frac{m_{2}}{m_{1}}}
$$

onde: $\quad \sigma_{0}=\rho c_{0} v_{0}$ 
Uma outra aproximação é dada por SPOTTS \& SHOUP (1998) onde é assumido que após o impacto todos os elementos da viga têm velocidades proporcionais às suas distâncias do engaste. Partindo destas considerações e aplicando as equações de conservação da quantidade de movimento e de energia é possível obter a seguinte expressão para a tensão oriunda do impacto:

$$
\sigma_{\max }=\sigma_{0} \sqrt{\frac{m_{2}}{m_{1}}\left[\frac{1}{1+\frac{m_{1}}{3 m_{2}}}\right]}
$$

\subsubsection{Método da propagação de ondas para o impacto lon- gitudinal em vigas}

A determinação de expressões para a tensão a partir do enfoque de propagação de ondas contém várias simplificações pois é baseada na equação (2.47). Quando a propagação de ondas unidimensionais é considerada, a velocidade dos elementos na face de contato do impacto no instante $t=0$ é igual a $v_{0}$ e a tensão inicial de compressão igual a $\sigma_{0}=\rho c_{0} v_{0}$. Com o decorrer do tempo, a velocidade do impactador e a pressão sobre a viga decrescerão gradualmente devido à flexibilidade do sistema. Como consequência uma onda compressiva decrescente irá se propagar ao longo do comprimento da viga em direção ao engastamento. A intensidade dessa onda pode ser escrita, conforme TIMOSHENKO \& GOODIER (1980), como:

$$
\sigma=\sigma_{0} e^{-\left(t \frac{\sqrt{E}}{m_{2}}\right)}
$$

A equação (3.4) é verdadeira no intervalo $t<2 L / c_{0}$. Quando $t=2 L / c_{0}$ a onda, já refletida no engaste, atinge novamente a interface de contato e como a velocidade do impactador não pode ser alterada repentinamente ela será refletida novamente e a tensão de compressão na interface aumentará repentinamente devido o efeito de sobreposição das ondas. Com isso, a cada intervalo de tempo $T=2 L / c_{0}$ haverá o efeito de sobreposição e a equação (3.4) deve ser corrigida. 
Sejam $s_{1}(t), s_{2}(t), s_{3}(t) \ldots$ as tensões totais de compressão na extremidade livre, depois dos respectivos intervalos $T, 2 T, 3 T \ldots$ Conforme TIMOSHENKO \& GOODIER (1980) as expressões que representam a tensão total de compressão nos respectivos intervalos são dadas por:

$$
\begin{aligned}
s_{0}(t)= & \sigma_{0} e^{-\left(\frac{2 \alpha t}{T}\right)} \\
s_{1}(t)= & s_{0}(t)+\sigma_{0} e^{-2 \alpha\left[\frac{t}{T}-1\right]}\left[1+4 \alpha\left(1-\frac{t}{T}\right)\right] \\
s_{2}(t)= & s_{1}(t)+\sigma_{0} e^{-2 \alpha\left[\frac{t}{T}-2\right]}\left[1+8 \alpha\left(2-\frac{t}{T}\right)+8 \alpha^{2}\left(2-\frac{t}{T}\right)^{2}\right] \\
s_{3}(t)= & s_{2}(t)+\sigma_{0} e^{-2 \alpha\left[\frac{t}{T}-3\right]} \\
& {\left[1+12 \alpha\left(3-\frac{t}{T}\right)+24 \alpha^{2}\left(3-\frac{t}{T}\right)^{2}+\frac{32}{3} \alpha^{3}\left(3-\frac{t}{T}\right)^{3}\right] }
\end{aligned}
$$
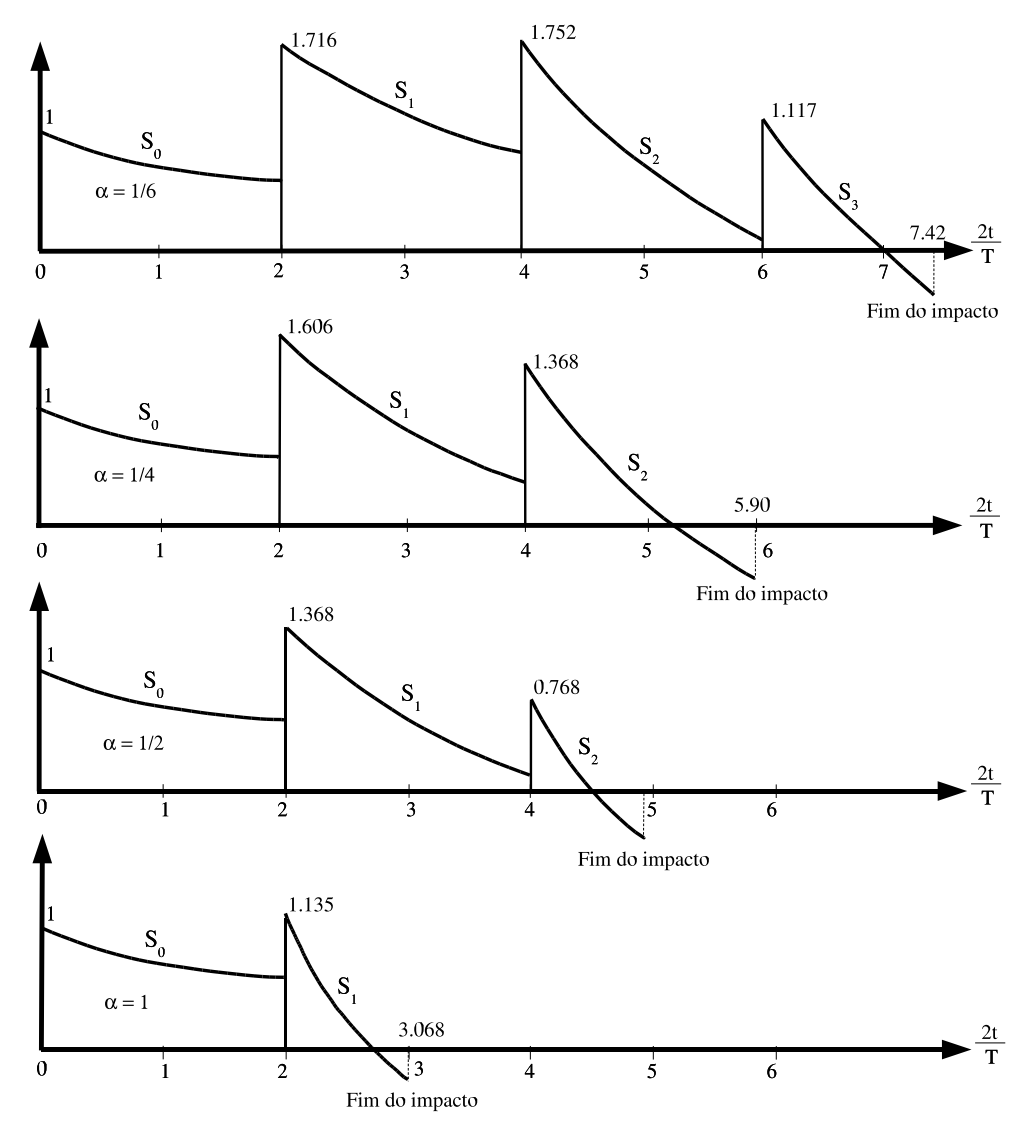

Figura 3.2: Tensão na extremidade livre, TIMOSHENKO \& GOODIER (1980) 
A figura 3.2 mostra as curvas de tensão, para diferentes relações de massa $\alpha=m_{1} / m_{2}$, na extremidade livre. É possível notar os picos de tensão devido ao efeito de sobreposição de ondas e que a máxima tensão depende do valor de $\alpha$. Para $\alpha=1, \alpha=1 / 2$ e $\alpha=1 / 4$ essa tensão tem seu máximo em $t=T$, enquanto que para $\alpha=1 / 6$ o máximo ocorre em $t=2 T$.

\subsection{Impacto Flexional em Vigas}

\subsubsection{Método da energia para o impacto flexional em vigas}

A aproximação mais simples para o caso do impacto flexional de uma massa rígida $m_{2}$ com velocidade inicial $v_{0}$ sobre uma viga biapoiada de massa $m_{1}$ conforme mostrado na figura 3.3, consiste em considerar a viga como uma mola de rigidez $k=48 E I / L^{3}$. Fazendo o balanço de energia no instante de máximo deslocamento:

$$
\frac{m_{2} v_{0}^{2}}{2}=\frac{k u_{y}^{2}}{2} \quad \Rightarrow \quad u_{y}=v_{0} \sqrt{\frac{m_{2}}{k}}
$$

Se a energia potencial da massa $m_{2}$ for incluída então:

$$
\frac{m_{2} v_{0}^{2}}{2}=\frac{k u_{y}^{2}}{2}-m_{2} g u_{y} \quad \Rightarrow \quad \frac{u_{y}}{u_{s}}=1+\sqrt{1+\frac{k v_{0}^{2}}{m_{2} g^{2}}}
$$

onde: $u_{s}=m_{2} g / k$ é a deflexão estática

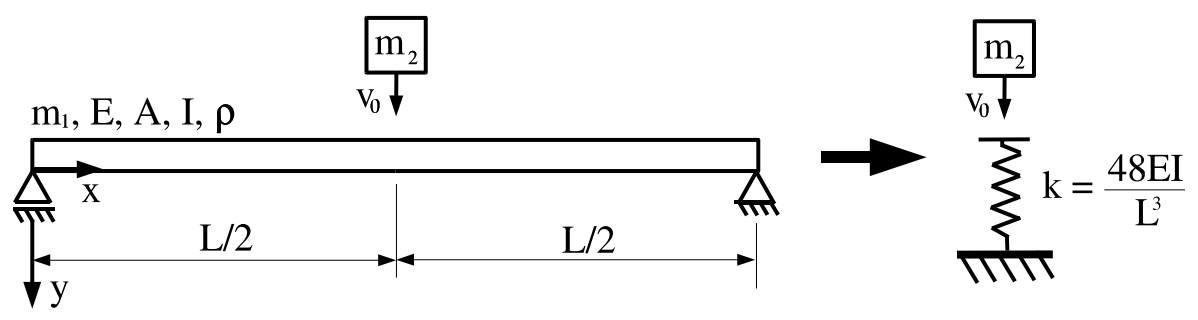

Figura 3.3: Impacto transversal viga bi-apoiada 
De acordo com GOLDSMITH (1960), significantes discrepâncias foram observadas entre os resultados fornecidos pela equação (3.10) e dados experimentais. Tais diferenças são atribuídas ao fato de que os efeitos inerciais da viga não serem considerados. Na tentativa de minimizar esses efeitos foi desenvolvida uma equação baseada na conservação de quantidade de movimento conhecida como equação de Cox.

$$
\frac{u_{y}}{u_{s}}=1+\sqrt{\left[1+\frac{v_{0}^{2} k}{m_{2} g^{2}\left(1+\frac{17}{35} \frac{m_{1}}{m_{2}}\right)}\right]}
$$

O valor da tensão máxima é obtido na secção onde o momento fletor $M_{f}$, oriundo da força $P=k \cdot u_{y}$ devido ao impacto, também é máximo, ou seja, no centro da viga. Assim:

$$
\sigma_{\max }=\frac{M_{f}}{W_{f}} \quad \Rightarrow \quad \sigma_{\max }=\frac{P L / 4}{W_{f}} \quad \Rightarrow \quad \sigma_{\max }=\frac{k \cdot u_{y} \cdot L}{4 W_{f}}
$$

onde: $W_{f}$ é o módulo de resistência a flexão.

No caso da viga engastada de massa $m_{1}$ submetida ao impacto de uma massa rígida $m_{2}$ com velocidade inicial $v_{0}$ conforme mostrado na figura 3.4, o método da energia considera a viga como uma mola de rigidez $k=3 E I / L^{3}$.

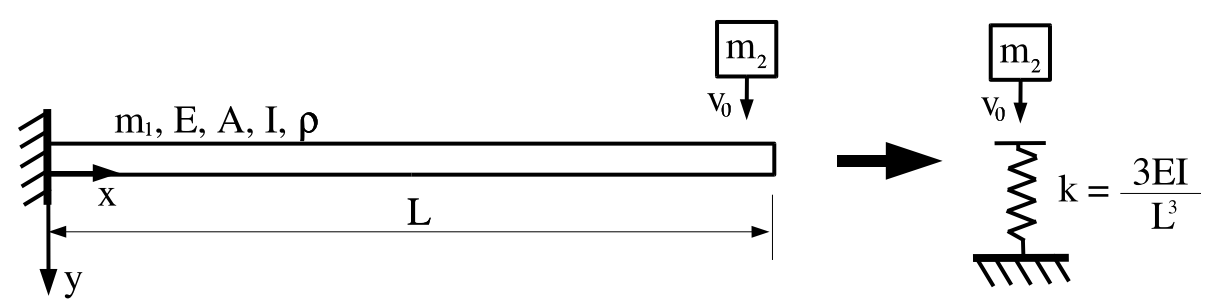

Figura 3.4: Impacto transversal viga engastada 
Da mesma forma que o caso anterior, igualando-se a energia cinética com a energia de deformação elástica obtém-se:

$$
u_{y}=v_{0} \sqrt{\frac{m_{2}}{k}}
$$

A máxima tensão ocorrerá onde o momento fletor $M_{f}$ também é máximo, ou seja, no engaste e terá seu valor dado por:

$$
\sigma_{\max }=\frac{M_{f}}{W_{f}} \quad \Rightarrow \quad \sigma_{\max }=\frac{P L}{W f} \quad \Rightarrow \quad \sigma_{\max }=\frac{k \cdot u_{y} \cdot L}{W_{f}}
$$

onde: $W_{f}$ é o módulo de resistência a flexão.

\subsubsection{Método da propagação de ondas para o impacto fle- xional em vigas}

A abordagem do problema do impacto transversal a partir da propagação de ondas é baseado na solução da equação de vibração forçada de vigas:

$$
E I \frac{\partial^{4} u_{y}}{\partial x^{4}}+\rho A \frac{\partial^{2} u_{y}}{\partial t^{2}}=F(x, t)
$$

Outras equações com fatores de correção para considerar os efeitos de inércia, cisalhamento, e contração lateral da viga também podem ser aplicadas, conforme já discutido no capítulo anterior. A deflexão $u_{y}$ neste caso, pode ser resolvida pelo método de separação de variáveis:

$$
u_{y}=\sum_{i=1}^{\infty} X_{i}(x) q_{i}(t)
$$

Uma solução para o problema pode ser encontrada em GOLDSMITH (1960) que deduz expressões da deflexão para o caso de vigas biapoiadas e engastadas. 
No caso da viga biapoiada submetida ao impacto central é obtida a seguinte expressão para o deslocamento $u_{y}$ :

$$
u_{y}(x, t)=\frac{L^{2} v_{0}}{a^{2}} \sum_{i=1}^{\infty} \frac{1}{\phi_{i}^{3}} \frac{\frac{\operatorname{sen}\left(\frac{2 \phi_{i} x}{L}\right)}{\cos \phi_{i}}-\frac{\operatorname{senh}\left(\frac{2 \phi_{i} x}{L}\right)}{\cosh \phi_{i}}}{\frac{1}{\cos ^{2} \phi_{i}}-\frac{1}{\cosh ^{2} \phi_{i}}+\frac{2 \alpha}{\phi_{i}^{2}}} \operatorname{sen}\left(\frac{4 \phi_{i}^{2} a^{2}}{L^{2}} t\right)
$$

onde: $\quad a^{4}=\frac{E I}{\rho A} \quad$ e os valores de $\phi_{i}$ são dados na tabela 3.1 para várias relações de massa .

Tabela 3.1: Valores de $\phi$ para diferentes relações de massa $\alpha=m_{1} / m_{2}$

\begin{tabular}{|c|c|c|c|c|c|c|}
\hline$\alpha$ & Pequeno & $1 / 10$ & $1 / 2$ & 1 & 2 & Grande \\
\hline \hline$\phi_{1}$ & $0.75 \alpha$ & 0.731 & 1.04799 & 1.191618 & 1.31965 & $0.5 \pi$ \\
$\phi_{2}$ & $1.25 \pi$ & 3.931 & 4.03652 & 4.11972 & 4.23720 & $1.5 \pi$ \\
$\phi_{3}$ & $2.25 \pi$ & 7.083 & 7.13400 & 7.18994 & 7.28084 & $2.5 \pi$ \\
$\phi_{4}$ & $3.25 \pi$ & 10.220 & 10.25664 & 10.29839 & 10.37041 & $3.5 \pi$ \\
$\phi_{5}$ & $4.25 \pi$ & & 13.38770 & 13.42093 & 13.48020 & $4.5 \pi$ \\
$\phi_{6}$ & $5.25 \pi$ & & 16.52269 & 16.55021 & 16.60043 & $5.5 \pi$ \\
$\phi_{7}$ & $6.25 \pi$ & & 19.65969 & 19.68824 & 19.72671 & $6.5 \pi$ \\
\hline
\end{tabular}

Partindo-se da equação do deslocamento $u_{y}(x, t)$, pode-se determinar uma expressão para a tensão $\sigma(x, t)$ considerando-se apenas o primeiro termo da série. A tensão $\sigma(x, t)$ pode ser escrita como:

$$
\sigma(x, t)=\frac{M_{f}}{I} e
$$

onde: $e$ é a distância da linha neutra a fibra externa e $M_{f}=E I \frac{\partial^{2} u_{y}}{\partial x^{2}}$

Aplicando a derivada segunda na expressão do deslocamento $u_{y}$ e considerando apenas o primeiro termo da série, tem-se:

$$
\sigma(x, t)=\frac{E L^{2} v_{0} e}{a^{2}}\left[\frac{1}{\phi_{1}^{3}} \frac{\frac{\left(\frac{2 \phi_{1}}{L}\right)^{2} \operatorname{sen}\left(\frac{2 \phi_{1} x}{L}\right)}{\cos \phi_{1}}-\frac{\left(\frac{2 \phi_{1}}{L}\right)^{2} \operatorname{senh}\left(\frac{2 \phi_{1} x}{L}\right)}{\cosh \phi_{1}}}{\frac{1}{\cos ^{2} \phi_{1}}-\frac{1}{\cosh ^{2} \phi_{1}}+\frac{2 \alpha}{\phi_{1}^{2}}}\right] \operatorname{sen}\left(\frac{4 \phi_{1}^{2} a^{2}}{L^{2}} t\right)
$$

Pela equação acima, pode-se verificar que a tensão será máxima no centro da viga, ou seja, quando $x=0.5 L$ e ocorrerá no tempo $t=\pi L^{2} / 8 a^{2} \phi_{1}^{2}$. 
No caso da viga engastada em $x=0$ e impactada em $x=L$ é fornecida a seguinte expressão para o deslocamento $u_{y}(x, t)$ :

$$
\begin{aligned}
u_{y}(x, t)= & \frac{2 L^{2} v_{0}}{a^{2}} \sum_{i=1}^{\infty} \frac{1}{\phi_{i}^{2}} \\
& {\left[\frac{\left(\operatorname{sen} \phi_{i} \cosh \phi_{i}-\cos \phi_{i} \operatorname{senh} \phi_{i}\right)\left(\operatorname{sen} \phi_{i}+\operatorname{senh} \phi_{i}\right)\left(\cos \phi_{i}+\cosh \phi_{i}\right)}{\left(\operatorname{sen} \phi_{i} \cosh \phi_{i}-\cos \phi_{i} \operatorname{senh} \phi_{i}\right)^{2}+Q\left(\operatorname{sen} \phi_{i}+\operatorname{senh} \phi_{i}\right)^{2}}\right] } \\
& {\left[\frac{\cosh \frac{\phi_{i} x}{L}-\cos \frac{\phi_{i} x}{L}}{\cosh \phi_{i}+\cos \phi_{i}}-\frac{\operatorname{senh} \frac{\phi_{i} x}{L}-\operatorname{sen} \frac{\phi_{i} x}{L}}{\operatorname{senh} \phi_{i}+\operatorname{sen} \phi_{i}}\right] \operatorname{sen} \frac{\phi_{i}^{2} a^{2} t}{L^{2}} }
\end{aligned}
$$

onde: $Q=\frac{\phi_{i}\left(\operatorname{sen} \phi_{i} \cosh \phi_{i}-\cos \phi_{i} \operatorname{senh} \phi_{i}\right)}{1+\cos \phi_{i} \cosh \phi_{i}}$ e os valores de $\phi_{i}$ são dados na tabela 3.1

A figura 3.5 mostra, para uma relação de massas $\alpha=1$, a variação do deslocamento $u(x, t)$ em função do tempo, em termos adimensionais, para diferentes posições da viga.

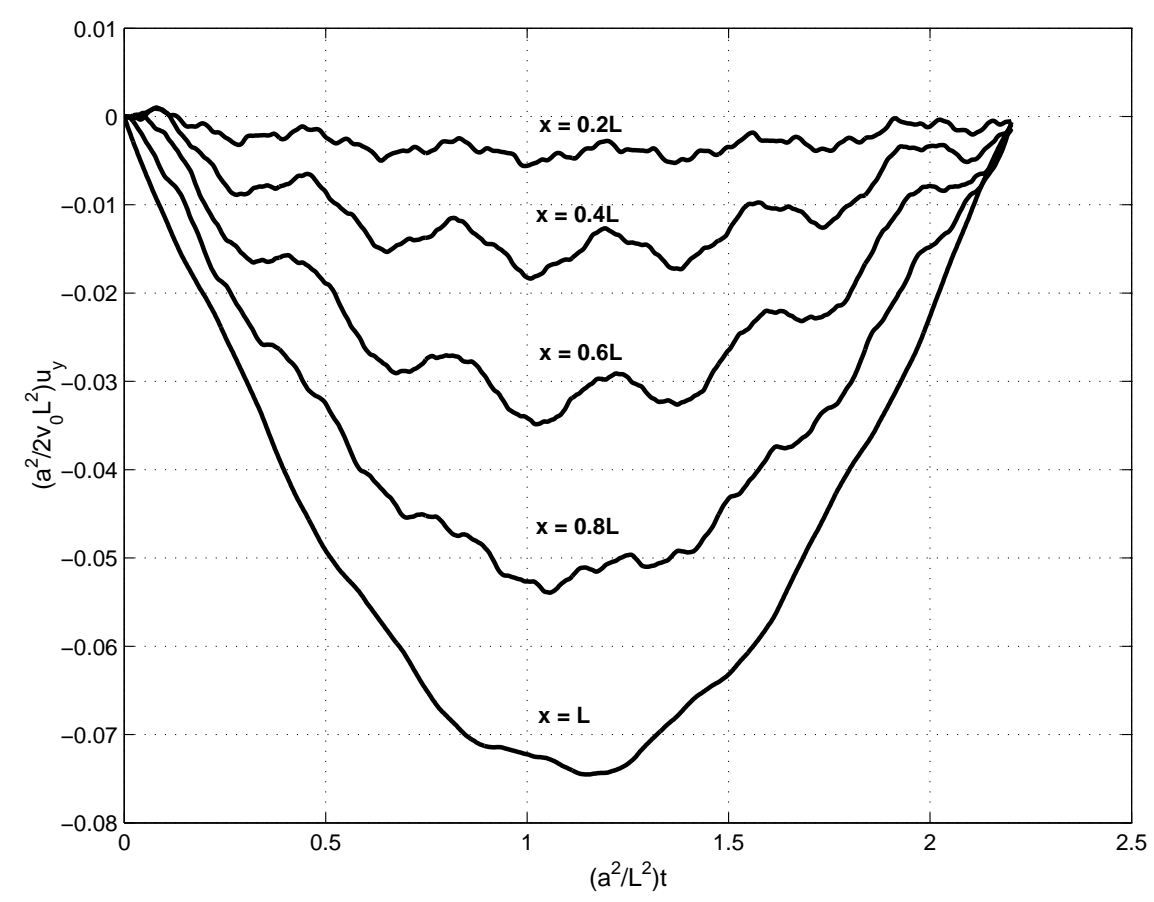

Figura 3.5: Deslocamento $u_{y}$ para viga engastada quando $\alpha=1$ 
Procedendo-se como anteriormente, a expressão para a tensão $\sigma(x, t)$ é determinada partindo-se da equação (3.17) e considerando-se apenas o primeiro termo da série. Assim:

$$
\begin{aligned}
\sigma(x, t)= & \frac{2 E L^{2} v_{0} e}{a^{2}} \frac{1}{\phi_{1}^{2}} \\
& {\left[\frac{\left(\operatorname{sen} \phi_{1} \cosh \phi_{1}-\cos \phi_{1} \operatorname{senh} \phi_{1}\right)\left(\operatorname{sen} \phi_{1}+\operatorname{senh} \phi_{1}\right)\left(\cos \phi_{1}+\cosh \phi_{1}\right)}{\left(\operatorname{sen} \phi_{1} \cosh \phi_{1}-\cos \phi_{1} \operatorname{senh} \phi_{1}\right)^{2}+Q\left(\operatorname{sen} \phi_{1}+\operatorname{senh} \phi_{1}\right)^{2}}\right] } \\
& {\left[\frac{\left(\frac{\phi_{1}}{L}\right)^{2} \cosh \frac{\phi_{1} x}{L}-\left(\frac{\phi_{1}}{L}\right)^{2} \cos \frac{\phi_{1} x}{L}}{\cosh \phi_{1}+\cos \phi_{1}}-\frac{\left(\frac{\phi_{1}}{L}\right)^{2} \operatorname{senh} \frac{\phi_{1} x}{L}-\left(\frac{\phi_{1}}{L}\right)^{2} \operatorname{sen} \frac{\phi_{1} x}{L}}{\operatorname{senh} \phi_{1}+\operatorname{sen} \phi_{1}}\right] \operatorname{sen} \frac{\phi_{1}^{2} a^{2} t}{L^{2}} }
\end{aligned}
$$

Neste caso a tensão será máxima no engaste, ou seja, em $x=0$ e ocorrerá quando $t=\pi L^{2} / 2 a^{2} \phi_{1}^{2}$. A figura 3.6 representa em diferentes posições $x / L$ da viga a variação da tensão $\sigma(x, t)$ em função do tempo, ambos adimensionalizados, para uma relação de massas $\alpha=1$.

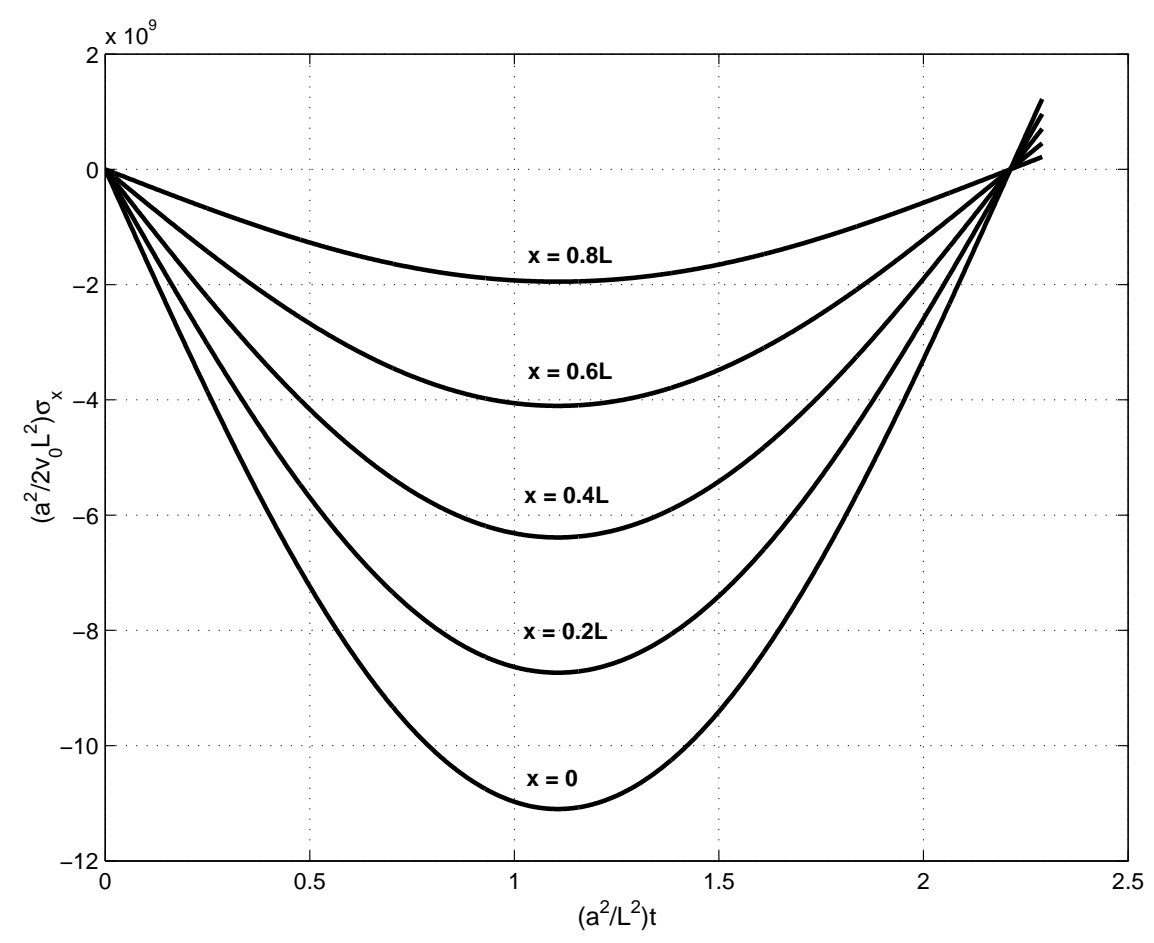

Figura 3.6: Tensão normal $\sigma_{x}$ para viga engastada quando $\alpha=1$ 


\subsection{Impacto Torcional em Vigas}

\subsubsection{Método da energia para o impacto torcional em vi- gas}

A aproximação mais elementar para o caso do impacto torcional considera a viga engastada de comprimento $L$ submetida à um impacto que gera um momento torçor $M_{t}$ em sua extremidade livre, como uma mola de rigidez $k=\mu J_{t} / L$ conforme ilustrado na figura 3.7, onde $J_{t}$ é o momento polar de inércia. Igualando-se a energia potêncial elástica absorvida pela viga, com a energia cinética dos dois impactadores tem-se:

$$
\frac{m_{2} v_{0}^{2}}{2}=\frac{k \theta^{2}}{2} \quad \Rightarrow \quad \theta=v_{0} \sqrt{\frac{m_{2}}{k}}
$$

A tensão de cisalhamento máxima, $\tau_{\max }$, será dada por:

$$
\tau_{\max }=\frac{M_{t}}{W_{t}} \quad \Rightarrow \quad \tau_{\max }=\frac{k \cdot \theta}{W_{t}}
$$

onde: $W_{t}$ é o módulo de resistência a torção.

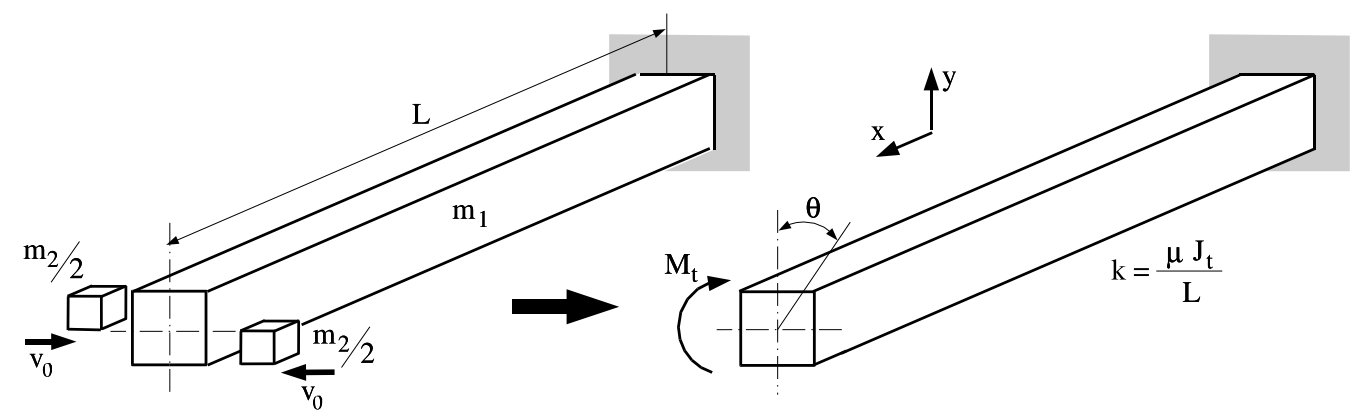

Figura 3.7: Viga submetida à um impacto torcional 


\subsubsection{Método da propagação de ondas para o impacto tor- cional em vigas}

De acordo com JOHNSON (1972), quando a abordagem do problema é feita a partir da teoria de propagação de ondas deve-se assumir a solução do ângulo de rotação $\theta$ na forma $\theta=f\left(x-c_{t} t\right)$. Assim:

$$
\begin{aligned}
& \frac{\partial \theta}{\partial x}=f^{\prime}\left(x-c_{t} t\right) \\
& \frac{\partial \theta}{\partial t}=-c_{t} f^{\prime}\left(x-c_{t} t\right)
\end{aligned}
$$

A partir das equações acima é possível escrever:

$$
\frac{\partial \theta}{\partial x}=-\frac{1}{c_{t}} \frac{\partial \theta}{\partial t}
$$

Mas da teoria elementar de torção:

$$
M_{t}=\mu J \frac{\partial \theta}{\partial x}
$$

Combinando as equações tem-se:

$$
M_{t}=-\frac{\mu J_{t}}{c_{t}} \frac{\partial \theta}{\partial t}=J_{t} \sqrt{\mu \rho} \cdot \frac{\partial \theta}{\partial t}
$$

onde: $\partial \theta / \partial t$ é a velocidade angular da secção.

A tensão de cisalhamento máxima pode então ser determinada dividindo-se o momento torçor $M_{t}$ pelo módulo de resistência a torção $W_{t}$ supondo ser conhecido o valor da velocidade angular da secção.

$$
\tau_{\max }=\frac{M_{t}}{W_{t}}
$$




\section{Capítulo 4}

\section{MEF aplicado à Dinâmica não-Linear}

\subsection{Introdução}

Atualmente, com o acesso a computadores potentes, o método dos elementos finitos (MEF) tornou-se uma importante e frequentemente indispensável ferramenta de análise e projeto em engenharia, podendo ser integrado ao ambiente CAD/CAM minimizando o tempo e os custos do produto. Programas computacionais de elementos finitos são aplicados na análise de sólidos e estruturas, no estudo de transferência de calor e de escoamento de fluídos.

A figura 4.1 resume o processo de análise pelo MEF. O problema físico envolve uma estrutura real ou componentes estruturais sujeitos a certos carregamentos. A idealização do problema para um modelo matemático requer certas considerações que permitem obter equações diferenciais que governam o modelo. O MEF resolve estas equações e como é um procedimento numérico torna-se necessário o refinamento dos parâmetros de solução até que a acuracidade desejada seja alcançada. Então os resultados devem ser interpretados e pode-se optar pelo refinamento do modelo matemático. 


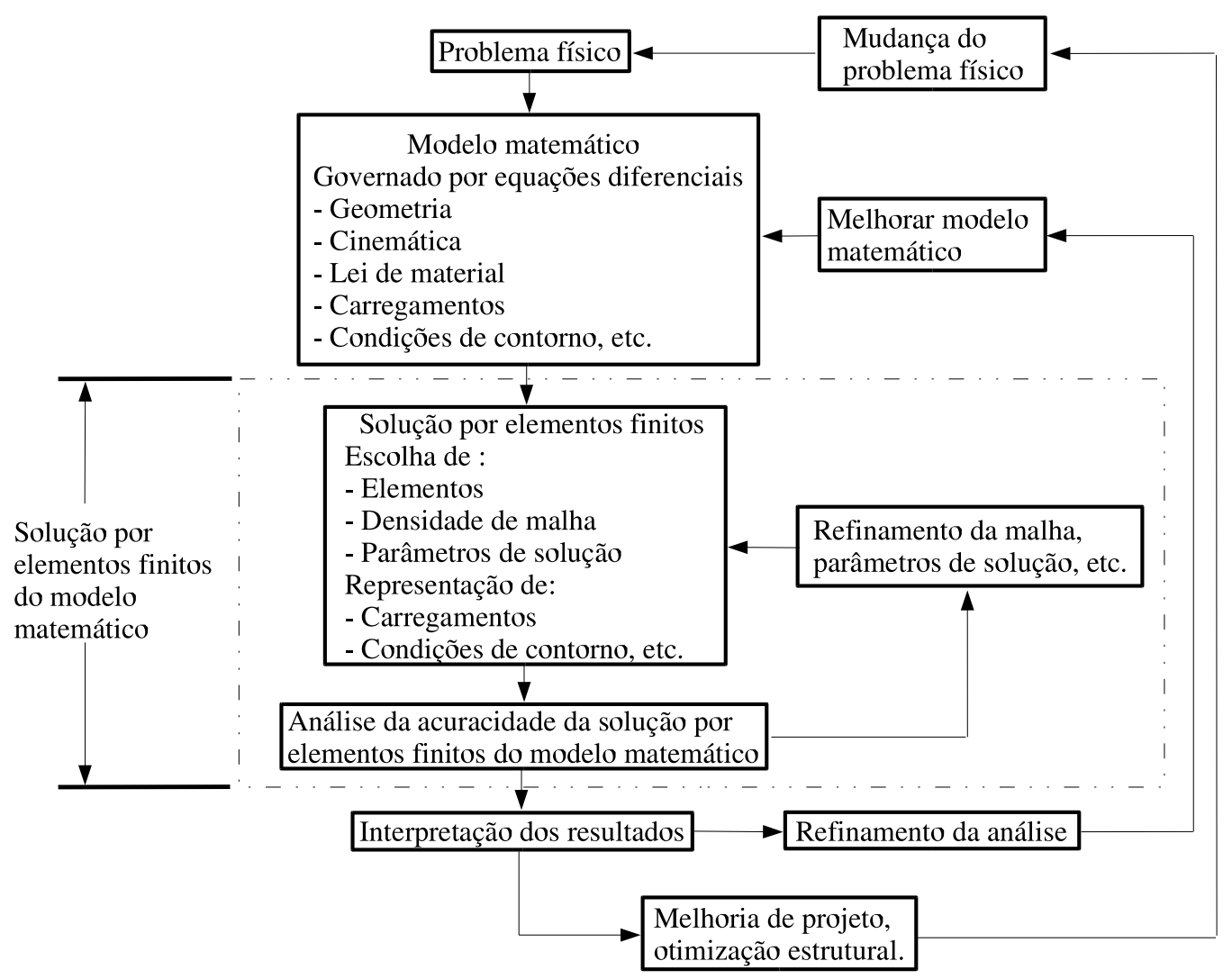

Figura 4.1: Processo de análise por elementos finitos BATHE (1996)

De acordo com HUEBNER et al. (1994) o MEF pode ser sumarizado basicamente em três etapas: pré-processamento, solução e pós-processamento.

- Pré-processamento: é a etapa de preparação onde é feita a modelagem do problema, a escolha do tipo de análise assumindo hipóteses, condições iniciais e de contorno, carregamentos, escolha dos elementos e das propriedades do material.

- Solução: é baseada em algorítmos numéricos que visam solucionar de maneira rápida e acurada as equações diferenciais com as condições iniciais e de contorno advindas da modelagem.

- Pós-processamento: é a etapa onde o conjunto de soluções obtidas, como deslocamentos, deformações, tensões, temperaturas, frequências naturais, etc; são visualizadas e interpretadas. 
No presente capítulo serão apresentados os métodos da integração implícita e explícita no tempo para a solução do problema dinâmico não-linear e além de serem apresentados alguns parâmetros de contato utilizados nos softwares comerciais ANSYS ${ }^{\circledR} 5.7$ e LS-DYNA ${ }^{\circledR} 960$.

\subsection{Análise Dinâmica de Sistemas Lineares: in- tegração no tempo}

A equação de equilíbrio para a resposta dinâmica linear de um sistema mecânico é dada por:

$$
[M]\{\ddot{u}\}+[C]\{\dot{u}\}+[K]\{u\}=\{F\}
$$

onde $[M],[C]$ e $[K]$ são as matrizes de massa, amortecimento e rigidez respectivamente; $\{F\}$ é o vetor de forças externas aplicadas; e $\{\ddot{u}\},\{\dot{u}\}$ e $\{u\}$ são os vetores de aceleração, velocidade e deslocamento respectivamente.

Matematicamente a equação (4.1) representa um sistema de equações diferenciais de segunda ordem e, em princípio, sua solução pode ser obtida por procedimentos padrões de solução de equações diferenciais com coeficientes constantes. $\mathrm{Na}$ análise por elementos finitos dois principais métodos são aplicados: o método de integração direta e o de sobreposição modal.

No caso dos métodos de integração, a idéia básica é de tentar satisfazer a equação (4.1) em intervalos de tempo discretos $\Delta t$ assumindo uma variação dos vetores de deslocamento, velocidade e aceleração dentro destes intervalos. A forma de variação destes vetores é que determina a acuracidade e estabilidade dos métodos.

Diferentes expressões para a aproximação dos vetores de aceleração $\{\ddot{u}\}$ e velocidade $\{\dot{u}\}$ em termos do deslocamento $\{u\}$ podem ser obtidas a partir do método de diferenças finitas. Dentre as possibilidades destaca-se o método das 
diferenças centrais que considera:

$$
\{\ddot{u}\}_{(t)}=\frac{1}{\Delta t^{2}}\left[\{u\}_{(t-\Delta t)}-2\{u\}_{(t)}+\{u\}_{(t+\Delta t)}\right]
$$

O erro da aproximação é da ordem de $\Delta t^{2}$ e é o mesmo para a expresão da velocidade:

$$
\{\dot{u}\}_{(t)}=\frac{1}{2 \Delta t}\left[\{u\}_{(t+\Delta t)}-\{u\}_{(t-\Delta t)}\right]
$$

$\mathrm{O}$ valor do deslocamento no passo seguinte $t+\Delta t$ é obtido substituindo as expressões de $\{\ddot{u}\}_{(t)}$ e $\{\dot{u}\}_{(t)}$ na equação de equilíbrio, assim:

$$
\begin{aligned}
\left(\frac{1}{\Delta t^{2}}[M]+\frac{1}{2 \Delta t}[C]\right)\{u\}_{(t+\Delta t)}= & \{F\}_{(t)}-\left([K]-\frac{2}{\Delta t^{2}}[M]\right)\{u\}_{(t)} \\
& -\left(\frac{1}{\Delta t^{2}}[M]-\frac{1}{2 \Delta t}[C]\right)\{u\}_{(t-\Delta t)}
\end{aligned}
$$

\subsubsection{Método da Integração Implícita no Tempo}

A equação (4.4) pode ser escrita na seguinte forma:

$$
[\bar{K}]\{u\}_{(t+\Delta t)}=\{\bar{F}\}_{(t)}
$$

onde:

$$
\begin{aligned}
{[\bar{K}] } & =\frac{1}{\Delta t^{2}}[M]+\frac{1}{2 \Delta t}[C] \\
\{\bar{F}\}_{(t)} & =\{F\}_{(t)}-\left([K]-\frac{2}{\Delta t^{2}}[M]\right)\{u\}_{(t)}-\left(\frac{1}{\Delta t^{2}}[M]-\frac{1}{2 \Delta t}[C]\right)\{u\}_{(t-\Delta t)}
\end{aligned}
$$

No caso em que as matrizes de massa e amortecimento são consistentes, a equação (4.5) caracteriza o algorítmo implícito desde que, um conjunto de equações algébricas tem que ser resolvido simultaneamente a cada passo de tempo, ou seja, as equações estão acopladas e é preciso inverter a matriz de rigidez efetiva $[\bar{K}]$ em cada passo. 
As principais vantagens do algorítmo dinâmico implícito são:

- A convergência é garantida independente do tamanho do incremento de tempo $\Delta t$ adotado, ou seja, ele é incondicionalmente convergente.

- A solução do problema não contém simplificações de diagonalização das matrizes.

As desvantagens do algorítmo dinâmico implícito são:

- Requer grandes recursos computacionais de memória e processamento.

- É mais sensível a instabilidade quando em situações especiais a matriz de rigidez tende a singularidade (instabilidade elástica).

- Pacotes comerciais são limitados.

\subsubsection{Método da Integração Explícita no Tempo}

Quando são utilizadas matrizes de massa e amortecimento diagonalizadas na equação (4.5), a matriz de rigidez efetiva $[\bar{K}]$ torna-se diagonal $[\backslash \bar{K} \backslash]$ e o sistema de equações algébricas fica desacoplado. Com isso não é necessário inverter a matriz de rigidez efetiva a cada passo de tempo.

$$
\left[\nwarrow \bar{K} \backslash\{u\}_{(t+\Delta t)}=\{\bar{F}\}_{(t)}\right.
$$

onde:

$$
\begin{aligned}
& {[\nwarrow \bar{K} \backslash]=\frac{1}{\Delta t^{2}}\left[{ }^{\searrow} M \backslash\right]+\frac{1}{2 \Delta t}[{ } C \backslash]} \\
& \{\bar{F}\}_{(t)}=\{F\}_{(t)}-\left([K]-\frac{2}{\Delta t^{2}}\left[\nwarrow_{M \backslash}\right]\right)\{u\}_{(t)}- \\
& \left(\frac{1}{\Delta t^{2}}\left[{ }^{\nwarrow} M \backslash-\frac{1}{2 \Delta t}\left[{ }_{\searrow}\right]\right)\{u\}_{(t-\Delta t)}\right.
\end{aligned}
$$


As principais vantagens do algorítmo dinâmico explícito são:

- É um algorítmo robusto e mais simples de implementar computacionalmente que o implícito.

- É mais rápido e requer menos memória.

- Tem bom desempenho para instabilidade da matriz de rigidez.

A principal desvantagen do algorítmo dinâmico explícito é que sua convergência depende da escolha do incremento de tempo $\Delta t$, ou seja, o algorítmo é condicionalmente convergente.

No caso do problema de propagação de ondas gerada pelo impacto, o incremento de tempo $\Delta t$ deve ser capaz de representar a passagem da onda por um comprimento efetivo $L_{e}$. O valor de $L_{e}$ depende do tipo de elemento e do método de integração aplicado. Assim, o incremento de tempo crítico $\Delta t_{\text {crit }}$ que corresponde ao limite de estabilidade do método explícito é dado por

$$
\Delta t_{c r i t}=\frac{L_{e}}{c}
$$

onde $c$ é a velocidade de propagação da onda $(c=\sqrt{E / \rho})$

A condição $\Delta t \leq \Delta t_{\text {crit }}$ que permite a estabilidade do método e é conhecida como condição CFL dada por: R. Courant, K. Friedrichs e H. Lewy.

A aplicação do método da integração explícita no tempo na resolução do problema de propagação de ondas tem sido investigada por diferentes autores. Conforme BATHE (1996) quando o método explícito é aplicado, o uso de elementos de baixa ordem de quatro nós no caso plano e de oito nós no caso tridimensional, com uma densidade de malha regular é mais eficiente e o $L_{e}$ é igual a menor distância entre quaisquer dois nós da malha. Um estudo sobre a instabilidade da integração explícita devido a variação dos incrementos de tempo abaixo do $\Delta t_{c r i t}$ é apresentada em WRIGHT (1998). Uma comparação com outros métodos é apresentada em SERON et al. (1990) que conclui que a integração explícita é adequada para o estudo do fenômeno. Em KRENK (2001) é apresentado um método de correção 
para a dispersão numérica oriunda da discretização. Acrescentando alguns termos na formulação das matrizes de massa e de rigidez ele obteve uma amenização da dispersão no algorítmo de integração explícita no tempo. Já CHRISTON (1999) discute a influência da matriz de massa na dispersão numérica. O problema da dispersão numérica devido a discretização temporal e espacial também é discutido em SCHREYER (1983).

\subsection{Análise Dinâmica de Sistemas não-Lineares}

Um dos problemas mais comuns e difíceis em engenharia é a solução de movimentos transientes em sistemas não lineares. Citam-se como principais exemplos os problemas de impacto e os problemas de conformação. Nestes tipos de problema os deslocamentos $\{u\}$ não variam linearmente com a carga aplicada, ou seja, a matriz de rigidez $[K]$ é não-linear sendo função dos deslocamentos $\{u\}$. A equação (4.1) torna-se então:

$$
[M]\{\ddot{u}\}+[C]\{\dot{u}\}+[K(u)]\{u\}=\{F\}
$$

De acordo com BATHE (1996) a não linearidade pode ser atribuída à três fatores principais:

- Grandes deslocamentos, rotações e deformações, caracterizando uma não linearidade cinemática.

- Plasticidade e viscoplasticidade, caracterizando uma não-linearidade de material.

- Contato e atrito, caracterizando uma não-linearidade de condição de contorno.

Nos problemas de impacto em estudo neste trabalho, a única não-linearidade presente será a de condição de contorno devido ao contato entre os corpos. 


\subsubsection{Contato}

O problema de contato entre dois ou mais corpos é particularmente difícil de ser analisado devido, não somente a não linearidade de condição de contorno, mas também devido aos modelos de atrito aplicados, na sua maioria não lineares. Considere-se $N$ corpos que estão em contato no tempo $t$. Seja ${ }^{t} S_{c}$ a área de contato para cada corpo $L, L=1, \cdots, N$. O princípio dos trabalhos virtuais para os $N$ corpos, no tempo $t$ fornece, conforme BATHE (1996), o seguinte funcional П:

$$
\begin{aligned}
\Pi= & \sum_{L=1}^{N} \int_{V} \sigma \cdot \delta \epsilon \cdot d V+\sum_{L=1}^{N} \int_{V} \delta u \cdot F^{B} \cdot d V+ \\
& \sum_{L=1}^{N} \int_{S} \delta u^{S} \cdot F^{S} \cdot d S+\sum_{L=1}^{N} \int_{C} \delta u^{C} \cdot F^{C} \cdot d S
\end{aligned}
$$

onde:

$$
\begin{array}{ll}
\sigma & : \text { Tensões internas } \\
\delta \epsilon & : \text { Deformações virtuais internas } \\
\delta u & : \text { Deslocamento virtual } \\
\delta u^{S} & : \text { Deslocamento virtual na superfície de forças de superfícies } \\
\delta u^{C} & : \text { Deslocamento virtual na superfície de contato } \\
F^{B} & : \text { Forças de campo } \\
F^{S} & : \text { Forças de superfície } \\
F^{C} & : \text { Forças de contato }
\end{array}
$$

O efeito das forças de contato, presentes no último termo da equação (4.9), é incluído como uma contribuição às forças de superfície aplicadas externamente. Seja $f^{I J}$ o vetor contendo as forças de superfície devido ao contato do corpo $I$ causada pelo corpo $J$, e $f^{I J}=-f^{J I}$ conforme a figura 4.2. O trabalho virtual devido as forças de tração do contato pode ser escrito como:

$$
\int_{S^{I J}} \delta u_{i}^{I} \cdot f_{i}^{I J} \cdot d S^{I J}+\int_{S^{J I}} \delta u_{i}^{J} \cdot f_{i}^{J I} \cdot d S^{J I}=\int_{S^{I J}} \delta u_{i}^{I J} \cdot f_{i}^{I J} \cdot d S^{I J}
$$

onde: $\delta u_{i}^{I}$ e $\delta u_{i}^{J}$ são as componentes de deslocamento virtual sobre as superfícies de contato dos corpos $I$ e $J$ respectivamente e o termo $\delta u_{i}^{I J}=\delta u_{i}^{I}-\delta u_{i}^{J}$. 
O par de superfícies $S^{I J}$ e $S^{J I}$ que estão em contato, não têm necessariamente o mesmo tamanho e são denominadas de superfície contatora e superfície alvo, respectivamente. Contudo, a área atual de contato em um tempo $t$ para os corpos $I$ e $J$ é ${ }^{t} S_{C}$, e em cada caso está área é parte de $S^{I J}$ e $S^{J I}$. O lado direito da equação (4.10) pode ser interpretado como o trabalho virtual que as forças de contato produzem sobre o deslocamento virtual relativo do par de superfícies em contato.
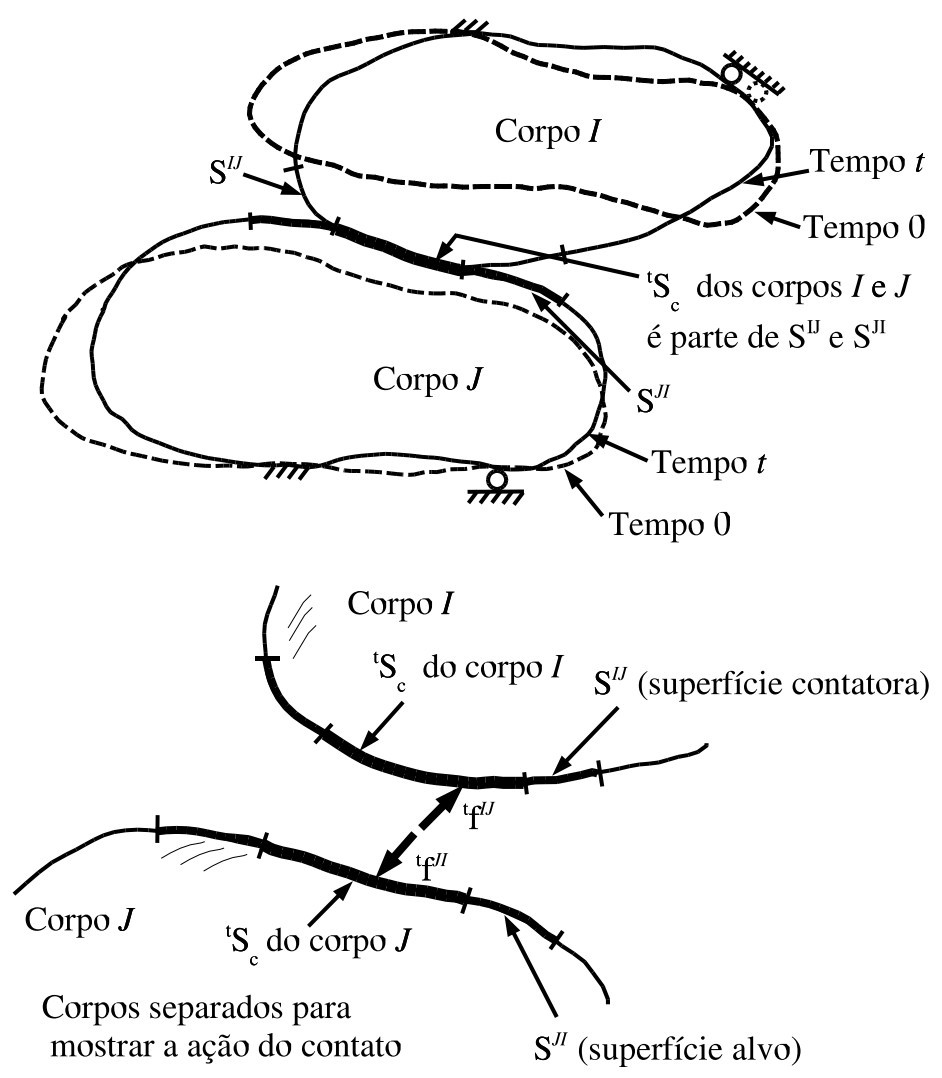

Figura 4.2: Corpos em contato, BATHE (1996)

Basicamente existem dois métodos para a solução do problema de contato entre sólidos disponíveis na literatura e em softwares comerciais. São eles:

- Método dos Multiplicadores de Lagrange

- Método da Penalização 
O primeiro calcula de modo exato as restrições de contato, sendo vantajoso quando se quer extremizar um funcional com restrições adicionais impostas. Como inconveniente apresenta um aumento do número de incógnitas devido aos multiplicadores associados com as forças de contato e ainda induz o aparecimento de zeros na diagonal principal da matriz de rigidez.

O segundo método requer que as restrições de contato sejam calculadas de forma aproximada através de um fator de penalização. O problema passa a ser a escolha adequada deste fator uma vez que, na medida em que o fator de penalização aumenta, a matriz de rigidez torna-se mau-condicionada e por outro lado, valores muito baixos do fator, podem levar a penetrações inaceitáveis de um sólido em outro. Em MOTTERSHEAD et al. (1992) é proposto um algorítmo geral que aplica o método dos multiplicadores ou da penalização para o tratamento do contato entre corpos elásticos. Já FARAHANI et al. (2000) apresenta um método de análise para o problema de contato-impacto que minimiza as desvantagens destes dois métodos. No caso de grandes deformações devido ao impacto entre os corpos, HEINSTEIN et al. (2000) discute alguns aspectos do problema de contato.

\section{Contato no ANSYS ${ }^{\circledR} 5.7$ e LS-DYNA ${ }^{\circledR} 960$}

Diferentes opções e tipos de contato estão disponíveis no software comercial ANSYS ${ }^{\circledR} 5.7$ e LS-DYNA ${ }^{\circledR} 960$ com o objetivo de descrever a interação entre geometrias complexas durante o contato com grandes deformaçẽs e/ou impactos dinâmicos.

A seguir serão descritos alguns procedimentos de análise e modelagem do

problema de contato no ANSYS ${ }^{\circledR} 5.7$ conforme o manual teórico devido à HALLQUIST (1993).

\section{(1) Determinação do tipo de contato e opções}

A tabela 4.1 mostra as opções e os tipos de contato disponíveis no software. 
Tabela 4.1: Tipos de contato, HALLQUIST (1993)

\begin{tabular}{|c|c|c|c|}
\hline Contato & $\begin{array}{c}\text { Superfície } \\
\text { simples }\end{array}$ & $\begin{array}{c}\text { Nó } \\
\mathbf{x} \\
\text { Superfície }\end{array}$ & $\begin{array}{c}\text { Superfície } \\
\mathbf{x} \\
\text { Superfície }\end{array}$ \\
\hline \hline Geral & SS & NTS & STS, OSTS \\
\hline Automático & ASSC & ANTS & ASTS \\
\hline Rígido & - & RNTR & ROTR \\
\hline Tied & - & TDNS & TDSS \\
\hline Tiebreak & - & TNTS & TSTS \\
\hline Eroding & ESS & ENTS & ESTS \\
\hline Drawbead & - & DRAWBEAD & - \\
\hline
\end{tabular}

i) Contato automático de superfície simples : É estabelecido quando uma superfície entra em contato consigo mesma ou com a superfície de outro corpo. É o tipo de contato mais simples de ser definido uma vez que não é necessário definir as superfícies contatora e alvo. Pode ser utilizado em aplicações de impacto.

ii) Contato de nó contra superfície : É estabelecido quando um nó contator penetra uma superfície alvo e é comumente utilizado para contatos gerais entre superfícies.

iii) Contato de superfície contra superfície : É estabelecido quando a superfície de um corpo penetra a superfície de outro sendo mais aplicado em corpos que possuem formas arbitrárias e áreas de contato relativamente grandes.

Para os diferentes tipos de contato, existem as seguintes opções:

a) Contato geral: Utiliza o mais simples algorítmo de contato e tem como principal vantagem ser extremamente rápido e robusto. O orientação do contato é feita automaticamente para elementos sólidos mas o mesmo não ocorre no caso de elementos shell.

b) Contato automático : Este algorítmo de contato se diferencia do primeiro caso apenas por determinar automaticamente a orientação da superfície de contato para elementos do tipo shell. 
c) Contato rígido : Tipicamente utilizado na dinâmica de multicorpos, onde todos os corpos são rígidos.

d) Contato tied : Os nós da superfície contatora, são colados à superfície alvo após o contato.

e) Contato tiebreak : Cola os nós da superfície contatora à superfície de contato apenas até que algum critério de falha seja alcançado.

f) Contato eroding : É utilizado quando uma das superfícies de contato está sujeita a falhas.

g) Contato drawbead : Tipicamente utilizado em problemas de conformação de chapas.

\section{(2) Definição do contato entre entidades}

Com exceção dos tipos de contato de superfície simples (ASSC, SS e ESS), todas as outras opções de contato requerem que sejam identificadas as superfícies contatora e alvo onde possa ocorrer o contato. Tal identificação pode ser feita utilizando-se componentes feitos de nós e/ou partes.

\section{(3) Especificação do coeficiente de atrito}

O coecifiente de atrito é determinado a partir dos coeficientes de atrito estático e dinâmico e é assumido ser dependente da velocidade relativa entre as superfícies de contato.

$$
\mu_{c}=F D+(F S-F D) e^{-D C \cdot V_{r e l}}
$$

onde : FD - coeficiente de atrito dinâmico

FS - coeficiente de atrito estático

$D C$ - coeficiente exponencial de decaimento

$V_{\text {rel }}$ - velocidade relativa 


\section{(4) Profundidade de contato}

Toda vez que um nó contator atravessa a superfície alvo, ou vice-versa, o contato é definido e uma força proporcional a profundidade de contato é gerada. As vezes, numa análise dinâmica, contatos indesejados denominados de falsoscontatos podem ser gerados devido a geometria das partes que podem estar em movimento relativo. Nestes casos, quando o contato não é genuíno e as profundidade de contato é relativamente alta, as forças de contato podem se tornar excessivas e criar instabilidades no modelo. Por está razão o software permite especificar uma profundidade de contato máxima além da qual o contato é ignorado. O valor da profundidade de contato $(P C)$ para os contatos STS, NTS e OSTS é dada pela software sendo igual a $1 \cdot 10^{10}$. O controle da profundidade de contato $(P C)$ para os outros tipos é dada pela seguinte expressão no caso de elementos sólidos:

$$
P C=\min \left[\frac{\text { volume }}{\text { área }}, 0.5 \cdot \sqrt{\text { área }}\right]
$$

\section{(5) Rigidez de contato}

A rigidez de contato $k$ deve ser estabelecida para que o contato ocorra sem que os corpos atravessem um ao outro. Este parâmetro é definido pelo software através da seguinte expressão, no caso de elementos sólidos:

$$
k=\frac{f s \cdot A^{2} \cdot K}{\text { volume }}
$$

onde : $f s$ - fator de penalização

$A$ - área do segmento de contato

$K$ - bulk módulo do elemento contactado

$\mathrm{Na}$ maioria dos casos, a rigidez de contato é determinada automaticamente pelo software e fornece resultados satisfatórios. Porém é possível alterar o valor da rigidez de contato adotando-se outros valores para o fator de penalização. Na prática, valores de $f s$ superiores a 0.1 podem causar instabilidades no modelo. 


\subsubsection{Solução de Problemas não-lineares}

A solução da maioria dos problemas não lineares requer a solução de um conjunto de equações da forma:

$$
[H(\Phi)]\{\Phi\}+\{f\}=0
$$

onde $\{\Phi\}$ é o vetor de incógnitas.

A equação (4.14) pode representar a equação (4.5) quando a matriz de rigidez se torna função dos deslocamentos nodais. Como a solução da equação (4.14) não pode ser obtida diretamente é exigido o uso de métodos numéricos.

\section{Método das Aproximações sucessivas}

Neste método o vetor de incógnitas $\{\Phi\}$ da iteração anterior é usado na determinação dos coeficientes da matriz $[H(\Phi)]$. Assim, na iteração $r+1$ :

$$
\{\Phi\}^{r+1}=-\left[H\left(\Phi^{r}\right)\right]\{f\}
$$

Se o processo é convergente, então quando $r$ tende a infinito o vetor $\{\Phi\}$ será levado para a solução correta. A figura 4.3 esquematiza o procedimento quando a matriz $[H]$ e o vetor $\{\Phi\}$ são reduzidos aos seus equivalentes escalares. A convergência ocorre quando a diferença entre dois valores consecutivos de $\Phi$ for menor que uma dada tolerância.

As mairoes desvantagens deste método são:

- Requer o cálculo e a inversão da matriz $[H]$ a cada iteração.

- Requer um valor inicial arbtrário.

- A convergência não está garantida e não pode ser estimada no primeiro passo da solução. 


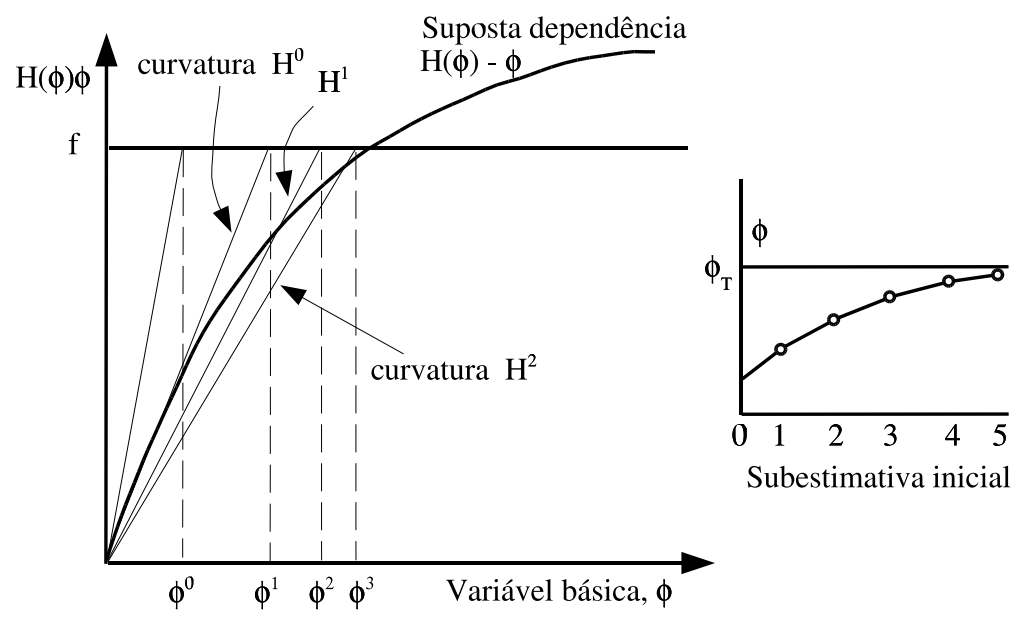

Figura 4.3: Método das aproximações sucessivas, OWEN \& HINTON (1980)

\section{Método de Newton-Raphson}

Considere-se um sistema de valores residuais que obedecem:

$$
\Psi=[H(\phi)]\{\phi\}+\{f\} \neq\{0\}
$$

onde: $\Psi$ são os valores residuais

Como $H$ é função de $\phi$ e possivelmente de suas derivadas, então pode-se afirmar que $\Psi=\Psi(\phi)$ e se a solução existe como $\phi^{r}+\Delta \phi^{r}$, então pelo método de Newton-Raphson:

$$
\Psi_{i}^{r}=-\sum_{j=1}^{n} \Delta \phi_{j}^{r}\left(\frac{\partial^{r} \Psi_{i}}{\partial \phi_{j}^{r}}\right)
$$

onde: $n$ é o número de variáveis do sistema e $r$ denota a r-ésima aproximação.

Substituindo-se o valor de $\Psi$ da equação (4.16) na expressão acima pode-se escrever na forma matricial:

$$
\left[\Psi\left(\phi^{r}\right)\right]=-\left[J\left(\phi^{r}\right)\right]\left\{\Delta \phi^{r}\right\}
$$




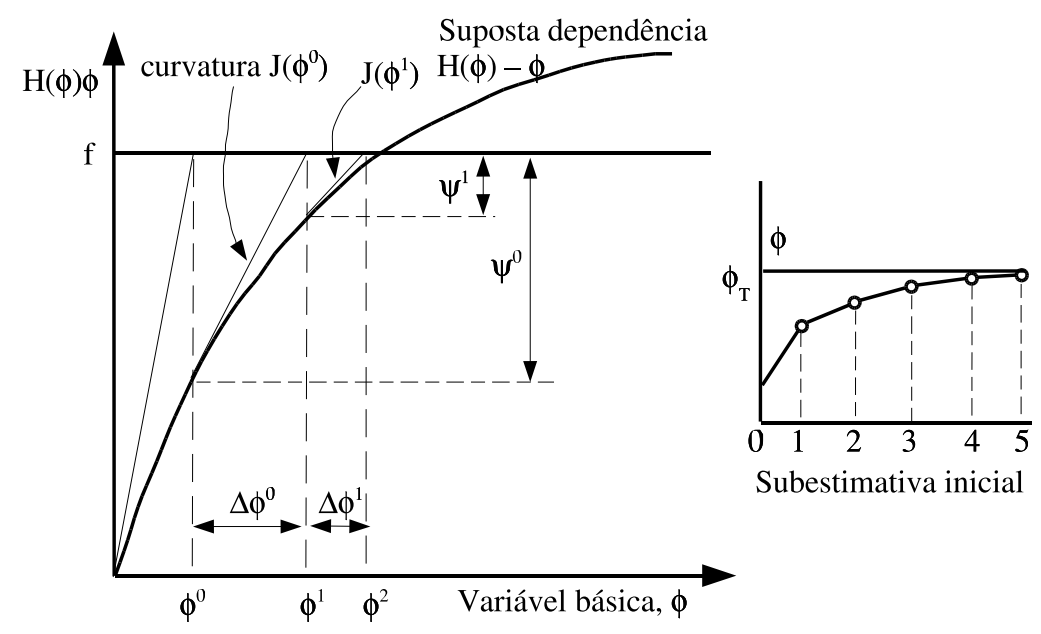

Figura 4.4: Método de Newton-Raphson, OWEN \& HINTON (1980)

Os termos $j_{i j}$ da matriz Jacobiana $[J]$ são dados por:

$$
j_{i j}=\left(\frac{\partial \Psi_{i}}{\partial \phi_{j}}\right)^{r}=h_{i j}^{r}+\sum_{k=1}^{m}\left(\frac{\partial h_{i k}}{\partial \phi_{j}}\right)^{r} \phi_{k}^{r}
$$

onde: $h_{i j}$ são os termos da matriz $[H]$

A equação pode ser rearranjada da seguinte maneira:

$$
J(\phi)=H(\phi)+H^{\prime}(\phi)
$$

onde a primeira parcela representa os termos simétricos e a segunda os termos assimétricos.

O método de Newton-Raphson pode ser escrito usando-se as equações (4.18) e (4.20):

$$
\Delta \phi^{r}=-\left[J\left(\phi^{r}\right)\right]^{-1} \Psi\left(\phi^{r}\right)=-\left[H\left(\phi^{r}\right)+H^{\prime}\left(\phi^{r}\right)\right]^{-1} \Psi\left(\phi^{r}\right)
$$


Esta expressão permite corrigir o vetor de incógnitas nodais $\phi$ a partir do vetor de valores residuais $\Psi$ calculado para cada iteração conforme ilustrado na figura 4.4. O método é finalizado quando o valor de $\Psi$ torna-se suficientemente pequeno, de acordo com um valor pré-estipulado. A grande vantagem deste método sobre o anterior é que, pelo uso das derivadas, a matriz $[H]$ é melhor estimada a cada passo obtendo-se assim maior rapidez na solução. 


\section{Capítulo 5}

\section{Modelagem de Impacto em Vigas}

\subsection{Introdução}

No presente capítulo, a solução do problema do impacto de massas rígidas sobre vigas engastadas será feita a partir do uso do Método dos Elementos Finitos e da integração explícita no tempo. Para cada tipo de impacto (longitudinal, flexional e torcional) será realizada uma comparação dos resultados com os métodos analíticos apresentados no capítulo 3, possibilitando verificar se a integração explícita no tempo fornece resultados satisfatórios. Também serão apresentadas as superfícies de tensão máxima que posteriormente serão aplicadas na metodologia proposta.

\subsection{Detalhes das modelagens de impacto em vi- gas}

As modelagens de impacto em vigas foram realizadas no Laboratório de Mecânica Aplicada e Computacional (LaMaQ) do Departamento de Engenharia Mecânica da Escola de Engenharia de São Carlos (EESC). Para tal, foram utilizados os softwares comerciais ANSYS ${ }^{\circledR} 5.7$ e LS-DYNA ${ }^{\circledR 960}$ que utiliza o algorítmo dinâmico explícito na resolução da equação do movimento. 
Foram modeladas vigas engastadas de secção transversal quadrada submetidas ao impacto axial, flexional e torcional em sua extremidade livre por uma massa rígida. As vigas tiveram seu comprimento fixado em $L=500[\mathrm{~mm}]$ com aresta $h=30$ [mm]. Em todos os casos foi utilizado o modelo de material elástico linear para a viga, com módulo de elasticidade $E=2.03 \cdot 10^{11}\left[\mathrm{~N} / \mathrm{m}^{2}\right]$, coeficiente de Poisson $\nu=0.3$ e densidade $\rho=7850\left[\mathrm{Kg} / \mathrm{m}^{3}\right]$. Já o impactador foi modelado como rígido com densidade variável em função da massa de impacto desejada. Em nenhum modelo é considerado o amortecimento nem o atrito. A condição de contorno aplicada nas vigas foi a retirada de todos os graus de liberdade dos nós da face oposta ao impacto (engastamento), enquanto que para o impactador, permitiu-se apenas o movimento na direção do impacto. Já a condição inicial aplicada foi a velocidade inicial de todos os nós do impactador. A malha de cada modelo foi gerada com elementos sólidos de oito nós (SOLID 164) de forma a satisfazer as condições discutidas no capítulo anterior. O contato aplicado foi o geral de nós contra superfície (NTS) também já comentado no capítulo anterior.

Para cada tipo de solicitação de impacto, são apresentados alguns resultados como a distribuição de tensão em secções transversais da viga e sua variação ao longo do tempo. Os valores das tensões máximas obtidas, para determinados valores da massa e da velocidade do impactador, foram comparados com os métodos de energia e de propagação de ondas apresentados no capítulo 3. Ainda, seguindo os mesmos passos de TEIXEIRA (2002), para cada modelagem de impacto, são apresentados as superfícies de tensão máxima. Tais superfícies representam um conjunto de situações de impacto no qual as variáveis massa $m$ e velocidade $v$ do impactador assumem valores conhecidos dentro de um intervalo. Desta forma, para cada valor de $m$ e $v$, existe uma tensão máxima correspondente ocorrida no corpo que sofre o impacto e sua equação pode ser representada na forma:

$$
\sigma_{\max }=c \cdot m^{a} \cdot v^{b}
$$

onde: $a, b$ e $c$ são os coeficientes a serem determinados. 
Com a faixa de $m$ e $v$ definidas, é possível determinar-se os coeficientes $a, b$ e $c$ por meio de uma regressão linear múltipla a partir dos dados de tensão máximas obtidos das simulações numéricas. Em TEIXEIRA (2002), foi adotado um intervalo de dez pontos igualmente espaçados para a massa $m$, variando de $0.2[\mathrm{Kg}]$ até $2.0[\mathrm{Kg}]$. O mesmo intervalo foi adotado para a faixa de velocidade $v$ do impactador, totalizando cem simulações distintas de impacto para a determinação da superfície de tensão máxima.

Em todos os casos modelados foi constatado que a tensão máxima de impacto, $\sigma_{\text {max }}$, é aproximadamente proporcional a raiz quadrada da energia cinética do impactador rígido, ou seja, o coeficiente $a$ assume valores entre 0.4 e 0.5 e o coeficiente $b$ assumindo valores próximos de 1.0. O coeficiente $c$ é função da faixa de massas e velocidades adotadas e da geometria da peça.

A figura 5.1 ilustra algumas geometrias modeladas por TEIXEIRA (2002). Em todos os casos o impactador foi considerado rígido.

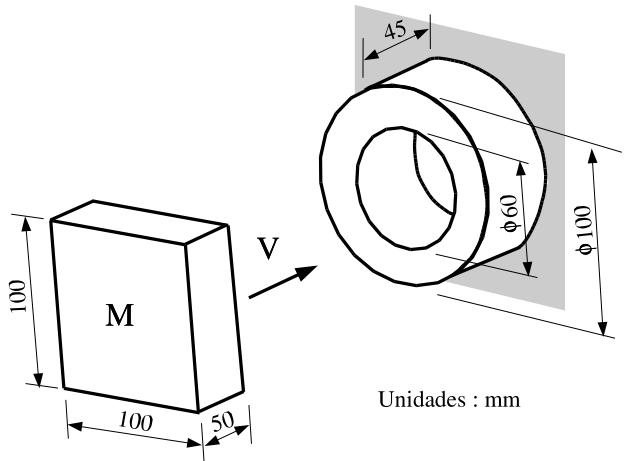

(A)

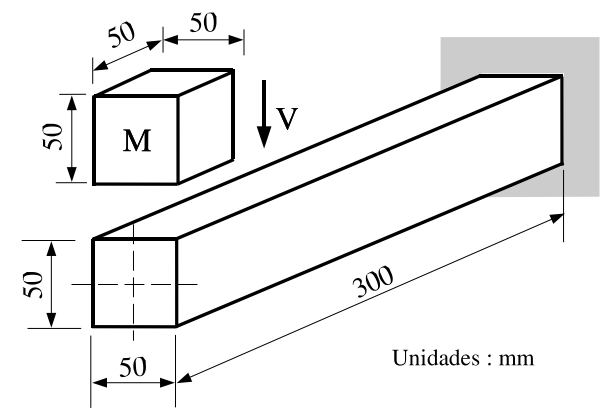

(C)
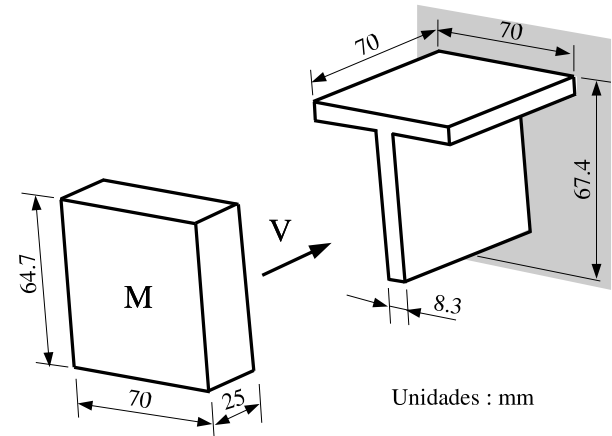

(B)

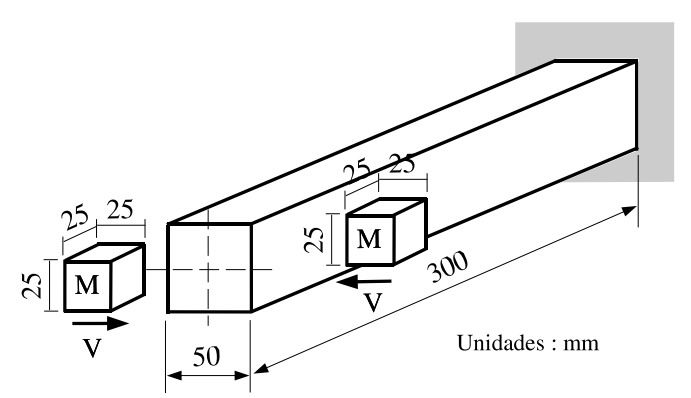

(D)

Figura 5.1: Modelagens de impacto, TEIXEIRA (2002) 
A tabela 5.1 ilustra as equações da superfície de tensão máxima obtidas para cada caso:

Tabela 5.1: Equação da superfície de tensão máxima para cada caso

\begin{tabular}{|c|c|}
\hline Modelo & Equação \\
\hline \hline caso $(\mathrm{A})$ & $\sigma_{\max }=20.8424 \cdot 10^{6} m^{0.4185} v^{1.0115}$ \\
\hline caso (B) & $\sigma_{\max }=81.858 \cdot 10^{6} m^{0.5306} v^{1.0331}$ \\
\hline caso (C) & $\sigma_{\max }=31.97 \cdot 10^{6} m^{0.3842} v^{1.0009}$ \\
\hline caso (D) & $\sigma_{\max }=52.81 \cdot 10^{6} m^{0.4937} v^{1.0047}$ \\
\hline
\end{tabular}

No presente trabalho a faixa de massa e velocidade do impactador foi definida com valores diferentes daqueles apresentados em TEIXEIRA (2002) no intuito de verificar a validade de que a tensão máxima de impacto é proporcional a raiz quadrada da energia cinética do impactador rígido. Para a massa $m$ adotou-se um intervalo com cinco pontos igualmente espaçados variando de $0.5[\mathrm{Kg}]$ até $2.5[\mathrm{Kg}]$. Para a velocidade $v$ também adotou-se um intervalo de cinco pontos igualmente espaçado variando de $2.0[\mathrm{~m} / \mathrm{s}]$ até $10[\mathrm{~m} / \mathrm{s}]$ totalizando vinte e cinco modelagens distintas de impacto para a determinação da superfície de tensão máxima. A tabela abaixo ilustra os valores adotados.

Tabela 5.2: Faixa de velocidade e massa do impactador adotada nas modelagens

\begin{tabular}{|c|c|c|c|c|c|}
\hline $\begin{array}{c}\text { Massa } \\
{[\mathrm{Kg}]}\end{array}$ & 0.5 & 1.0 & 1.5 & 2.0 & 2.5 \\
\hline \hline $\begin{array}{c}\text { Velocidade } \\
{[\mathrm{m} / \mathrm{s}]}\end{array}$ & 2.0 & 4.0 & 6.0 & 8.0 & 10 \\
\hline
\end{tabular}

Todo o processo é considerado no regime elástico, apesar de que em alguns casos a tensão máxima do impacto chegou a valores superiores a 1000 [MPa]. Conforme STRONGE (2000) a velocidade requerida para causar grandes deformações plásticas no contato é da ordem de $10[\mathrm{~m} / \mathrm{s}]$ a $100[\mathrm{~m} / \mathrm{s}]$ para metais. 


\subsection{Modelagem de Impacto Longitudinal}

A modelagem do impacto longitudinal de uma de uma massa rígida $m_{2}$ com velocidade $v$ colidindo na extrermidade livre de uma viga de aço engastada de massa $m_{1}$ é esquematizada na figura 5.2. As dimensões e o número de divisões da malha também são ilustrados.

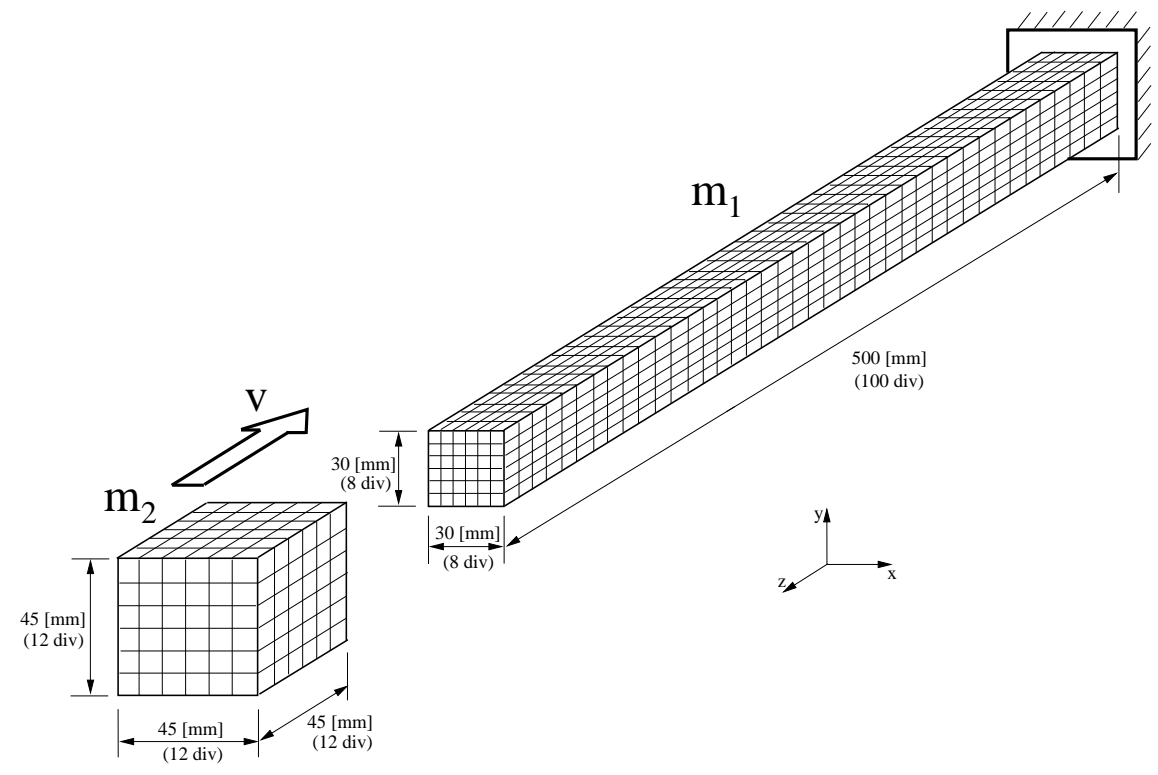

Figura 5.2: Modelagem do impacto axial

Os resultados mostrados e discutidos a seguir, para a modelagem do impacto axial, foram obtidos para $m_{2}=3.5325[\mathrm{Kg}]$ e $v=4[\mathrm{~m} / \mathrm{s}]$. A massa $m_{2}$ foi adotada de forma a se obter uma relação de massas $\alpha$ igual a 1. Na figura 5.3 é mostrado a distribuição da tensão equivalente de Von Mises decorridos $3.3 \cdot 10^{-5}$ [s] após o impacto. É possível notar a propagação da onda de tensão no sentido do engaste e que a viga está livre de tensões até que a onda percorra esta região. 


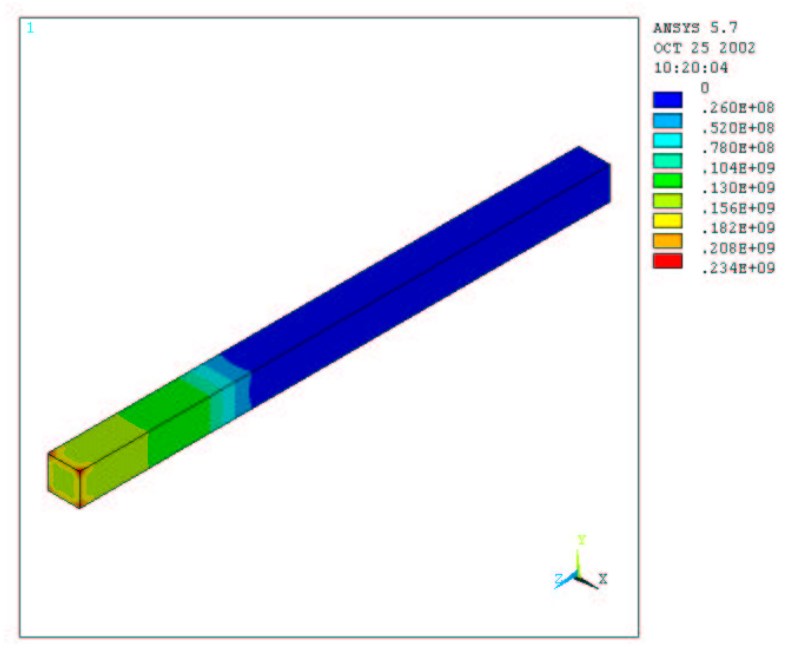

Figura 5.3: Distribuição de tensão decorridos $3.3 \cdot 10^{-5}[\mathrm{~s}]$

Os resultados das tensões ao longo do tempo foram obtidos para os pontos $A$ e $B$ no plano da interface de contato conforme ilustrado na figura abaixo. A linha diagonal com os nós variando da posição -4 a 4 foi utilizada para verificar a variação da tensão equivalente ao longo deste caminho.

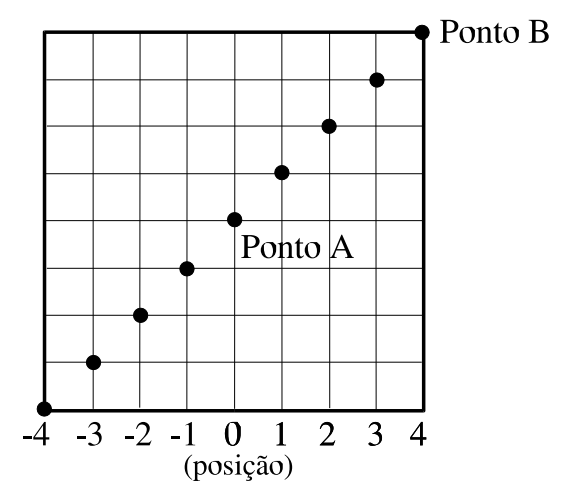

Figura 5.4: Localização dos pontos estudados na interface de contato

A distribuição da tensão equivalente de Von Mises na interface de contato no instante em que atinge o seu máximo valor é mostrada na figura 5.5 e a variação desta tensão ao longo da linha diagonal da secção também no instante de máximo é mostrada no gráfico da figura 5.6. 


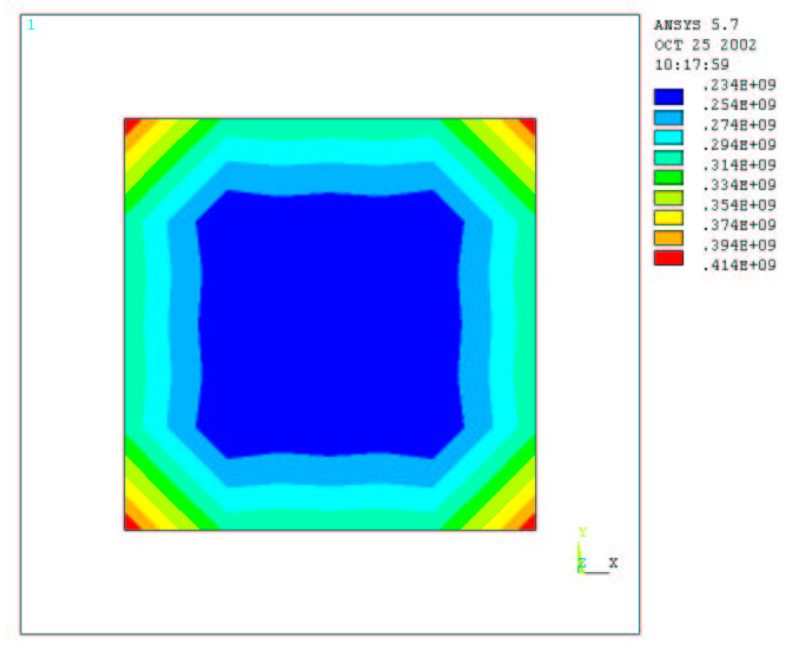

Figura 5.5: Distribuição de tensão da interface de contato no instante de máximo.

Pode-se verificar que o ponto $B$ na quina da viga apresenta um pico de tensão aproximadamente $67.61 \%$ maior que o ponto central $A$. Essa variação de tensão da secção é decorrente do efeito de borda. A região central dos nós da secção (posições de -2 a 2) apresenta uma distribuição mais uniforme com a tensão oscilando em torno de aproximadamente 240 [MPa].

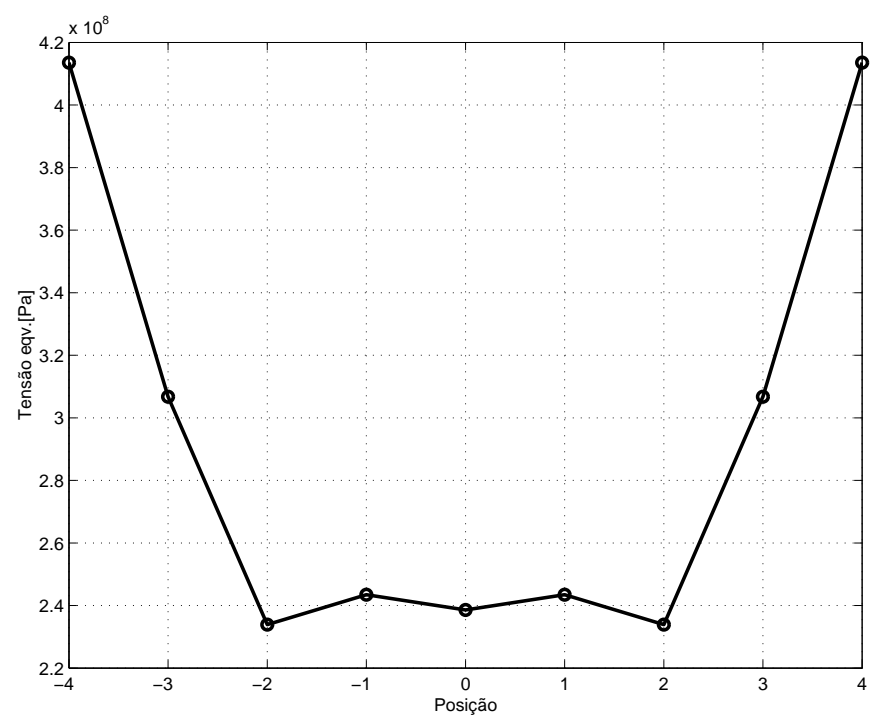

Figura 5.6: Distribuição de tensão ao longo da linha diagonal. 
A variação da tensão equivalente de Von Mises ao longo do tempo nos pontos $A$ e $B$ da face de contato é ilustrada no gráfico da figura 5.7. É possível verificar que a tensão é nula até que o impactador atinja a viga e então a tensão é repentinamente aumentada para $156[\mathrm{MPa}]$ no ponto $A$ e $238[\mathrm{MPa}]$ no ponto $B$. Após primeiro período de reflexão da onda, novamente a tensão sofre um aumento repentino decorrentes da sobreposição e tem seu máximo valor obtido de 247 [MPa] para o ponto $A$ e $414[\mathrm{MPa}]$ para o ponto $B$. Também podem-se notar as oscilações no sinal da tensão, possivelmente decorrentes do algorítmo numérico, principalmente para o ponto $A$. Após atingir a máxima tensão acontece a separação dos corpos e a viga vibra livre, consequentemente, a tensão na extremidade passa a ser nula (superfície livre).

Note que o tempo para a onda longitudinal percorrer $2 L=1[\mathrm{~m}]$ considerandose a velocidade de propagação unidimensional $c_{0}=\sqrt{E / \rho}$ é de $1.96 \cdot 10^{-4}[\mathrm{~s}]$. Levando em conta o tempo de aproximação do impactador que é de $3.75 \cdot 10^{-5}$ [s] tem-se $2.34 \cdot 10^{-4}[\mathrm{~s}]$ que é aproximadamente o tempo em que ocorre o pico de tensão conforme a figura 5.7 .

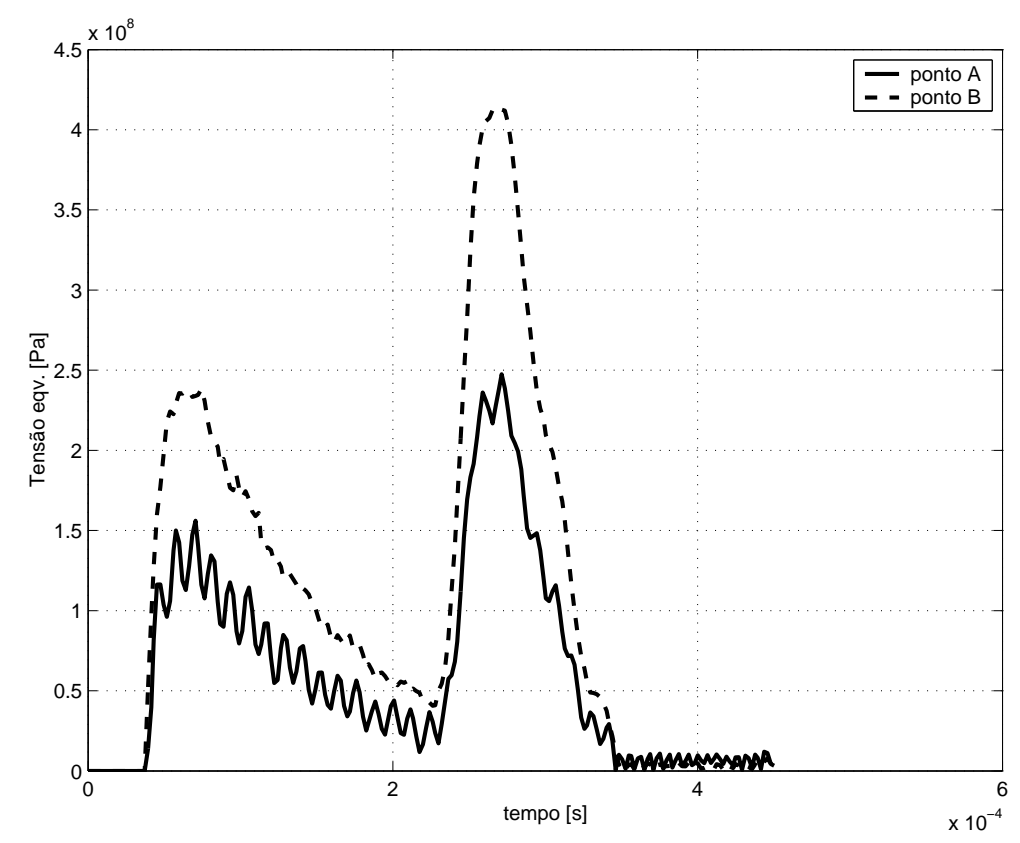

Figura 5.7: Variação da tensão equivalente para os pontos $A$ e $B$ em função do tempo 
Aplicando-se o método da energia para a determinação da tensão máxima, equação (3.2), obtém-se $\sigma_{\max }=159.68$ [MPa]. Já a outra aproximação, equação (3.3) fornece $\sigma_{\max }=138.28$ [MPa]. Pela teoria unidimensional de propagação de ondas, o valor da tensão inicial decorrente do impacto é dada por $\sigma_{0}=\rho c_{0} v$ onde $c_{0}$ é a velocidade de propagação unidimensional, $\rho$ é a densidade da viga e $v$ a velocidade do impacto. Conforme a figura 3.2 do capítulo 3, para uma relação de massas $\alpha=1$, o pico de tensão é atingido no primeiro período de reflexão da onda e tem seu valor $1.135 \%$ maior que $\sigma_{0}$. Substituindo-se os valores adotados encontramos $\sigma_{0}=159.68[\mathrm{MPa}]$ e o pico de tensão $\sigma_{\max }=181.24$ [MPa].

As diferenças encontradas podem ser explicadas pelo fato de que, primeiro, a modelagem do impacto longitudinal é tridimensional e considera o coeficiente de Poisson, enquanto que a teoria unidimensional de propagação de ondas considera apenas a tensão na direção do eixo da viga e que ela é constante em toda a secção. Já o método da energia despreza os efeitos de inércia do sistema. A tabela abaixo mostra os valores da tensão máxima obtidos pelo método da energia, pelo método de propagação de ondas e pelo algorítmo dinâmico explícito.

Tabela 5.3: Valores da tensão máxima para diferentes abordagens

\begin{tabular}{|c|cc|}
\hline $\begin{array}{c}\text { Método } \\
\text { da } \\
\text { Energia }\end{array}$ & $\sigma_{\max }=159.68[\mathrm{MPa}]$ & $($ eq. 3.2) \\
$\sigma_{\max }=138.28[\mathrm{MPa}]$ & $($ eq. 3.3$)$ \\
\hline \hline $\begin{array}{c}\text { Propagação } \\
\text { de }\end{array}$ & $\sigma_{\max }=181.24[\mathrm{MPa}]$ & $($ eq. $3.5 \cdots 3.8)$ \\
Ondas & & \\
\hline \hline $\begin{array}{c}\text { Algorítmo } \\
\text { explícito }\end{array}$ & $\begin{array}{c}\sigma_{\max }=245[\mathrm{MPa}] \\
\sigma_{\max }=418[\mathrm{MPa}]\end{array}$ & $\begin{array}{c}\text { (ponto } A) \\
\text { (ponto } B)\end{array}$ \\
\hline
\end{tabular}




\section{Superfície de tensão máxima}

A superfície de tensão máxima para o caso longitudinal foi obtida variando-se a massa $m_{2}$ e a velocidade $v$ do impactador conforme a tabela 5.2, totalizando vinte e cinco situações distintas de impacto. A partir dos valores da tensão máxima dados pelo algorítmo numérico em cada modelagem, determinaram-se os coeficientes $a, b$ e $c$ da equação (5.1) por meio de uma regressão linear múltipla obtendo-se a seguinte equação:

$$
\sigma_{\max }=6.4794 \cdot 10^{7} m^{0.4511} v^{0.9922}
$$

onde o erro máximo foi de $8.84 \%$.

Note que os coeficientes $a$ e $b$ fornecem valores muito próximos de 0.5 e 1.0 respectivamente, confirmando a tendência do valor de tensão máxima ser aproximadamente proporcional à raiz quadrada da energia cinética do impactador rígido. A figura 5.8 ilustra a curva ajustada aos pontos obtidos pelas modelagens.

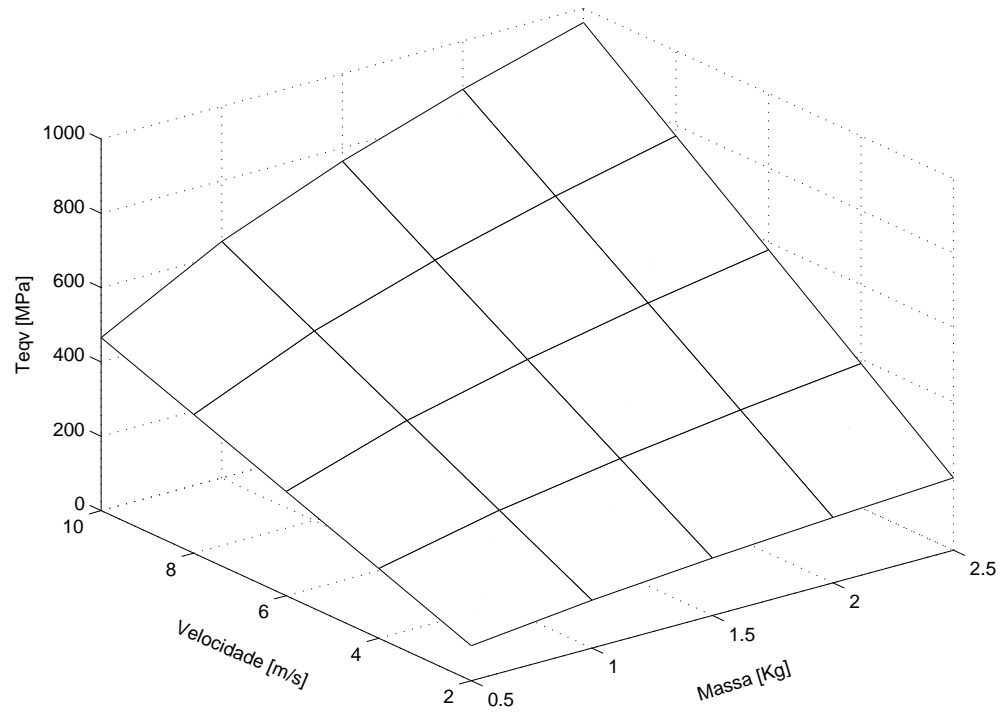

Figura 5.8: Superfície de tensão máxima para o impacto longitudinal 


\subsection{Modelagem de Impacto Transversal}

A figura 5.9 esquematiza a modelagem do impacto tranversal de uma massa rígida colidindo na extremidade livre de uma viga engastada. As dimensões e o número de divisões da malha também são ilustrados.

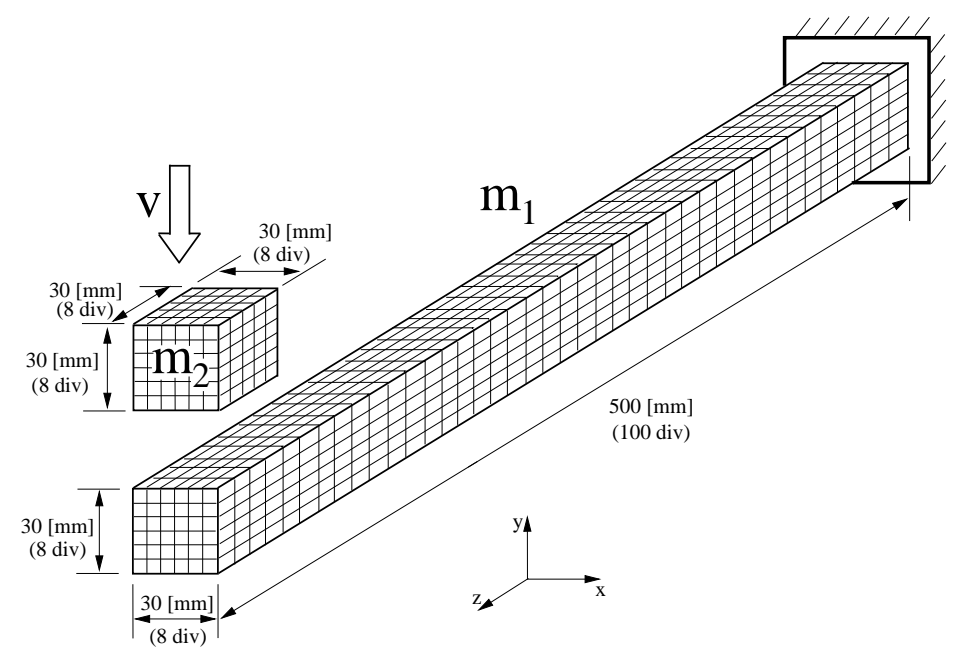

Figura 5.9: Modelagem do impacto flexional

O resultados discutidos a seguir são para $v=2[\mathrm{~m} / \mathrm{s}]$ e $m_{2}=3.5325[\mathrm{Kg}]$. Novamente a massa $m_{2}$ do impactador, foi adotada para obter-se uma relação de massas $\alpha=1$. A figura 5.10 mostra a propagação da onda de tensão na direção $z$ do eixo da viga, decorridos $1.3925 \cdot 10^{-4}[\mathrm{~s}]$ após o impacto. É possível verificar na onda flexional a região de tração na parte superior e de compressão na parte inferior da viga.

No gráfico da figura 5.11 é mostrado o deslocamento vertical $u_{y}$ do ponto central na extremidade livre da viga ao longo do tempo. Pode-se notar que durante os primeiros $0.01[\mathrm{~s}]$ a amplitude alcançada é de $5.8 \cdot 10^{-3}[\mathrm{~m}]$ que corresponde ao intervalo de tempo em que o impactador está em contato com a viga. Após os corpos se separarem, a viga vibra livremente numa amplitude menor e constante, já que o amortecimento não foi considerado. A frequência de vibração de aproximadamente $100[\mathrm{~Hz}]$, figura 5.12, corresponde ao primeiro modo de flexão da viga conforme análise modal. 


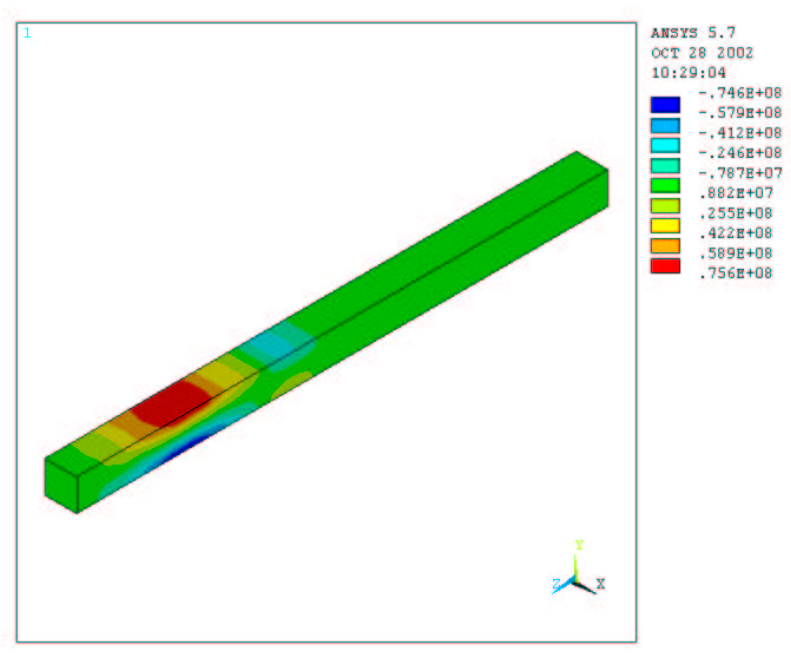

Figura 5.10: Propagação do pulso flexional decorridos $1.3925 \cdot 10^{-4}[\mathrm{~s}]$
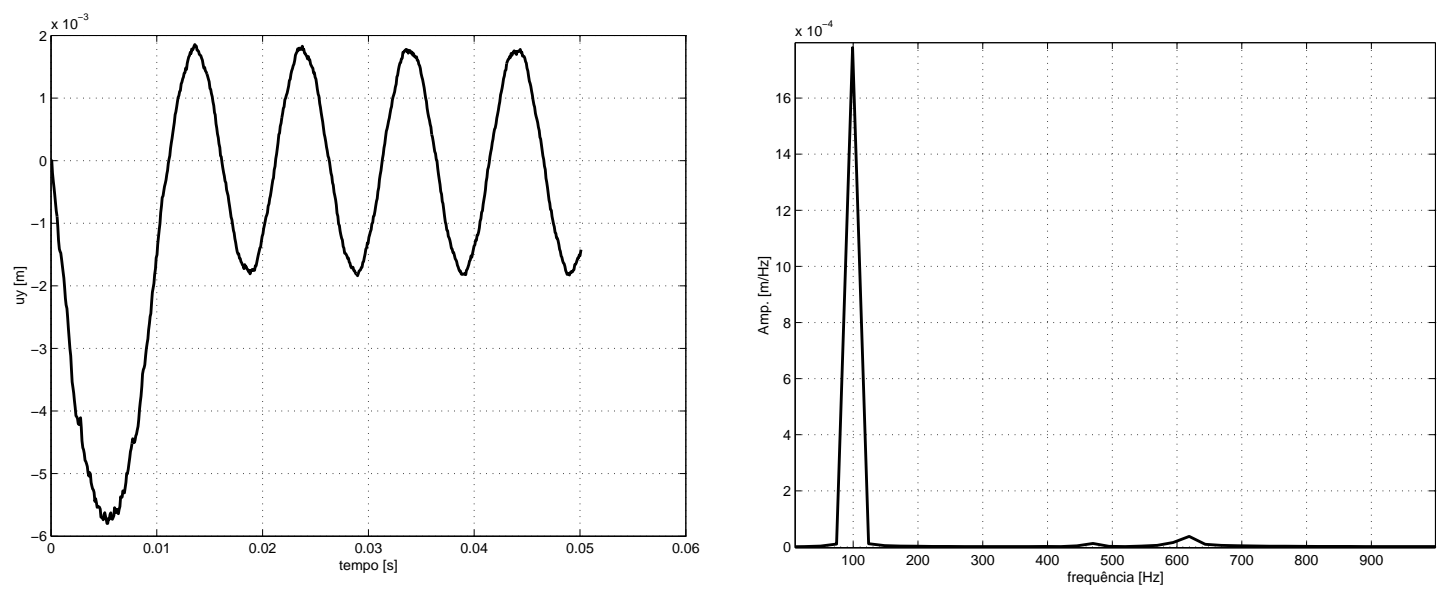

Figura 5.11: Deslocamento vertical $u_{y}$ do ponto central na extremidade livre

Figura 5.12: FFT do deslocamento $u_{y}$

A máxima tensão ocorre no engaste no instante de máxima amplitude da ponta da viga, ou seja, quando $t=5.3 \cdot 10^{-3}[\mathrm{~s}]$. A figura 5.13 mostra a distribuição da tensão equivalente de Von Mises, no plano do engaste, no instante de máximo. 


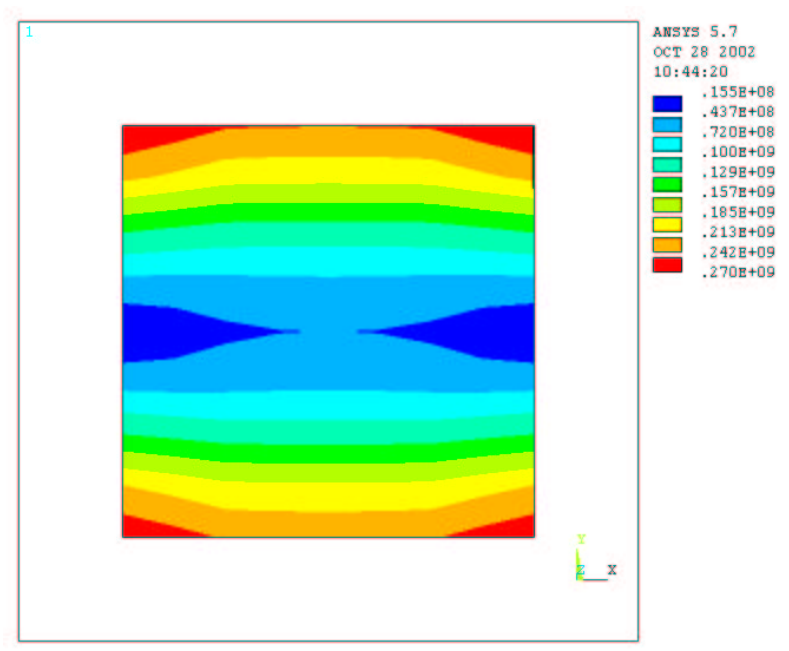

Figura 5.13: Distribuição no engaste da tensão equivalente de Von Mises no instante de máximo

A partir dos nós da linha vertical no plano do engaste, figura 5.14, foram traçados os gráficos da tensão equivalente de Von Mises e da tensão normal $\sigma_{z}$ em função da posição do nó no instante de máximo.

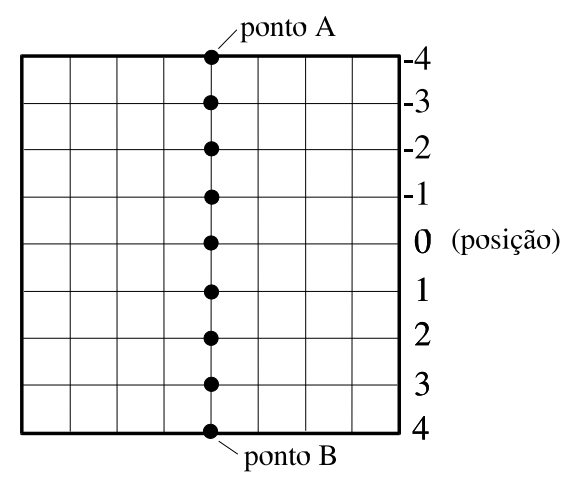

Figura 5.14: Linha de nós do plano do engaste

Pode-se observar que a máxima tensão equivalente ocorre nos pontos $A$ e $B$ que são os mais externos (figura 5.15) e que a tensão normal varia aproximadamente de forma linear do ponto $A$, de máxima tração, para o ponto $B$, de máxima compressão (figura 5.16), caracterizando uma flexão. 


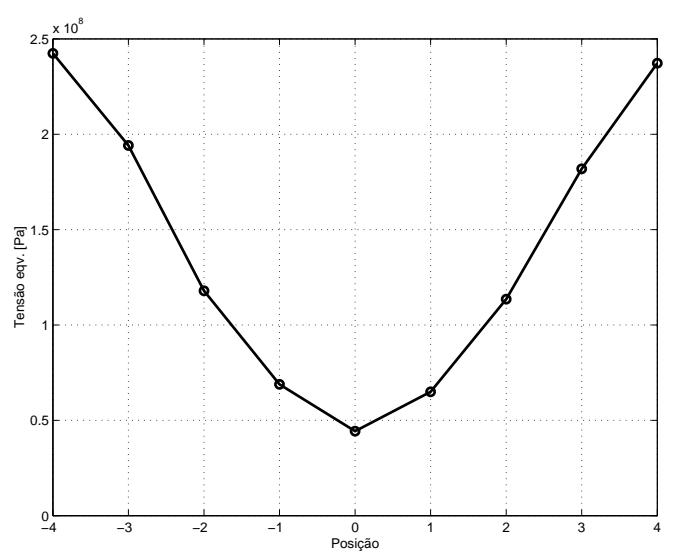

Figura 5.15: Variação da tensão equivalente ao longo da linha vertical do engaste no instante de máximo

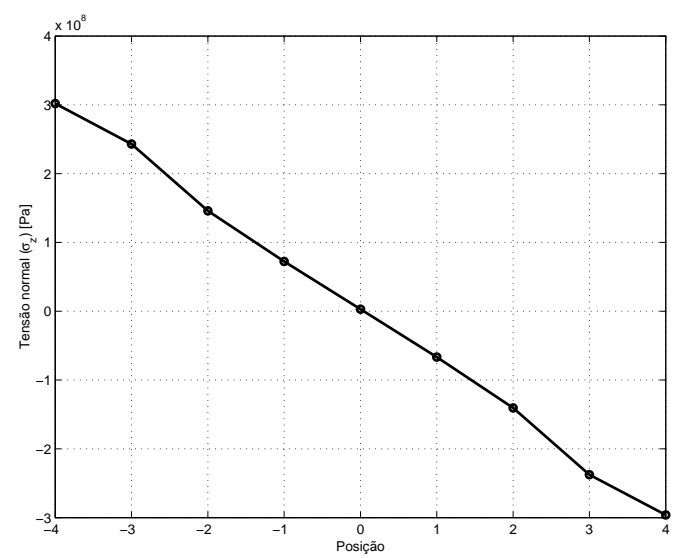

Figura 5.16: Variação da tensão normal ao longo da linha vertical do engaste no instante de máximo

Os valores da tensão normal ao longo do tempo para os pontos $A$ e $B$ é mostrado na figura 5.17. Pode-se notar que o intervalo de tempo em que o deslocamento vertical da ponta atinje a máxima amplitude, correponde ao intervalo de máxima tensão.

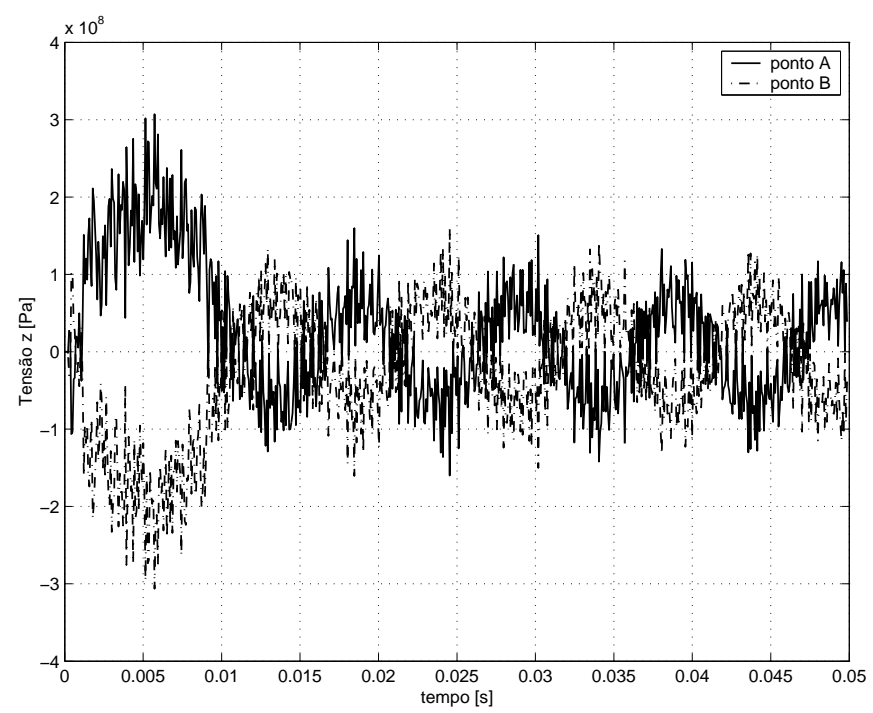

Figura 5.17: Tensão na direção $z$ em função do tempo 
Aplicando-se a FFT no sinal da tensão pode-se verificar que frequências bastante altas estão presentes no sinal mas a de maior amplitude é justamente a frequência do primeiro modo de vibrar da viga, correspondente à aproximadamente $100[\mathrm{~Hz}]$.

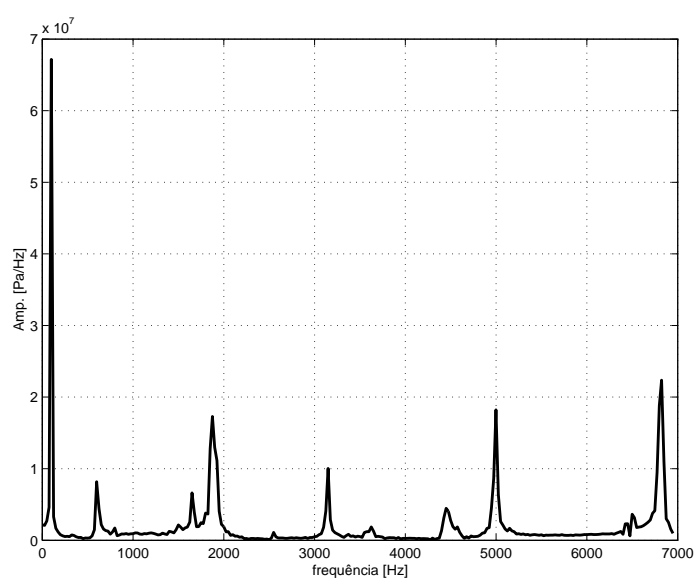

Figura 5.18: FFT do sinal de tensão

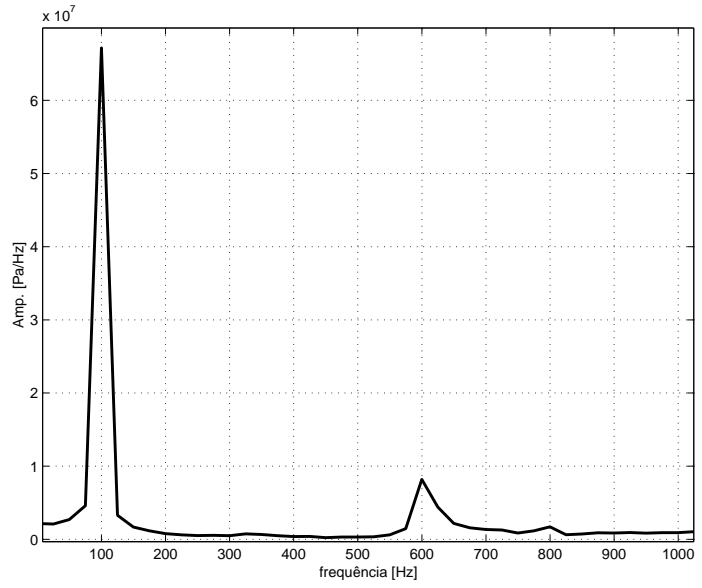

Figura 5.19: FFT do sinal mostrando a frequência de maior amplitude

Usando-se o método da energia para a determinação do máximo deslocamento $u_{y}$ da ponta, equação (3.13), e da tensão máxima, equação (3.14) obtém-se os seguintes valores $u_{y}=6.55 \cdot 10^{-3}[\mathrm{~m}]$ e $\sigma_{\max }=239.51[\mathrm{MPa}]$. Já o método de propagação de ondas fornece para o deslocamento, equação (3.19), $u_{y}=6.77 \cdot 10^{-3}$ [m] e para a tensão, equação $(3.20), \sigma_{\max }=252[\mathrm{MPa}]$.

A tabela 5.4 mostra os valores da tensão e do deslocamento obtidos pelas diferentes abordagens. No caso do algorítmo explícito, os dados são para o trecho onde a amplitude do deslocamento é máxima e para o trecho em que a viga passa a vibrar livremente, com amplitude menor, na sua primeira frequência natural de flexão. As diferenças observadas nos valores de tensão e deslocamento são, novamente, devidas aos modelos matemáticos variados. O método da energia despreza os efeitos de inércia da viga. As equações de propagação de ondas para o caso flexional que foram apresentadas no capítulo 3 assumem várias simplificações e não consideram o peso do impactador. O algorítmo explícito também apresenta suas simplificações como o uso de matrizes diagonais de massa e amortecimento. 
Tabela 5.4: Valores do deslocamento e da tensão máxima para diferentes abordagens

\begin{tabular}{|c|cc|}
\hline $\begin{array}{c}\text { Método } \\
\text { da } \\
\text { Energia }\end{array}$ & $u_{y}=6.55 \cdot 10^{-3}[\mathrm{~m}]$ & (eq. 3.13) \\
\hline $\begin{array}{c}\text { Propagação } \\
\text { de }\end{array}$ & $u_{y}=6.77 \cdot 10^{-3}[\mathrm{~m}]$ & (eq. 3.20) \\
Ondas & $\sigma_{\max }=252[\mathrm{MPa}]$ & (eq. 3.21) \\
\hline \hline & $u_{y}=5.8 \cdot 10^{-3}[\mathrm{~m}]$ & (trecho de máxima \\
Algorítmo & $\sigma_{\max }=307[\mathrm{MPa}]$ & amplitude) \\
explícito & $u_{y}=1.8 \cdot 10^{-3}[\mathrm{~m}]$ & (trecho de vibração \\
& $\sigma_{\max }=160[\mathrm{MPa}]$ & livre) \\
\hline
\end{tabular}

\section{Superfície de tensão máxima}

A superfície de tensão máxima para o impacto flexional foi obtida para a mesma faixa de massas e velocidades dadas na tabela 5.2. Da mesma forma que anteriormente, a partir dos valores da tensão máxima dados pelo algorítmo numérico em cada situação, determinou-se os coeficientes $a, b$ e $c$ da equação 5.1 por meio de uma regressão linear múltipla obtendo-se a seguinte equação:

$$
\sigma_{\max }=9.2785 \cdot 10^{7} m^{0.3522} v^{0.9967}
$$

onde o erro máximo foi de $8.06 \%$.

Pode-se verificar novamente, que o coeficiente $a$, apesar de um pequeno desvio, apresenta um valor próximo de 0.5 e o coeficiente $b$ próximo de 1.0. Apesar de não ter sido realizado um número maior de modelagens, acredita-se que o aumentando o número de pontos pode fazer o valor do coeficiente $a$ subir ligeiramente para valores entre 0.4 e 0.5. A curva que aproxima os pontos é mostrada a seguir: 


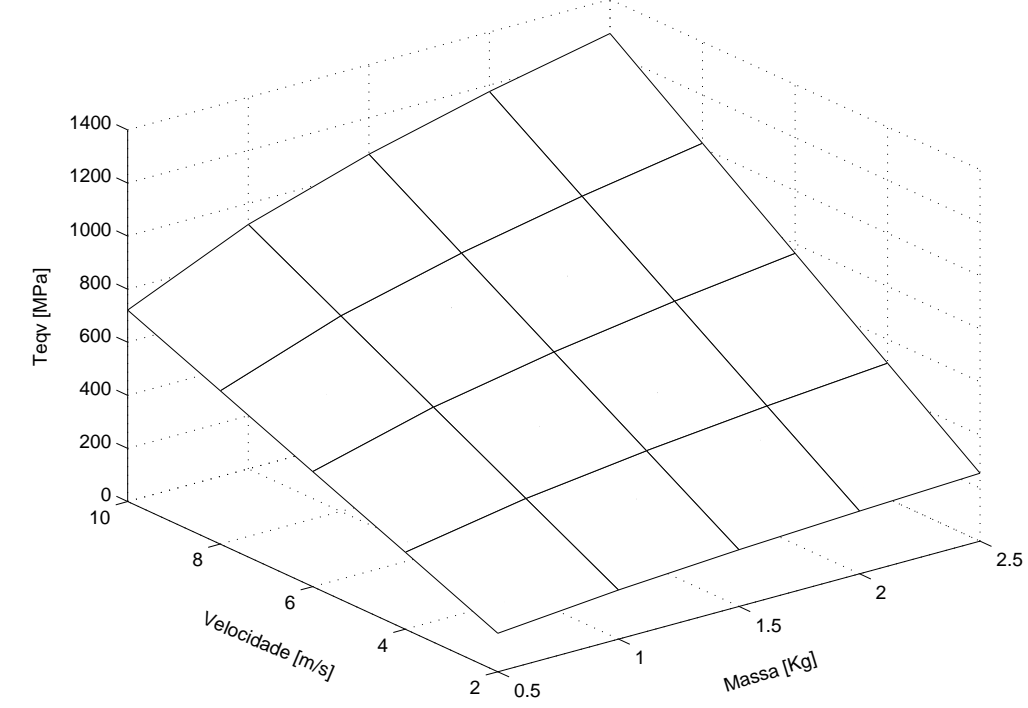

Figura 5.20: Superfície de tensão máxima para o impacto flexional

\subsection{Modelagem de Impacto Torcional}

A modelagem do impacto torcional é esquematizada na figura 5.21. As dimensões e o número de divisões da malha também são ilustrados.

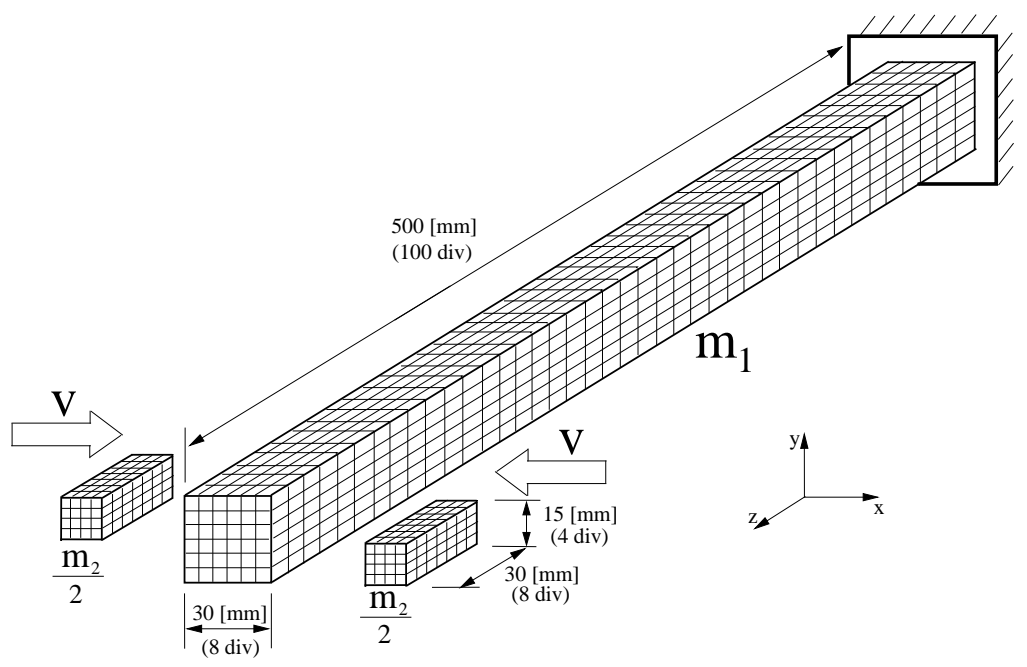

Figura 5.21: Modelagem do impacto torcional 
A seguir serão mostrados e discutidos alguns resultados da modelagem do impacto torcional quando $m_{2}=1.0[\mathrm{Kg}]$ e $v=2[\mathrm{~m} / \mathrm{s}]$. A massa $m_{2}$ é soma das massas dos dois impactadores. Os dados obtidos foram para os pontos localizados conforme a figura abaixo:

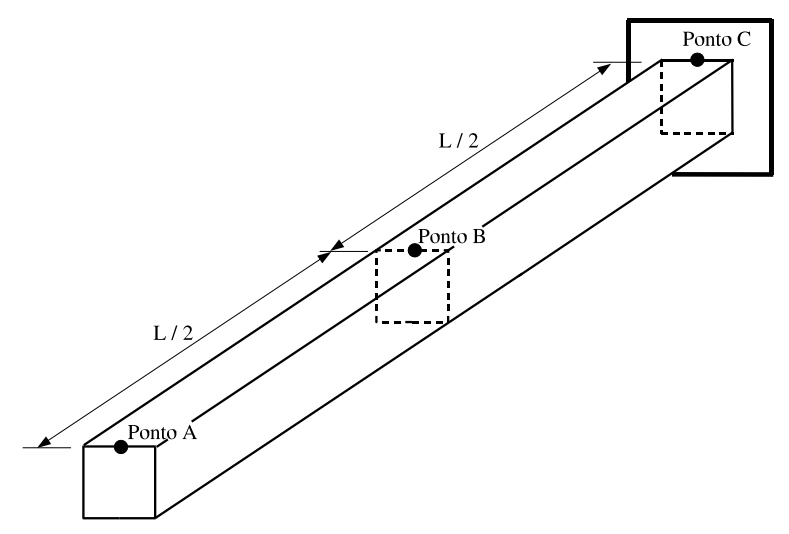

Figura 5.22: Localização dos pontos estudados

A figura 5.23 mostra a propagação da onda devido ao impacto torcional decorridos $0.1345 \cdot 10^{-3}[\mathrm{~s}]$ após o contato. Pode-se observar que os pontos que estão fora da frente de onda estão livres de tensão.

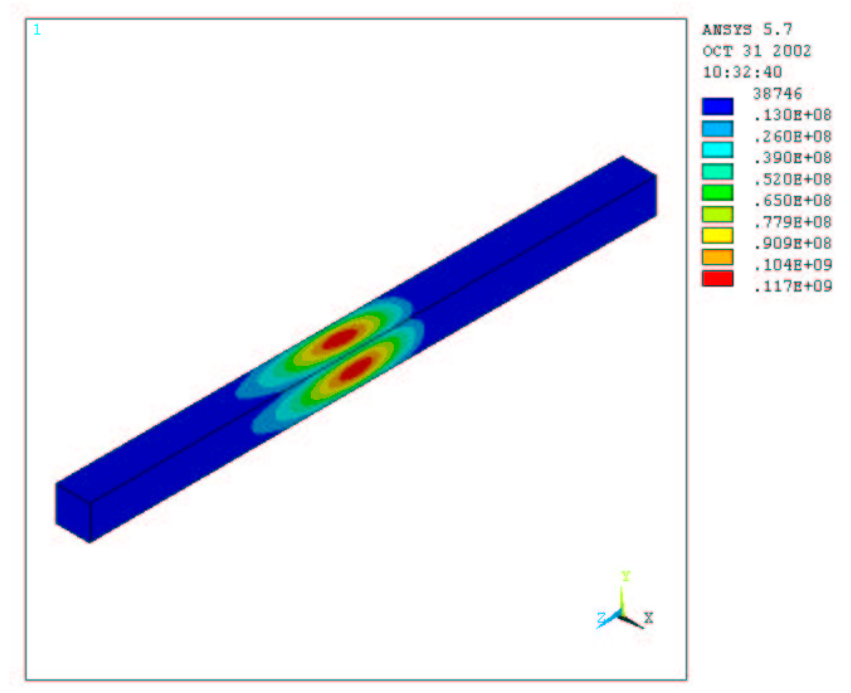

Figura 5.23: Propagação da onda torcional 
A variação do deslocamento angular $\theta$ do ponto $A$ em função do tempo é mostrada na figura 5.24. Aplicando-se a FFT nestes pontos verifica-se que a viga vibra no seu primeiro modo de torção, que corresponde a uma frequência de aproximadamente 1460 [Hz]. A figura 5.25 mostra esta frequência, como sendo a de maior amplitude, juntamente com os outros harmônicos.

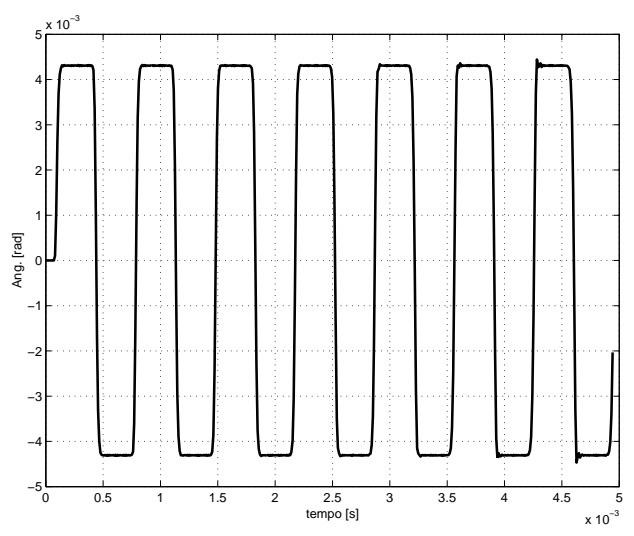

Figura 5.24: Variação do ângulo $\theta$ do ponto $A$ ao longo do tempo

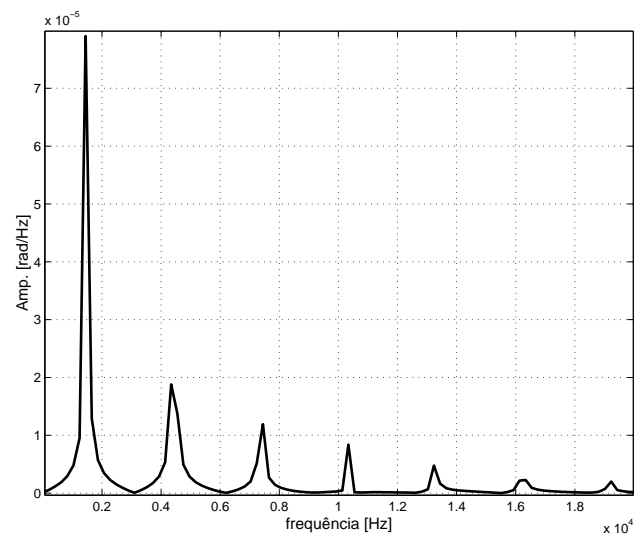

Figura 5.25: FFT do ângulo $\theta$

A variação da tensão equivalente de Von Mises do ponto $B$, do centro da viga, e do ponto $C$, no engaste, em função do tempo é mostrada na figura abaixo.

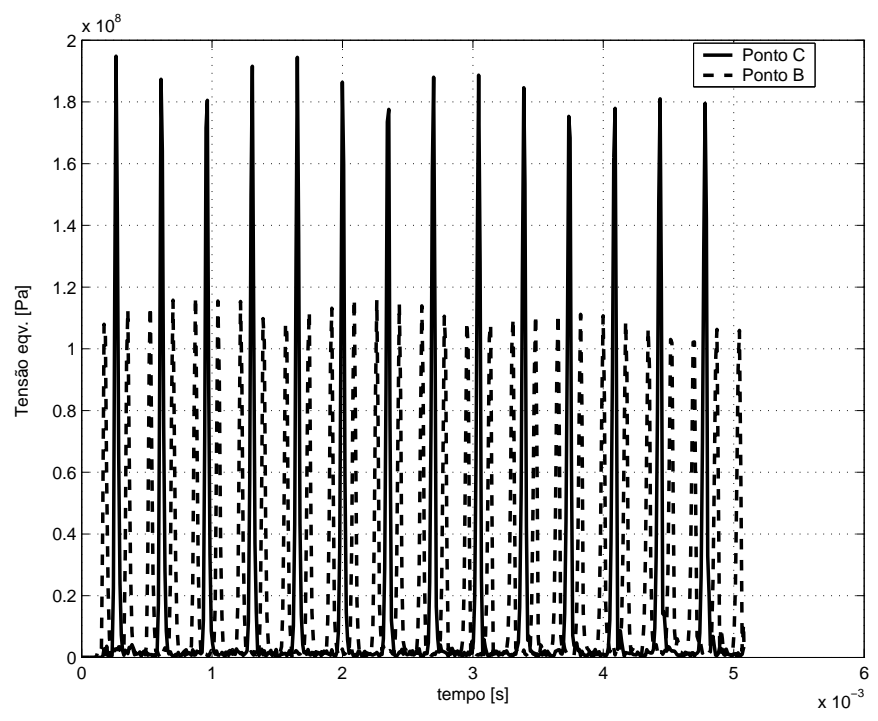

Figura 5.26: Variação do tensão equivalentenos pontos $B$ e $C$ 
Pode-se verificar que a tensão equivalente no engaste é aproximadamente 63.64 $\%$ maior que no plano central e que os picos de tensão correspondem à passagem da onda por estes pontos. A distribuição da tensão equivalente de Von Mises no plano central da viga no instante da primeira passagem da onda de tensão é mostrada na figura a seguir. É possível notar que a máxima tensão ocorre no centro das bordas.

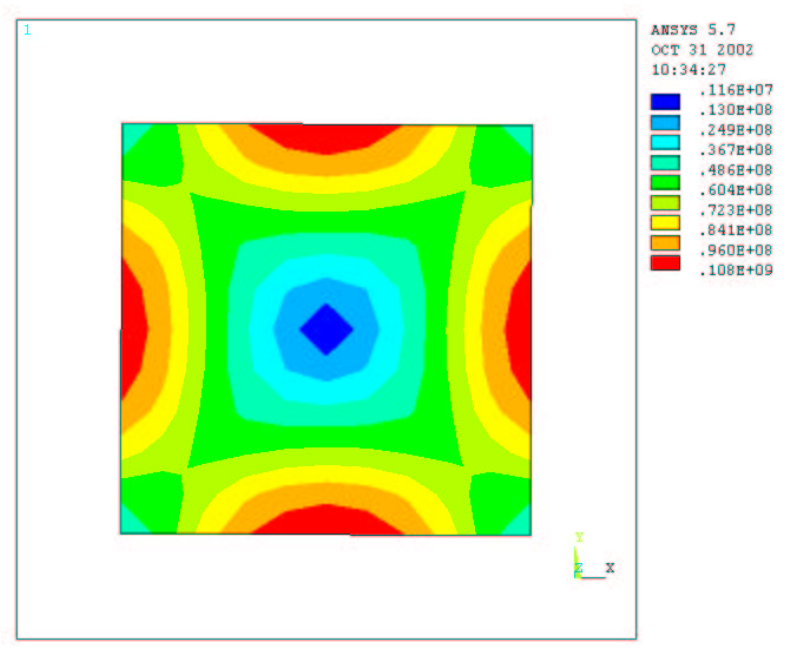

Figura 5.27: Distribuição da tensão equivalente no plano central

Aplicando-se o método da energia, equação (3.22) para a determinação da tensão máxima do impacto torcional, obtém-se $\tau_{\max }=47.4$ [MPa]. Já o método de propagação de ondas, equação (3.27) e (3.28), fornece, aproximando-se a velocidade angular da secção na extremidade livre como sendo a velocidade inicial do impacto $v_{0}$ dividido pela metade da aresta $h$, um valor de $\tau_{\max }=66.65[\mathrm{MPa}]$.

A tabela 5.5 ilustra os valores da tensão de cisalhamento máximas dadas pelas diferentes abordagens. No caso do algorítmo explícito, os dados são para as tensões de cisalhamento e equivalentes de Von Mises máximas, no plano central e no engaste da viga. Novamente as simplificações de cada método foram responsáveis pelos variados valores encontrados para a tensão máxima. 
Tabela 5.5: Valores da tensão máxima para diferentes abordagens

\begin{tabular}{|c|cc|}
\hline $\begin{array}{c}\text { Método } \\
\text { da } \\
\text { Energia }\end{array}$ & $\tau_{\max }=47.4[\mathrm{MPa}]$ & (eq. 3.23) \\
\hline $\begin{array}{c}\text { Propagação } \\
\text { de } \\
\text { Ondas }\end{array}$ & $\tau_{\max }=66.65[\mathrm{MPa}]$ & $($ eq. $3.28 \cdots 3.29)$ \\
\hline \hline $\begin{array}{c}\text { Algorítmo } \\
\text { explícito }\end{array}$ & $\tau_{\max }=64[\mathrm{MPa}]$ & (centro) \\
& $\tau_{\max }=100[\mathrm{MPa}]$ & (engaste) \\
& $\sigma_{\max }=110[\mathrm{MPa}]$ & (centro) \\
$\sigma_{\max }=180[\mathrm{MPa}]$ & (engaste) \\
\hline
\end{tabular}

\section{Superfície de tensão máxima}

A superfície de tensão máxima para o caso torcional também foi obtida a partir da mesma faixa de massas e velocidades do impactador dada na tabela 5.2. A figura a seguir mostra a curva ajustada aos pontos obtidos nas modelagens.

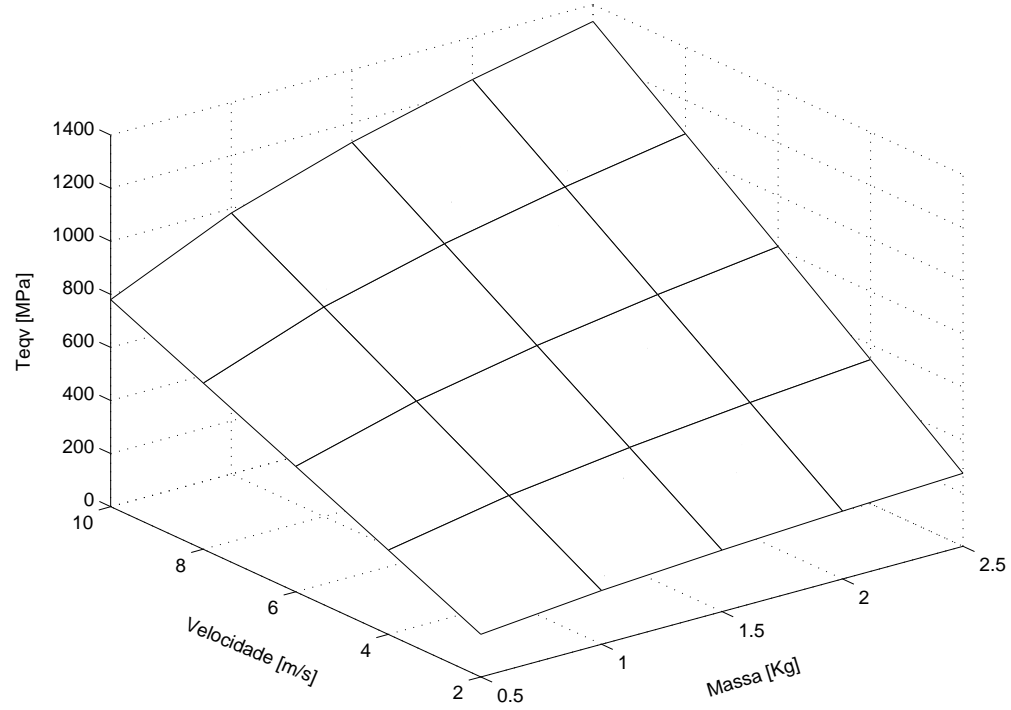

Figura 5.28: Superfície de tensão máxima para o impacto torcional 
Neste caso, a equação obtida pela regressão linear múltipla foi:

$$
\sigma_{\text {max }}=10.241 \cdot 10^{7} m^{0.3346} v^{0.9824}
$$

onde o erro máximo foi de $4.1 \%$.

Novamente apesar de não ter sido realizada um maior número de modelagens, acredita-se que o aumento do número de pontos pode fazer o coeficiente $a$ subir para valores entre 0.4 e 0.5 . 


\section{Capítulo 6}

\section{Metodologia para Análise de Impacto}

\subsection{Introdução}

Nos capítulos anteriores apresentou-se uma base teórica para a determinação das tensões máximas oriundas do impacto de massas rígidas sobre vigas engastadas enfocando-se o método da energia e o método de propagação de ondas. Os valores de tensão máxima fornecidos pelas expressões desenvolvidas foram comparados com aqueles obtidos pela integração explícita no tempo e pode-se constatar que o algorítmo numérico fornece valores satisfatórios, sendo capaz de reproduzir o fenômeno de propagação de ondas. Finalmente para cada caso modelado, apresentou-se a superfície de tensão máxima enfatizando-se a sua forma padrão de proporcionalidade com a raiz quadrada da energia cinética do impactador.

A seguir será apresentada a metodogia proposta para a análise de impacto de sistemas mecânicos elásticos usando-se o MEF e a integração explícita no tempo, partindo-se da hipótese de que essa forma padrão será mantida para as estruturas em estudo. 


\subsection{Metodologia}

A metodologia proposta para o projeto quanto ao impacto é baseada na hipótese de que a tensão máxima devido ao impacto é aproximadamente proporcional à raiz quadrada da energia cinética do impactador conforme as equações de superfície de tensão máxima obtidas nas modelagens descritas no capítulo 5 , e também já constatadas em TEIXEIRA (2002). Partindo-se deste pressuposto, propõe-se a resolver o seguinte problema : é dado um certo sistema elástico, com geometria definida, o qual é submetido a um impacto conhecido e quer-se determinar qual deve ser o valor de um parâmetro, por exemplo a área da secção transversal, para que a tensão máxima de impacto em uma região crítica de interesse, não ultrapasse um certo valor desejado. O parâmetro a ser estudado pode variar dentro de uma faixa de dimensões aceitáveis, por uma questão de projeto ou fabricação por exemplo.

A seguir serão descritos os passos adotados para a aplicação da metodologia de projeto quanto à impacto:

- Passo (1) : Inicialmente requer-se a definição da geometria do problema, da massa $m$ e velocidade $v$ do impactador, a indicação da região de interesse onde a tensão máxima deve ser inferior à uma tensão admissível e a definição da faixa de valores aceitáveis do parâmetro estudado. Com isso então, torna-se possível a modelagem do problema em elementos finitos passando pela escolha dos elementos, propriedades de material, tipo de contato, condições iniciais e de contorno, etc.

- Passo (2) : Com o modelo em elementos finitos pronto, realiza-se uma simulação para a análise do comportamento dinâmico da estrutura. Aqui adota-se a dimensão do parâmetro estudado no centro da faixa definida anteriormente. Pode-se então avaliar se a modelagem do problema foi satisfatória e determinar-se a frequência natural excitada, a região de máxima tensão, os instantes em que ocorrem os seus máximos valores, etc. 
- Passo (3) : Como os tempos de processamento numa análise usando o método da integração explícita no tempo são excessivamente longos, principalmente quando o modelo contém um expressivo número de elementos, torna-se necessário uma cautela ao se fixar o tempo total de simulação. No caso do impacto, este tempo de análise deve ser maior que o tempo de contato entre os corpos e ser da mesma ordem de grandeza do período da frequência natural do modo mais representativo excitado. Com isso, a adequação dos tempos de processamento foi obtida pela determinação das frequências naturais a partir da análise modal das estruturas com suas diferentes dimensões. Tendo os valores das frequências dos modos mais representativos, aqueles excitados pelo impacto, pode-se então limitar o tempo de processamento para que ele englobe o instante de ocorrência da tensão máxima.

- Passo (4) : Após a adequação dos tempos de processamento, determina-se os valores de $\sigma_{\max }$, a partir da integração explícita no tempo, para cada dimensão em estudo.

- Passo (5) : Partindo-se da forma padrão da equação da superfície de tensão máxima, determina-se para cada valor de $\sigma_{\max }$, o valor do coeficiente $c$ e então, por meio de uma regressão linear, determina-se a função que relaciona c com o parâmetro em estudo.

- Passo (6) : A partir de uma tensão admissível pré-estipulada, conhecendose a forma padrão da equação da superfície de tensão máxima, os dados do impacto ( $m$ e $v$ ) e a função que relaciona o parâmetro em estudo com o coeficiente $c$, pode-se então determinar a dimensão deste parâmetro para que a máxima tensão não ultrapasse essa tensão admissível.

A seguir serão apresentados dois exemplos de aplicação para melhor ilustrar a metodologia proposta. 


\subsection{Exemplo de Aplicação (1): Suporte}

\section{Passo (1) - Definição e modelagem do problema}

Considere-se a estrutura conforme a figura 6.1. Ela serve de suporte para uma esteira rolante sobre a qual caem de $0.80[\mathrm{~m}]$ de altura peças com massa de 1.0 [Kg]. Deseja-se saber qual a dimensão $h$ do lado da área da secção transversal, para que a tensão máxima de impacto na região de interesse não ultrapasse uma tensão admissível pré-estipulada $\left(\sigma_{\max } \leq \sigma_{a d m}\right)$. O valor de $h$ é limitado dentro de uma faixa conhecida previamente.

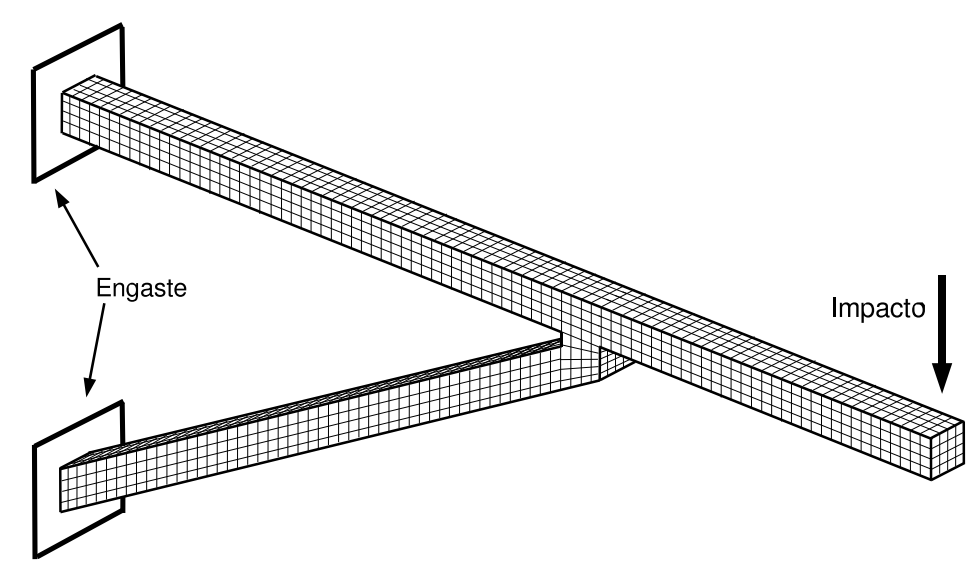

Figura 6.1: Esquema do suporte

A localização da região crítica do suporte e algumas dimensões são ilustradas na figura 6.2. Como se deseja avaliar apenas a aresta $h$ da secção transversal, as principais dimensões da estrutura foram mantidas fixas. A figura também mostra a localização dos pontos (1) e (2) que serão utilizados para fornecer alguns resultados ao longo do tempo. Os valores de $h$ em estudo foram : 20 [mm], 30 $[\mathrm{mm}], 40[\mathrm{~mm}]$ e $50[\mathrm{~mm}]$. 


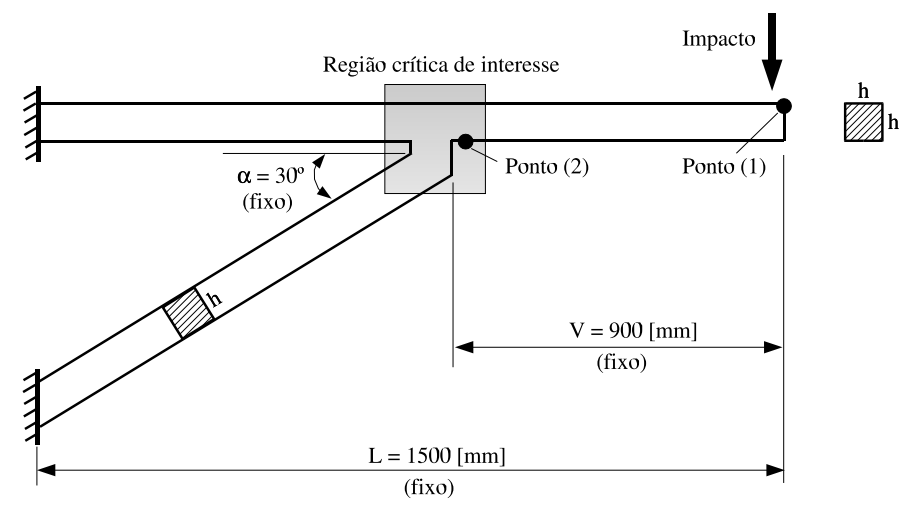

Figura 6.2: Dimensões do suporte e região de interesse

O suporte foi modelado com material elástico linear $\left(E=2.03 \cdot 10^{11}[\mathrm{~Pa}]\right.$, $\rho=7850\left[\mathrm{Kg} / \mathrm{m}^{3}\right]$ e $\left.\nu=0.3\right)$. O impacto foi gerado pelo choque de um cubo rígido, na ponta da estrutura, de dimensões iguais à $h$. As condições de contorno aplicadas foram: o engastamento do suporte e a limitação do movimento do impactador apenas na direção do impacto. A condição inicial foi a velocidade do impactador correspondente a velocidade final de queda para uma altura de $0.8[\mathrm{~m}]$, ou seja, $v=4[\mathrm{~m} / \mathrm{s}]$. A malha foi gerada com elementos sólidos de oito nós (SOLID-164) e contato aplicado entre o cubo e o suporte, foi o geral de nós contra superfície (NTS). A figura abaixo mostra o detalhe da malha na região de interesse.

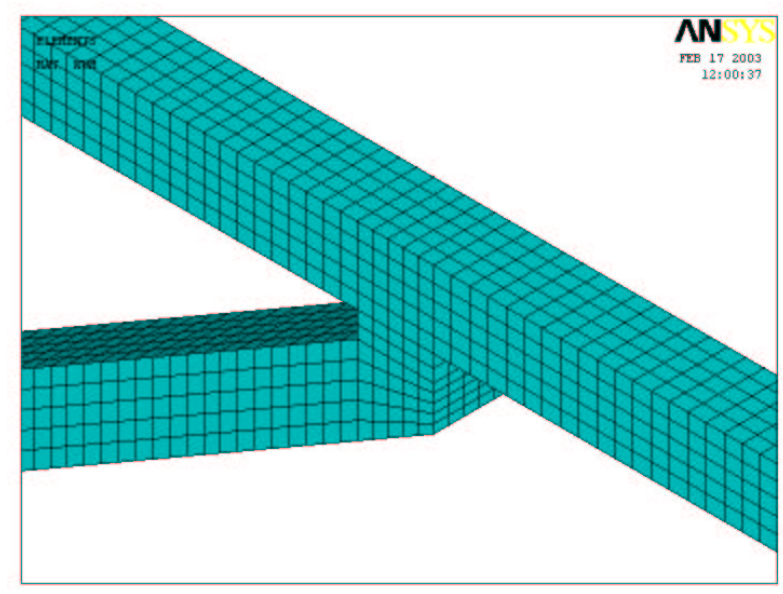

Figura 6.3: Detalhe da malha na região de interesse 


\section{Passo (2) - Análise do comportamento dinâmico da estrutura}

O entendimento do comportamento dinâmico da estrutura submetida ao impacto serve para, inicialmente, verificar se a modelagem do problema está fornecendo resultados satisfatórios ou se é necessário a melhoria de certos parâmetros como malha, contato, condições iniciais, condições de contorno, etc. Para este passo então adotou-se a dimensão do lado $h=30[\mathrm{~mm}]$ e os dados do impacto, massa e velocidade do impactador, $m=1[\mathrm{Kg}]$ e $v=4[\mathrm{~m} / \mathrm{s}]$.

As figuras 6.4 e 6.5 mostram a propagação da onda de tensão decorridos $0.998 \cdot 10^{-4}[\mathrm{~s}]$ e $0.017[\mathrm{~s}]$ após o impacto, respectivamente. Pode-se notar que o restante da estrutura está livre de tensões até que a onda atinja estes pontos. No primeiro trecho da estrutura, antes da junção, a onda é claramente flexional. Depois que a onda alcança este local o seu comportamento torna-se mais complexo devido a sua combinação com as reflexões de onda neste outro trecho.

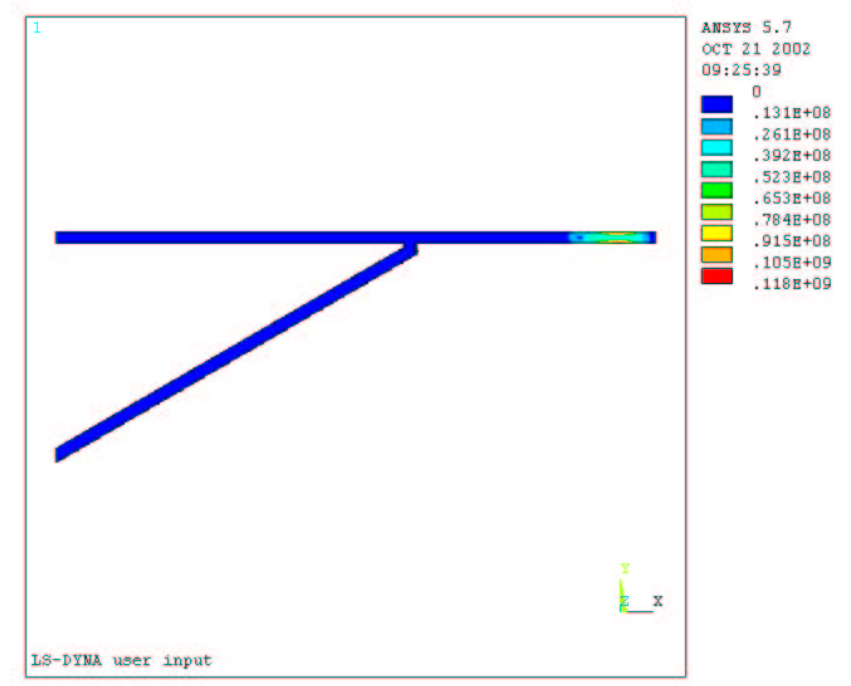

Figura 6.4: Distribuição de tensão decorridos $0.998 \cdot 10^{-4}[\mathrm{~s}]$ 


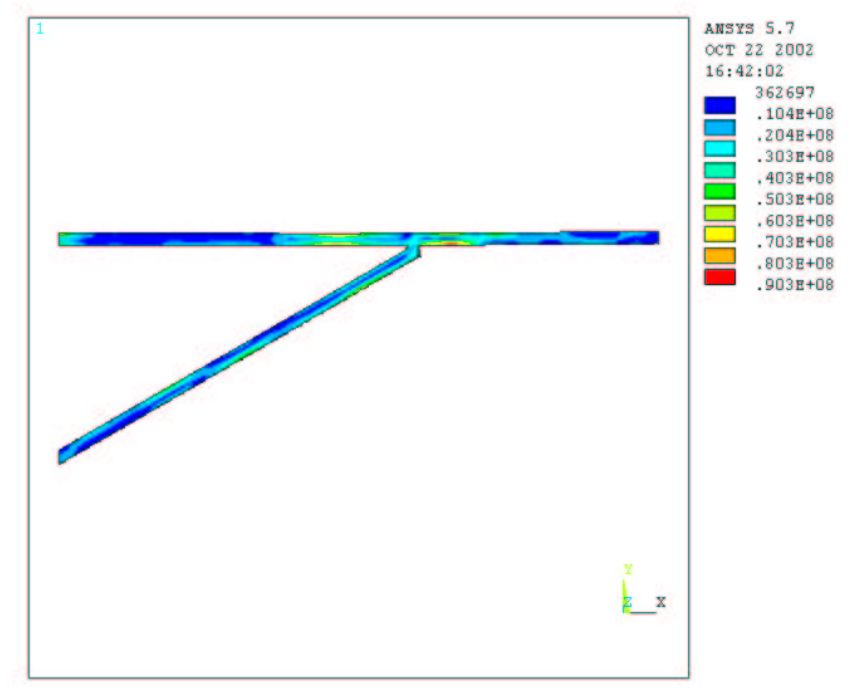

Figura 6.5: Distribuição de tensão decorridos 0.017 [s]

No gráfico da figura 6.6 mostra-se o deslocamento vertical da ponta da estrutura (ponto 1) ao longo do tempo. Pode-se notar que a deflexão tem seu máximo valor alcançado de aproximadamente $0.75 \cdot 10^{-3}[\mathrm{~m}]$ durante o intervalo de tempo em que o impactador está em contato com a estrutura. Após os corpos se separarem, a estrutura vibra numa amplitude menor e sem decaimento, já que o amortecimento não foi considerado. Aplicando-se a FFT nestes pontos verifica-se que praticamente apenas a frequência de 50 [Hz] é excitada que corresponde ao primeiro modo de flexão do suporte conforme a análise modal que, com $h=30$ [mm], forneceu a seguinte frequência natural para o primeiro modo de flexão: $\omega=51.20[\mathrm{~Hz}]$.

A máxima tensão na região crítica de interesse ocorre na junção (ponto 2) e acontece no intervalo de tempo em que a deflexão da ponta atinge também o seu máximo. A variação da tensão normal ao longo do tempo do ponto 2 é mostrada no gráfico da figura 6.8. É possível verificar como este ponto é periodicamente submetido a tração e a compressão numa frequência correspondente ao primeiro modo de flexão. As outras frequências bem mais altas são aparentemente oriundas do algorítmo numérico. 


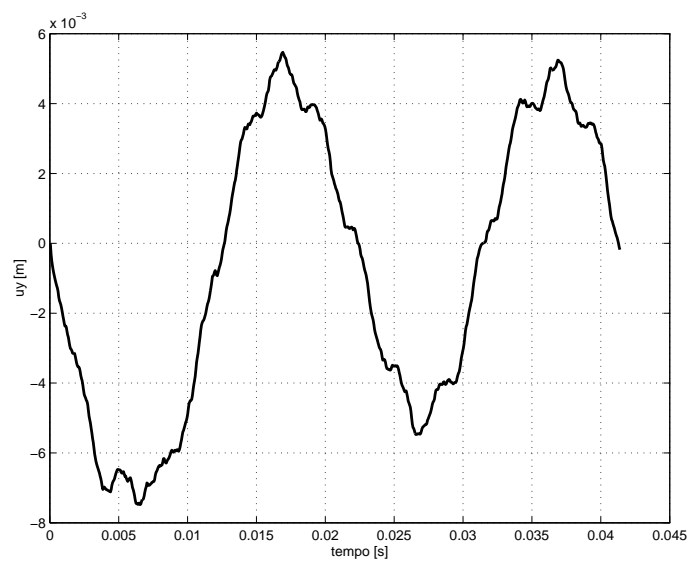

Figura 6.6: Deslocamento vertical do ponto 1 da estrutura ao longo do tempo.

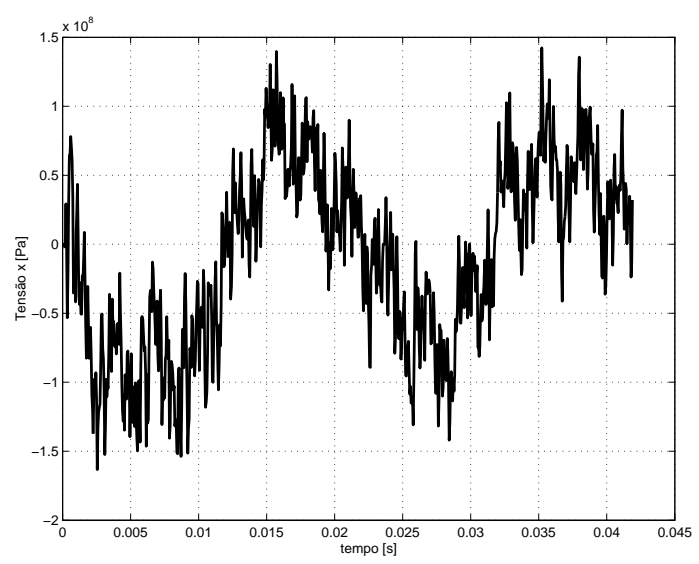

Figura 6.8: Tensão normal do ponto 2 da estrutura em função do tempo.

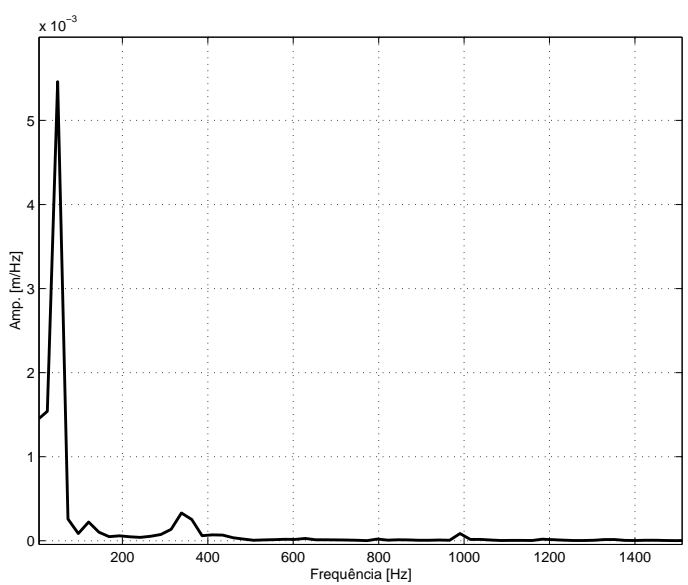

Figura 6.7: FFT do deslocamento do ponto 1 .

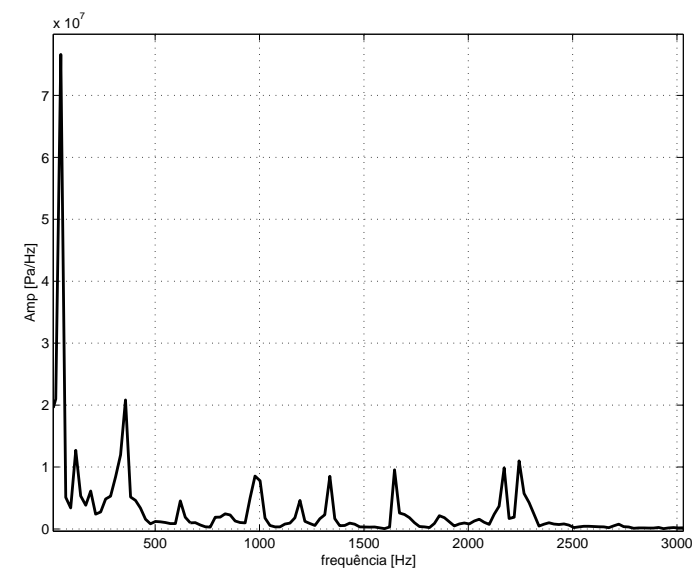

Figura 6.9: FFT da tensão do ponto 2.

\section{Passo (3) - Adequação do tempo de processamento}

A partir da análise do comportamento dinâmico da estrutura, torna-se possível adequar-se o tempo total de processamento conhecendo-se a frequência natural do primeiro modo de flexão. A tabela 6.1 apresenta os valores das frequências naturais do primeiro modo de flexão para cada aresta $h$ em estudo obtidas a partir da análise modal do suporte. 
Tabela 6.1: Frequências naturais do primeiro modo de flexão

\begin{tabular}{|c|c|}
\hline Dimensão $h$ & Frequência \\
\hline \hline $20[\mathrm{~mm}]$ & $33.90[\mathrm{~Hz}]$ \\
\hline $30[\mathrm{~mm}]$ & $51.20[\mathrm{~Hz}]$ \\
\hline $40[\mathrm{~mm}]$ & $68.63[\mathrm{~Hz}]$ \\
\hline $50[\mathrm{~mm}]$ & $85.74[\mathrm{~Hz}]$ \\
\hline
\end{tabular}

Assim o tempo total de análise em todas modelagens foi aplicado como sendo a metade do período da frequência natural do primeiro modo de flexão. Este tempo é suficiente para englobar a máxima tensão que ocorrerá quando o deslocamento da extremidade livre atinge sua máxima amplitude.

\section{Passo (4) - Determinação de $\sigma_{\max }$ para cada $h$}

Com a adequação dos tempos totais de simulação, determinaram-se para os diferentes valores da aresta $h$ dadas na tabela 6.1, a tensão máxima de impacto na região de interesse. As figuras 6.10 a 6.13 mostram a distribuição da tensão equivalente de Von Mises, na região de interesse, no instante em que ela atinge o seu máximo, para cada valor de aresta $h$.

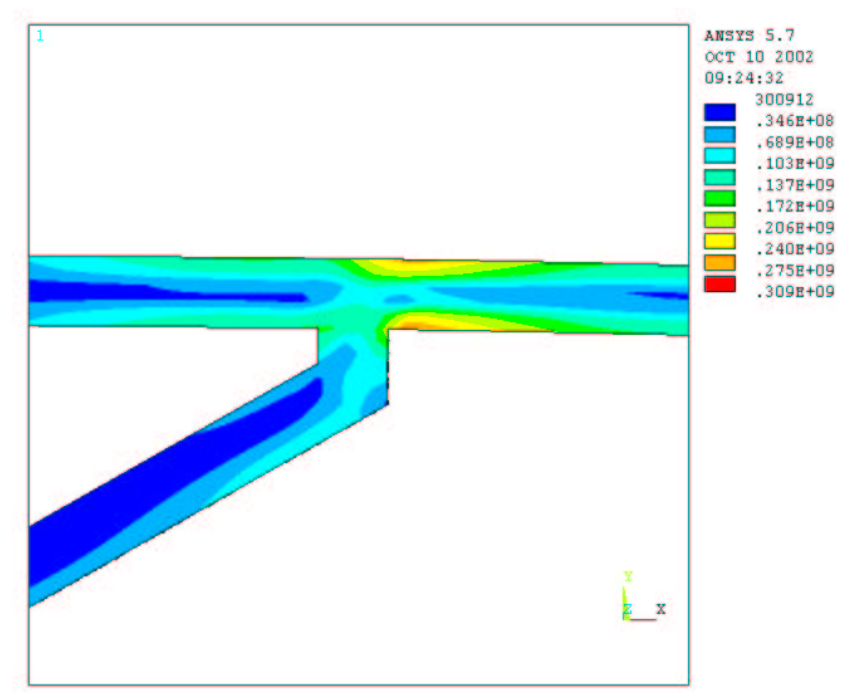

Figura 6.10: Distribuição da tensão equivalente de Von Mises para $\mathrm{h}=20$ [mm] 


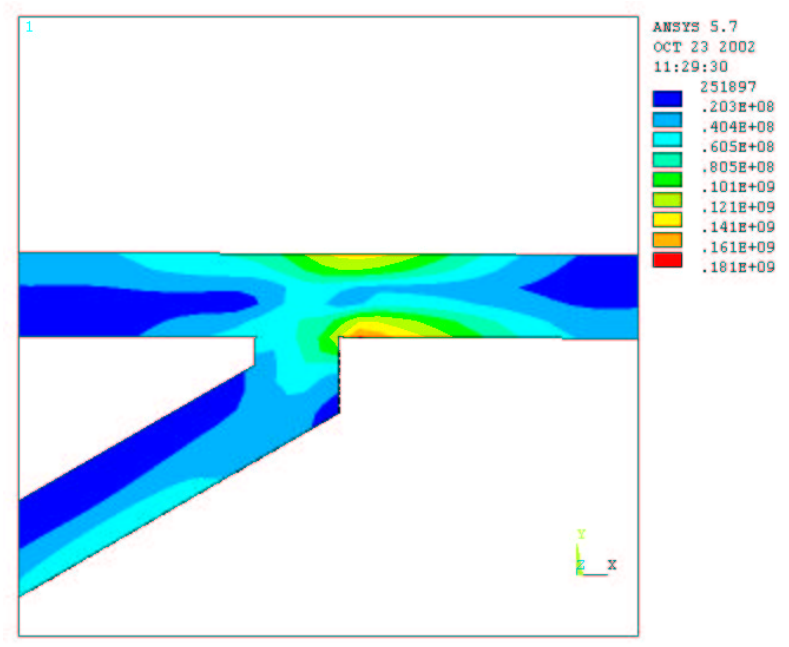

Figura 6.11: Distribuição da tensão equivalente de Von Mises para $\mathrm{h}=30[\mathrm{~mm}]$

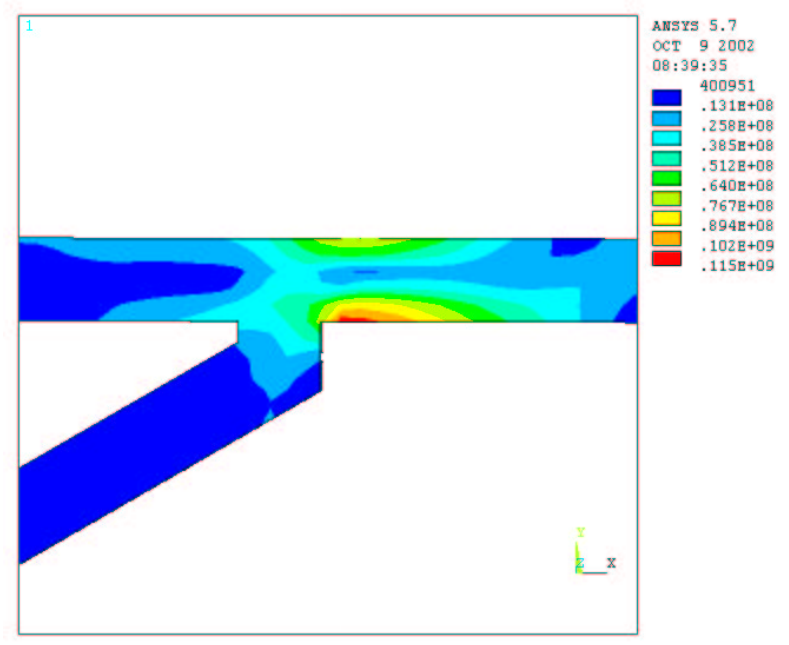

Figura 6.12: Distribuição da tensão equivalente de Von Mises para $\mathrm{h}=40[\mathrm{~mm}]$ 


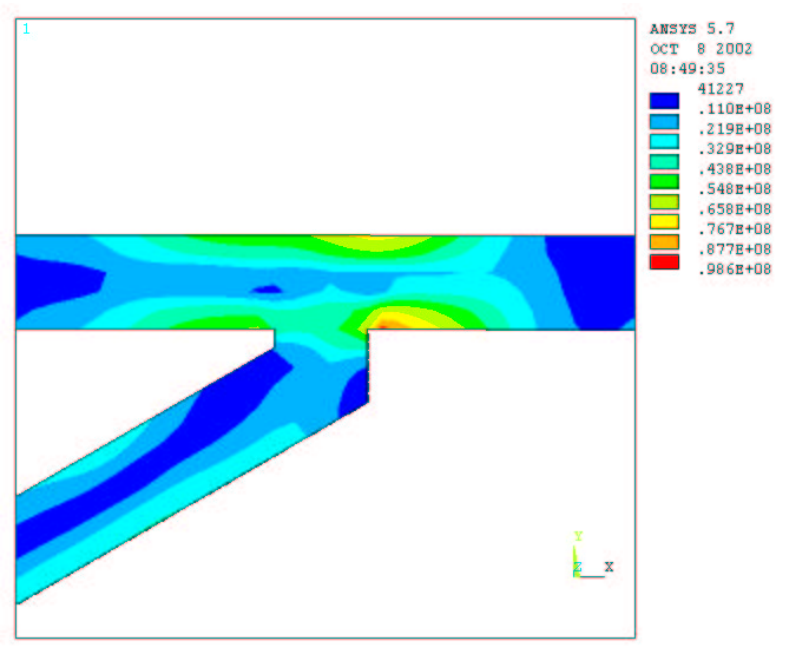

Figura 6.13: Distribuição da tensão equivalente de Von Mises para h $=50[\mathrm{~mm}]$

A tabela 6.2 mostra os valores da tensão equivalente de Von Mises máxima obtidas pelo algorítmo explícito para as diferentes arestas. Como esperado, podese constatar a queda de tensão na medida em que o valor de $h$ é aumentado.

Tabela 6.2: Tensão máxima de impacto em função da aresta $h$

\begin{tabular}{|c|r|}
\hline Dimensão $h$ & Tensão máxima \\
\hline \hline $20[\mathrm{~mm}]$ & $296.15[\mathrm{MPa}]$ \\
\hline $30[\mathrm{~mm}]$ & $170.65[\mathrm{MPa}]$ \\
\hline $40[\mathrm{~mm}]$ & $113.47[\mathrm{MPa}]$ \\
\hline $50[\mathrm{~mm}]$ & $95.43[\mathrm{MPa}]$ \\
\hline
\end{tabular}

\section{Passo (5) - Determinação da função $c=f(h)$}

A determinação do coeficiente $c$ é baseada na consideração, já discutida anteriormente, de que a máxima tensão devido ao impacto é proporcional a raiz quadrada da energia cinética do impactador. Desta forma o coeficiente $c$ foi calculado a partir da equação padrão da superfície de tensão máxima considerando-se os coeficientes $a=0.5$ e $b=1.0$.

$$
\sigma_{\max }=c \cdot m^{a} \cdot v^{b} \quad \Rightarrow \quad c=\frac{\sigma_{\max }}{m^{0.5} \cdot v^{1.0}}
$$


Como $m$ e $v$ são conhecidos, sendo a massa e a velocidade do impactador respectivamente, torna-se possível determinar-se $c$ conhecendo-se os valores de $\sigma_{\max }$. A tabela abaixo mostra os valores calculados para o coeficiente $c$ em função dos diferentes valores de $h$.

Tabela 6.3: Coeficiente $c$ em função da aresta $h$

\begin{tabular}{|c|cc|}
\hline Dimensão $h$ & \multicolumn{2}{|c|}{ Coeficiente $c$} \\
\hline \hline $20[\mathrm{~mm}]$ & $7.4037 \cdot 10^{7}$ & {$\left[\mathrm{Kg}^{0.5} / \mathrm{m}^{2} s\right]$} \\
\hline $30[\mathrm{~mm}]$ & $4.2663 \cdot 10^{7}$ & {$\left[\mathrm{Kg}^{0.5} / \mathrm{m}^{2} s\right]$} \\
\hline $40[\mathrm{~mm}]$ & $2.8367 \cdot 10^{7}$ & {$\left[\mathrm{Kg}^{0.5} / m^{2} s\right]$} \\
\hline $50[\mathrm{~mm}]$ & $2.3859 \cdot 10^{7}$ & {$\left[\mathrm{Kg}^{0.5} / m^{2} s\right]$} \\
\hline
\end{tabular}

A equação 6.2 foi determinada por meio de uma regressão linear sobre os pontos da tabela 6.3 e a curva que aproxima os pontos é mostrada na figura 6.14.

$$
c=e^{21.893} h^{-1.2668}
$$

onde o erro máximo foi de $8.23 \%$

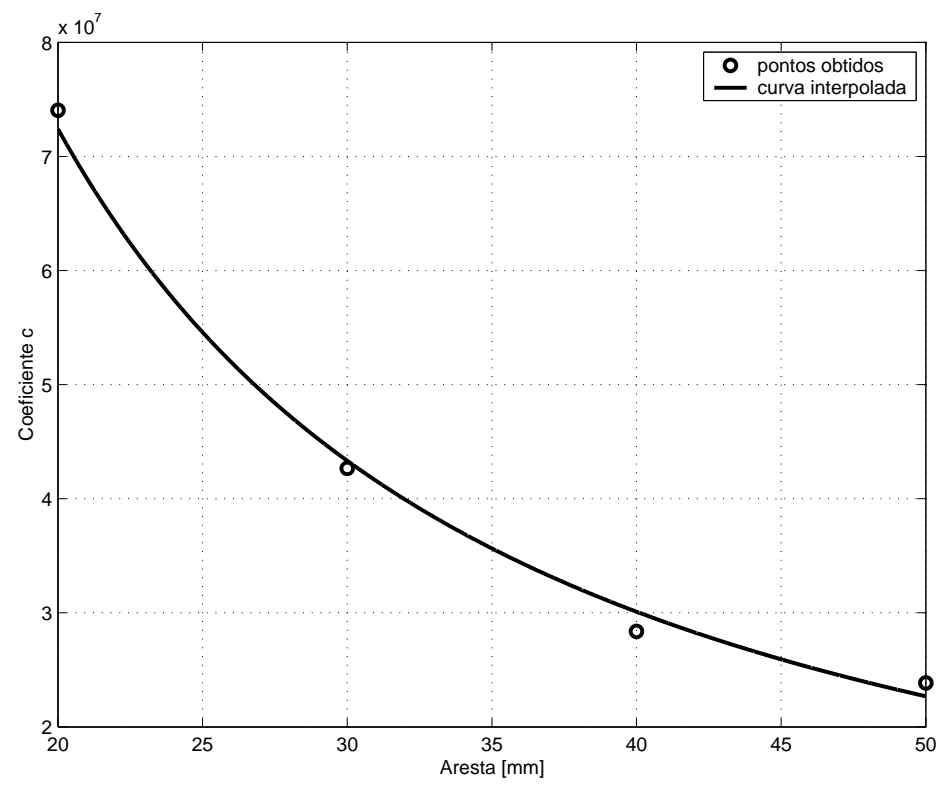

Figura 6.14: Curva aproximada pela regressão linear 


\section{Passo (6) - Solução}

De posse da curva $c=f(h)$ torna-se possível estimar o valor da aresta $h$ a partir de uma tensão admissível pré-estipulada. A tensão admissível, $\sigma_{a d m}$ pode ser calculada dividindo-se uma tensão perigosa $T P$ por um coeficiente de segurança $C S$.

$$
\sigma_{a d m}=\frac{T P}{C S}
$$

A tabela 6.4 mostra alguns valores ilustrativos de coeficientes de segurança sugeridos por alguns autores no caso de choques, baseado no limite de escoamento do material.

Tabela 6.4: Coeficientes de segurança sugeridos para choques

\begin{tabular}{|l|c|c|}
\hline CS & Tipo de material & Autor \\
\hline \hline$C S=5 \cdots 7$ & Aço e materiais dúcteis & FAIRES (1975) \\
\hline$C S=2$ & Materiais muito dúcteis & \\
$C S=1.5$ & Materiais menos dúcteis & SHIGLEY (1980) \\
\hline$C S=1.5 \cdots 2.5$ & Materiais dúcteis & BLACK (1955) \\
\hline
\end{tabular}

No presente exemplo, considerou-se uma tensão admissível $\sigma_{a d m}$ correspondente a $70 \%$ da tensão perigosa $T P$, que no caso é a tensão de escoamento $\sigma_{e}$ do material. Isto é equivalente a um coeficiente de segurança $C S=1.42$ cujo valor está abaixo dos valores sugeridos na literatura. Com isso, para $T P=\sigma_{e}=300$ [MPa] que corresponde à uma tensão de escoamento do material do suporte (aço ABNT-1030), a tensão admissível dada pela equação 6.3 é de $\sigma_{a d m}=210[\mathrm{MPa}]$.

Aplicando-se $\sigma_{\max }=210[\mathrm{MPa}]$ na equação padrão da superfície de tensão máxima com $m=1[\mathrm{Kg}]$ e $v=4[\mathrm{~m} / \mathrm{s}]$ tem-se:

$$
\sigma_{\max }=c \cdot m^{a} \cdot v^{b} \quad \Rightarrow \quad c=\frac{210 \cdot 10^{6}}{1^{0.5} \cdot 4^{1}} \quad \Rightarrow \quad c=5.25 \cdot 10^{7} \quad\left[\mathrm{Kg}^{0.5} / \mathrm{m}^{2} \mathrm{~s}\right]
$$

Substituindo-se este valor na equação (6.2) obtém-se o seguinte valor para a dimensão $h=25.78[\mathrm{~mm}]$. 
A modelagem da estrutura foi então realizada com esta dimensão e a tensão equivalente máxima de Von Mises fornecida pelo algorítmo explicíto foi de $\sigma_{\max }=$ 212.85 [MPa], ou seja, uma diferença de $1.36 \%$ do valor estipulado de 210 [MPa].

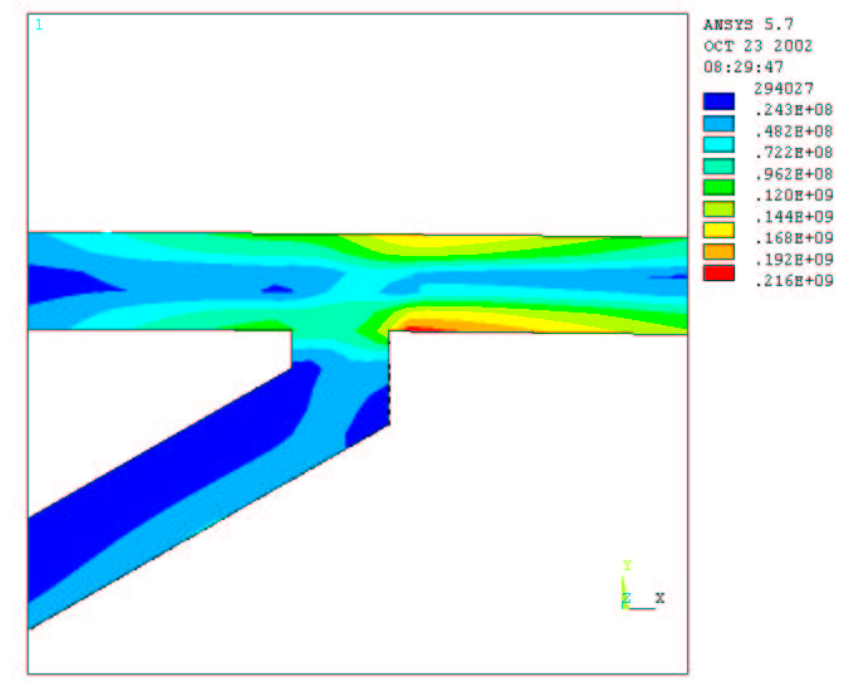

Figura 6.15: Distribuição da tensão equivalente de Von Mises para $h=25.78$ [mm]

\subsection{Exemplo de Aplicação (2): Eixo chavetado}

\section{Passo (1) - Definição e modelagem do problema}

A figura 6.16 esquematiza o quarto eixo de um redutor de velocidades acionado por um motor elétrico de 30 [CV] à 1600 [rpm]. A rotação do eixo é de 80 [rpm]. Deseja-se saber qual a dimensão do diâmetro $\phi_{2}$ para que a tensão máxima de impacto devido ao choque da chaveta no rasgo, quando o eixo tem sua rotação subitamente travada na região especificada, não ultrapasse a tensão admissível na região de interesse. 

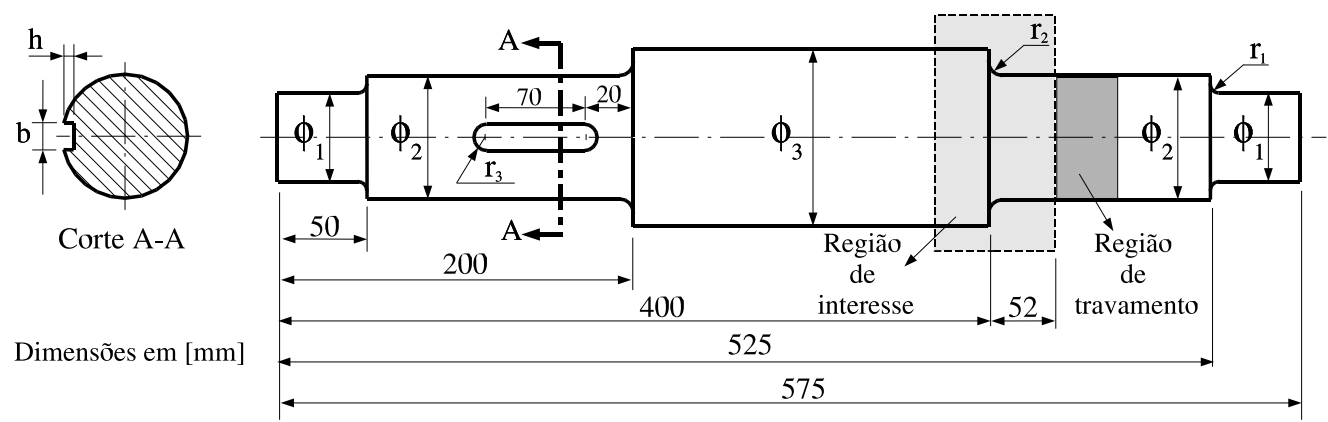

Figura 6.16: Esquema do eixo especificando as regiões de interesse e de travamento

A escolha da região de interesse fora de onde ocorre a máxima tensão (neste caso próximo à região do rasgo) foi feita para verificar se a metodologia continuava válida neste caso. Além disso, tentou-se estudar o efeito do impacto na região do escalonamento onde existe uma clássica concentração de tensão.

Considerando-se a potência do motor e a redução requerida, estimou-se a massa $m$ e a velocidade $v$ da chaveta, que seria equivalente à toda a inércia do conjunto, aplicando-se a seguinte relação:

$$
I_{\text {eqv }}=\left(I_{1}+I_{m}\right)\left(\frac{n_{1}}{n_{4}}\right)^{2}+I_{2}\left(\frac{n_{2}}{n_{4}}\right)^{2}+I_{3}\left(\frac{n_{3}}{n_{4}}\right)^{2}+I_{4}
$$

onde $I_{\text {eqv }}$ corresponde à inércia equivalente no eixo em estudo e as rotações $n_{i}$ são funções das reduções conforme ilustrado na figura abaixo.

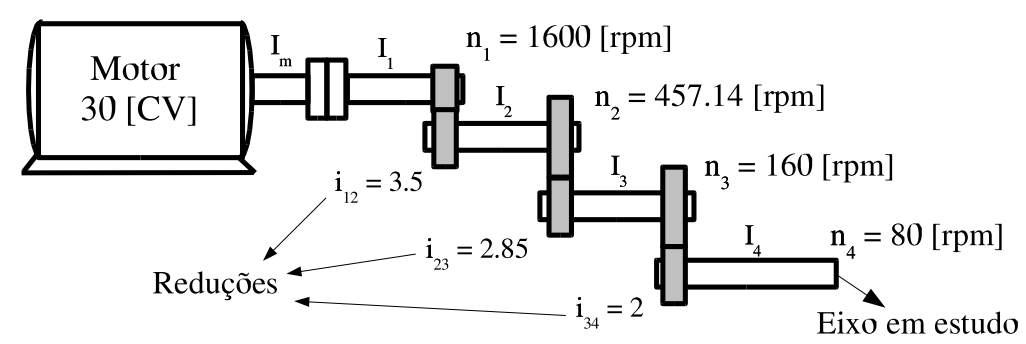

Figura 6.17: Esquema do redutor de velocidades 
A inércia do motor $I_{m}$ foi determinada a partir de um catálogo de fabricante e os valores das inércias parciais dos outros eixos foram calculadas a partir de valores adotados de suas dimensões considerando-se medidas aceitáveis para o conjunto moto-redutor. Desta forma, tendo-se a inércia equivalente e a rotação do eixo, determinou-se a massa $m$ e a velocidade $v$ da chaveta considerando-se a quantidade de movimento angular equivalente igual a quantidade de movimento linear da chaveta, assim:

$$
\begin{gathered}
I_{e q v} \cdot \omega_{4}=m \cdot v \quad \Rightarrow \quad m=\frac{I_{e q v} \cdot \omega_{4}}{v} \\
v=\omega_{4} \cdot R
\end{gathered}
$$

onde $R$ é o raio do eixo no escalonamento da chaveta e $\omega_{4}$ é a sua rotação em $[\mathrm{rad} / \mathrm{s}]$. Os valores obtidos para a massa e a velocidade de impacto foram, respectivamente, $m=1000[\mathrm{Kg}]$ e $v=0.3[\mathrm{~m} / \mathrm{s}]$.

Os escalonamentos dos diâmetros foram fixados em $\phi_{i+1}=1.4 \phi_{i}$ sendo os valores de $\phi_{2}$ estudados: $50[\mathrm{~mm}], 60[\mathrm{~mm}], 70[\mathrm{~mm}], 80[\mathrm{~mm}]$ e $100[\mathrm{~mm}]$. Para cada caso, ocorreu a simplificação do modelo substituindo-se os raios de arredondamento por chanfros e eliminando-se o raio do rasgo de chaveta. Tal simplificação foi necessária devido à dificuldade em se gerar a malha nestas regiões e também devido ao aumento expressivo do tempo de processamento com o aumento do número de elementos. As dimensões longitudinais foram mantidas fixas, variando-se apenas as dimensões do rasgo de chaveta e dos chanfros de acordo com o diâmetro. O eixo foi modelado com material elástico linear $\left(E=2.03 \cdot 10^{11}[\mathrm{~Pa}], \rho=7850\right.$ $\left[\mathrm{Kg} / \mathrm{m}^{3}\right]$ e $\left.\nu=0.3\right)$ e a chaveta como rígida $\mathrm{O}$ impacto foi gerado pelo choque da chaveta no rasgo devido uma folga de $0.01[\mathrm{~mm}]$ entre eles. A malha foi gerada com elementos sólidos de oito nós (SOLID-164), exceto na região dos chanfros onde utilizaram-se elementos sólidos de seis nós. O contato aplicado entre a chaveta e o rasgo foi o geral de nós contra superfície (NTS).

As condições de contorno aplicadas no eixo foram: a retirada dos graus de liberdade de deslocamento $u_{x}$ e $u_{y}$ e de rotação rot $_{x}$ e rot ${ }_{y}$ simulando um assento de rolamento do lado esquerdo (rolamento solto); a retirada dos graus de liberdade 
de deslocamento $u_{x}, u_{y}$ e $u_{z}$ e de rotação rot $_{x}$ e roty simulando um assento de rolamento do lado direito (rolamento preso); a retirada do grau de liberdade de rotação $\operatorname{rot}_{z}$ simulando o impedimento da torção do eixo naquele trecho. Na chaveta, permitiu-se o movimento apenas na direção do impacto. A figura 6.18 ilustra o detalhe da malha na região do rasgo e a figura 6.19 esquematiza as condições de contorno aplicadas.

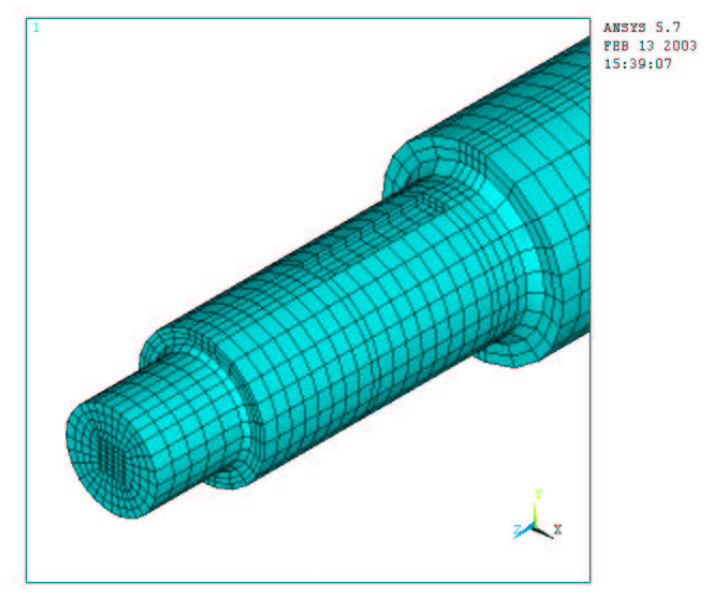

Figura 6.18: Detalhe da malha na região do rasgo.

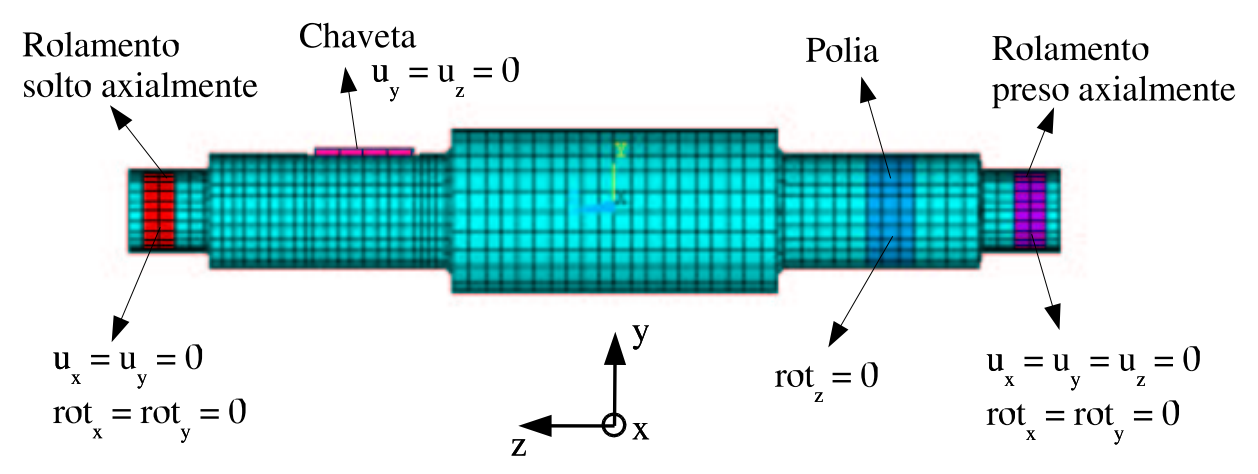

Figura 6.19: Condições de contorno aplicadas. 


\section{Passo (2) - Análise do comportamento dinâmico da estrutura}

Para a análise do comportamento dinâmico do eixo, adotou-se $\phi_{2}=70[\mathrm{~mm}]$ com $m=1000[\mathrm{Kg}]$ e $v=0.3[\mathrm{~m} / \mathrm{s}]$ sendo a massa e a velocidade de impacto da chaveta no rasgo, respectivamente.

A figura abaixo mostra a propagação da onda de tensão decorridos $3.386 \cdot 10^{-5}$ [s] após o impacto. Pode-se notar que a onda parte da região do rasgo onde ocorre o impacto e se propaga em direção aos escalonamentos.

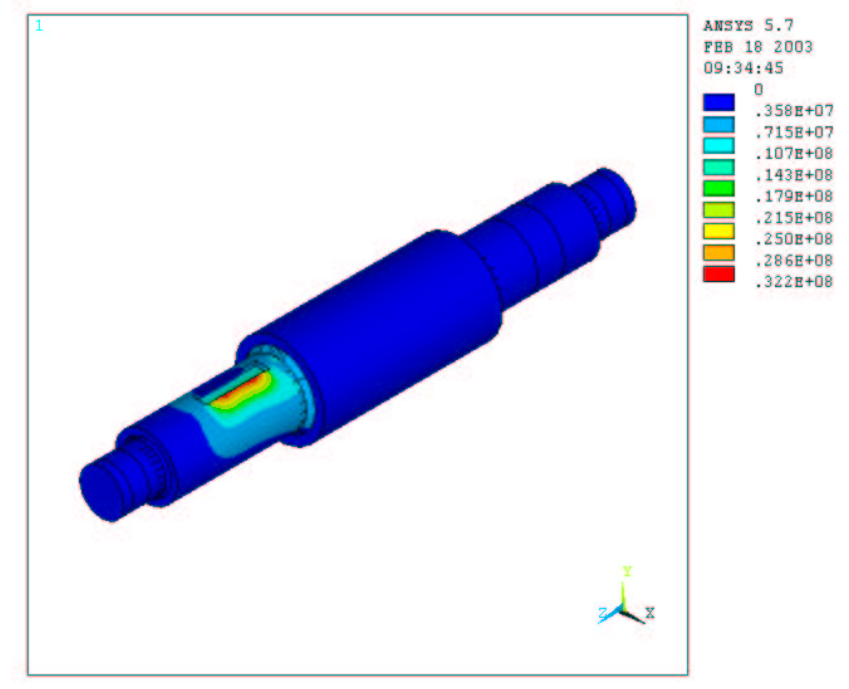

Figura 6.20: Propagação da onda decorridos $3.386 \cdot 10^{-5}[\mathrm{~s}]$

A figura 6.21 mostra a localização na região de interesse, do ponto de máxima tensão (ponto A) e o gráfico da figura 6.22 ilustra o seu deslocamento na direção $x$. Pode-se verificar pela aplicação da FFT neste pontos, que a frequência excitada pelo impacto corresponde a frequência natural do primeiro modo de flexão do eixo conforme a análise modal que com $\phi_{2}=70[\mathrm{~mm}]$ forneceu $\omega=83.5[\mathrm{~Hz}]$. Ou seja, apesar do impacto gerar uma flexo-torção no eixo, a parcela correspondente a flexão é predominante no problema. 

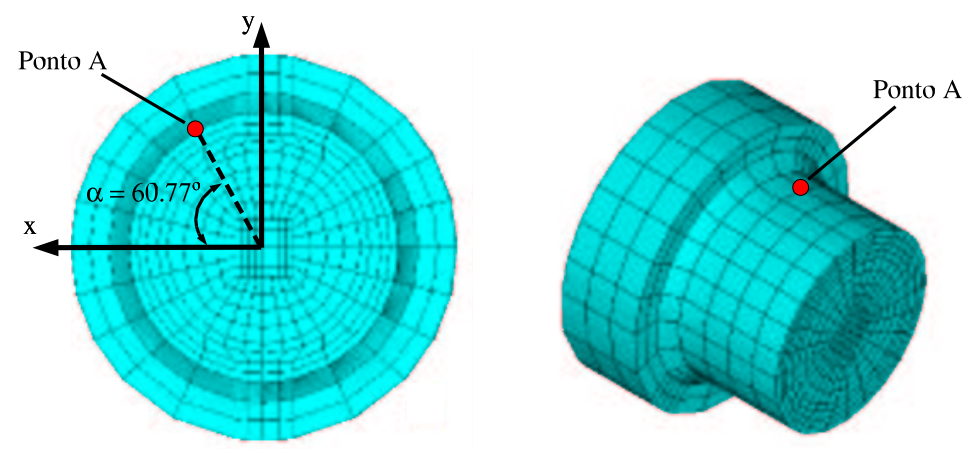

Figura 6.21: Localização do ponto A na região de interesse.

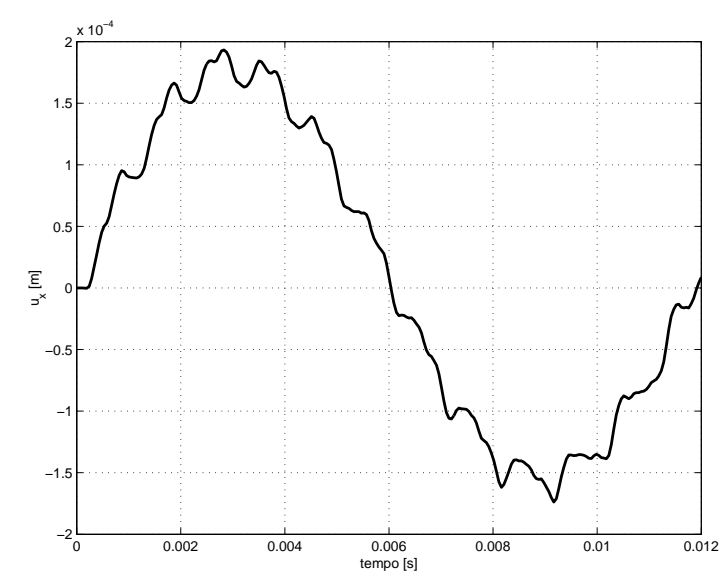

Figura 6.22: Deslocamento do ponto A na direção $x$.

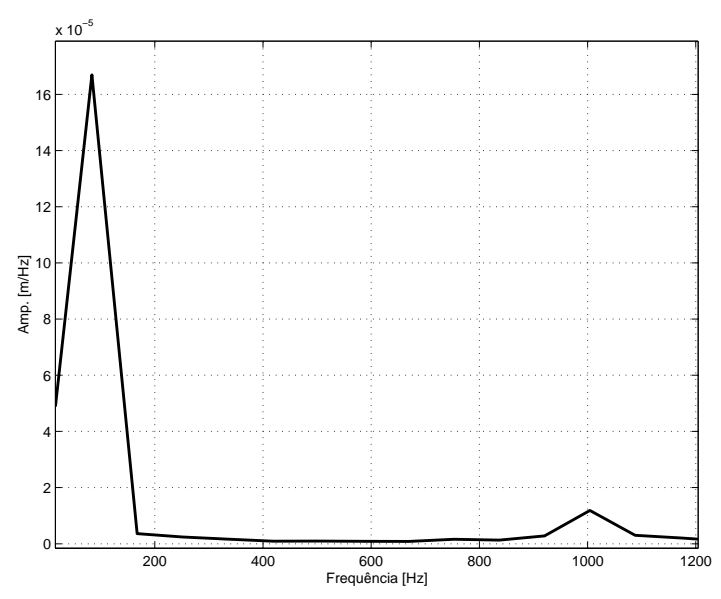

Figura 6.23: FFT do deslocamento.

\section{Passo (3) - Adequação do tempo de processamento}

O tempo total de processamento foi adequado a partir da frequência natural do primeiro modo de flexão que é predominante no problema. A tabela 6.5 apresenta os valores das frequências naturais do primeiro modo de flexão em função dos diâmetros $\phi_{2}$ estudados, obtidas a partir da análise modal do eixo. Novamente o tempo total de simulação foi adotado como sendo a metade o período destas frequências para que englobasse o instante de máxima tensão. 
Tabela 6.5: Frequências naturais do primeiro modo de flexão

\begin{tabular}{|c|c|}
\hline Dimensão & Frequência \\
\hline \hline$\phi_{2}=50[\mathrm{~mm}]$ & $50.04[\mathrm{~Hz}]$ \\
\hline$\phi_{2}=60[\mathrm{~mm}]$ & $66.00[\mathrm{~Hz}]$ \\
\hline$\phi_{2}=70[\mathrm{~mm}]$ & $83.50[\mathrm{~Hz}]$ \\
\hline$\phi_{2}=80[\mathrm{~mm}]$ & $93.28[\mathrm{~Hz}]$ \\
\hline$\phi_{2}=100[\mathrm{~mm}]$ & $127.28[\mathrm{~Hz}]$ \\
\hline
\end{tabular}

\section{Passo (4) - Determinação de $\sigma_{\max }$ para cada $\phi$}

Aplicando-se os tempos adequados, para cada valor do diâmetro $\phi_{2}$, obtiveramse as tensões máximas equivalentes de Von Mises, devido ao impacto, na região de interesse. Também tentou-se estudar o efeito de concentração de tensão devido ao escalonamento ao longo dos pontos ilustrados na figura 6.24. Note que a linha de nós passa pela localização do ponto A da figura 6.21. Um estudo mais profundo ficou prejudicado pelas limitações computacionais, pois seria necessário um refinamento bem maior da malha nesta região o que tornaria o tempo de processamento muito demorado.

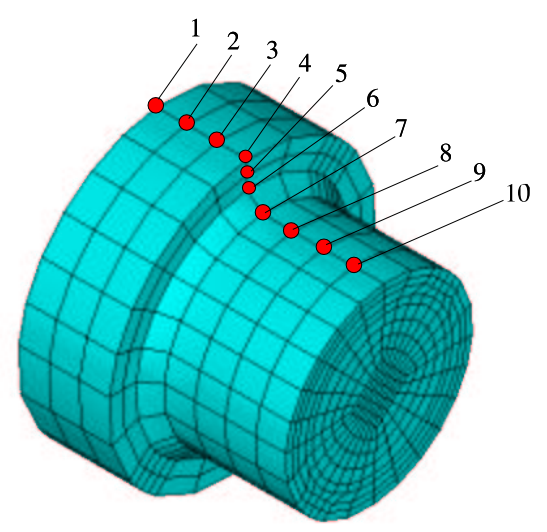

Figura 6.24: Linha de nós para o estudo da concentração de tensão

As figuras a seguir mostram a distribuição da tensão equivalente de Von Mises para os diferentes escalonamentos no instante de máximo. Também é mostrada a variação desta tensão ao longo da linha de pontos. Em todos os casos, a máxima 
tensão ocorreu no ponto de número 8, correspondente ao segundo nó depois do escalonamento e cuja localização é dada pela figura 6.21. Os gráficos fornecem uma boa visão qualitativa do salto da tensão quando ocorre a passagem do diâmetro maior para o menor. Mas um estudo mais apurado, necessitaria de um maior número de pontos como já comentado.

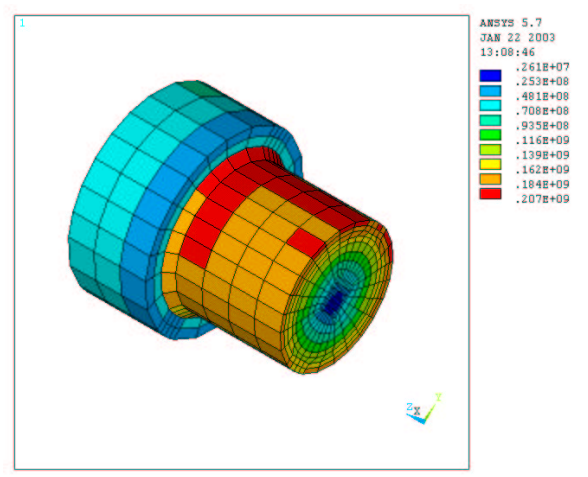

Figura 6.25: Distribuição de tensão na região de interesse - $\phi_{2}=50[\mathrm{~mm}]$

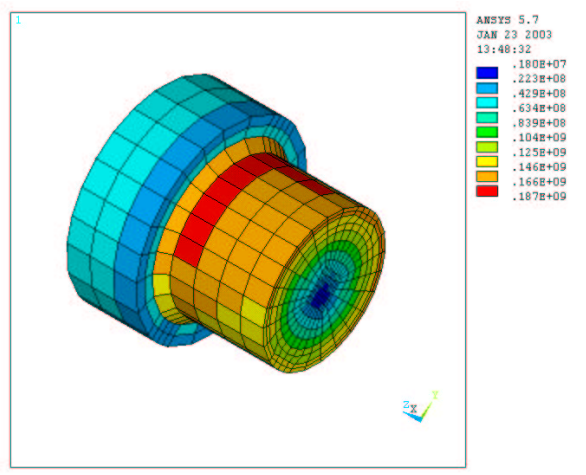

Figura 6.27: Distribuição de tensão na região de interesse $-\phi_{2}=60[\mathrm{~mm}]$

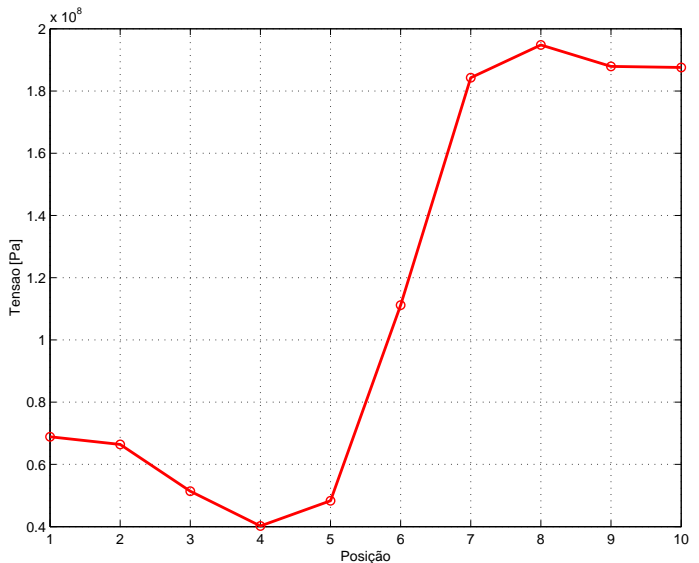

Figura 6.26: Variação da tensão ao longo da linha de nós

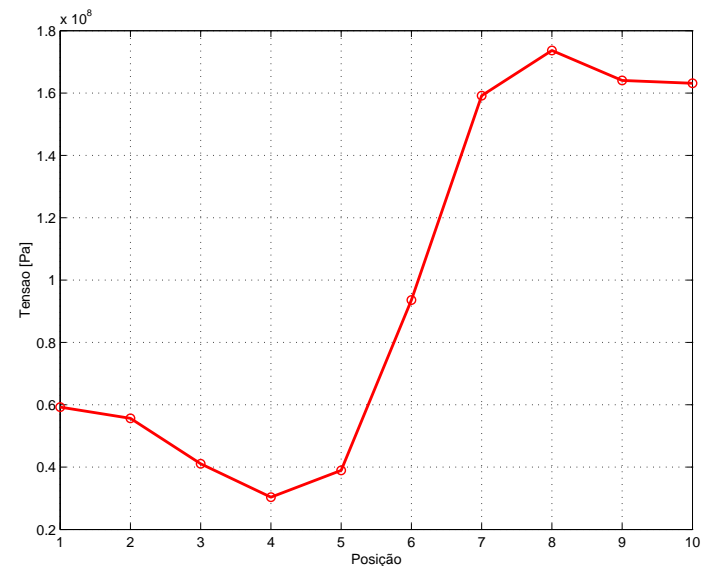

Figura 6.28: Variação da tensão ao longo da linha de nós 


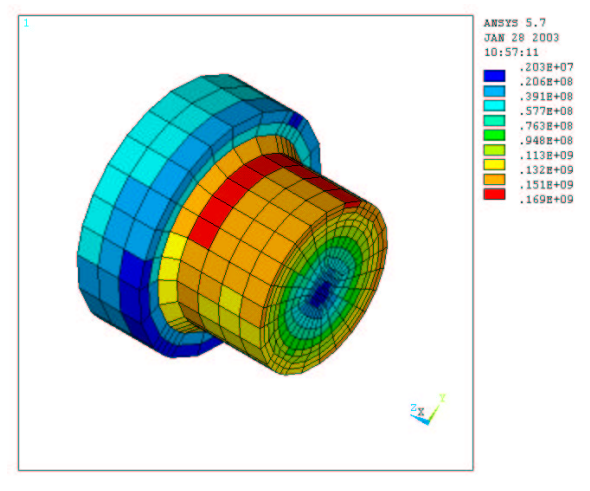

Figura 6.29: Distribuição de tensão na região de interesse - $\phi_{2}=70[\mathrm{~mm}]$

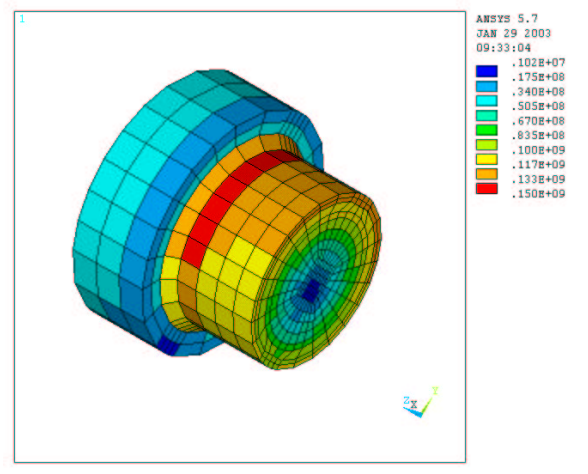

Figura 6.31: Distribuição de tensão na região de interesse $-\phi_{2}=80[\mathrm{~mm}]$

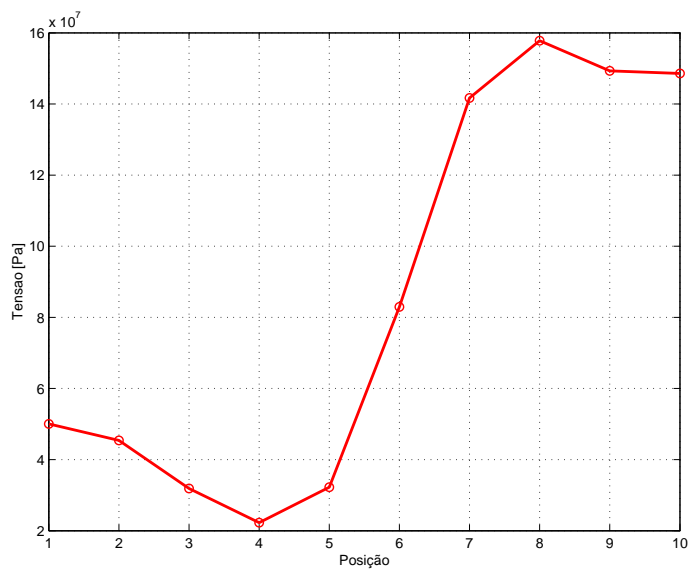

Figura 6.30: Variação da tensão ao longo da linha de nós

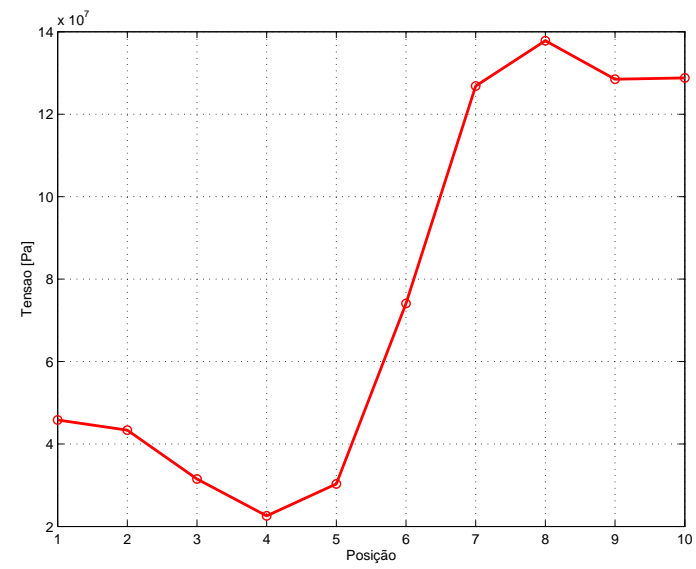

Figura 6.32: Variação da tensão ao longo da linha de nós 


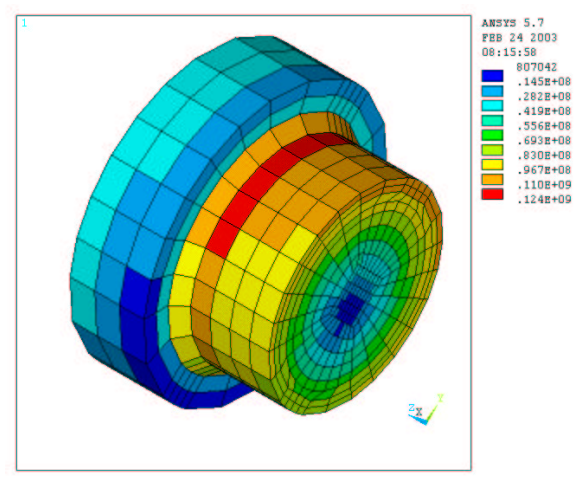

Figura 6.33: Distribuição de tensão na região de interesse $-\phi_{2}=100[\mathrm{~mm}]$

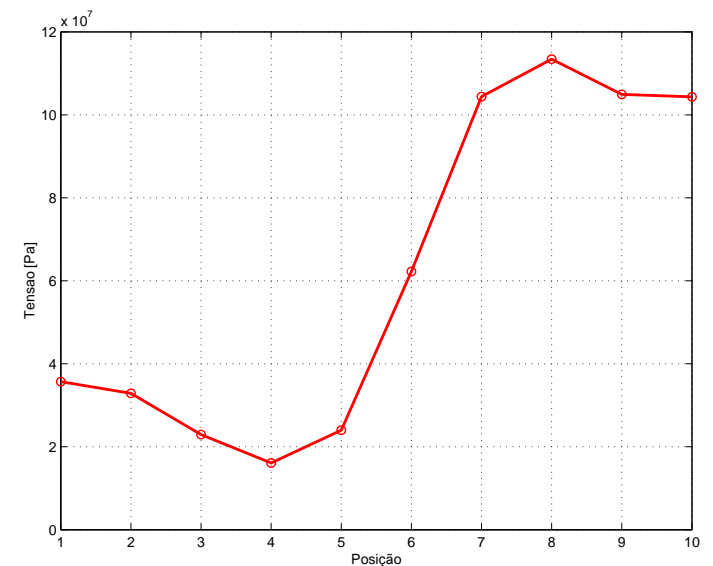

Figura 6.34: Variação da tensão ao longo da linha de nós

A tabela 6.6 contém as tensões equivalentes máximas de Von Mises para cada caso estudado.

Tabela 6.6: Tensão máxima de impacto em função do diâmetro $\phi_{2}$

\begin{tabular}{|l|c|}
\hline Dimensão $\phi$ & Tensão máxima \\
\hline \hline$\phi_{2}=50[\mathrm{~mm}]$ & $194.80[\mathrm{MPa}]$ \\
\hline$\phi_{2}=60[\mathrm{~mm}]$ & $173.64[\mathrm{MPa}]$ \\
\hline$\phi_{2}=70[\mathrm{~mm}]$ & $157.80[\mathrm{MPa}]$ \\
\hline$\phi_{2}=80[\mathrm{~mm}]$ & $137.80[\mathrm{MPa}]$ \\
\hline$\phi_{2}=100[\mathrm{~mm}]$ & $113.40[\mathrm{MPa}]$ \\
\hline
\end{tabular}

\section{Passo (5) - Determinação da função $c=f(\phi)$}

Considerando-se novamente a hipótese de que a máxima tensão devido ao impacto, é proporcional a raiz quadrada da energia cinética do impactador ( $a=$ 0.5 e $b=1.0)$ :

$$
\sigma_{\max }=c \cdot m^{a} \cdot v^{b} \quad \Rightarrow \quad c=\frac{\sigma_{\max }}{m^{0.5} \cdot v^{1.0}}
$$

Como $m$ e $v$ são conhecidos, torna-se possível determinar-se $c$ conhecendo-se os valores de $\sigma_{\max }$. A tabela abaixo mostra os valores calculados para o coeficiente $c$ em função dos diferentes valores do diâmetro $\phi_{2}$. 
Tabela 6.7: Coeficiente $c$ em função do diâmetro $\phi_{2}$

\begin{tabular}{|l|ll|}
\hline Dimensão $h$ & \multicolumn{2}{|c|}{ Coeficiente $c$} \\
\hline \hline$\phi_{2}=50[\mathrm{~mm}]$ & $20.533 \cdot 10^{6}$ & {$\left[\mathrm{Kg}^{0.5} / m^{2} s\right]$} \\
\hline$\phi_{2}=60[\mathrm{~mm}]$ & $18.303 \cdot 10^{6}$ & {$\left[\mathrm{Kg}^{0.5} / m^{2} s\right]$} \\
\hline$\phi_{2}=70[\mathrm{~mm}]$ & $16.633 \cdot 10^{6}$ & {$\left[\mathrm{Kg}^{0.5} / m^{2} s\right]$} \\
\hline$\phi_{2}=80[\mathrm{~mm}]$ & $14.525 \cdot 10^{6}$ & {$\left[\mathrm{Kg}^{0.5} / m^{2} s\right]$} \\
\hline$\phi_{2}=100[\mathrm{~mm}]$ & $11.953 \cdot 10^{6}$ & {$\left[\mathrm{Kg}^{0.5} / m^{2} s\right]$} \\
\hline
\end{tabular}

Aplicando-se uma regressão linear nos pontos da tabela 6.7, obteve-se a seguinte equação:

$$
c=(-0.17145 \phi+28.734) \cdot 10^{6}
$$

onde o erro máximo foi de $3.2 \%$

A figura abaixo representa a reta que aproxima os pontos:

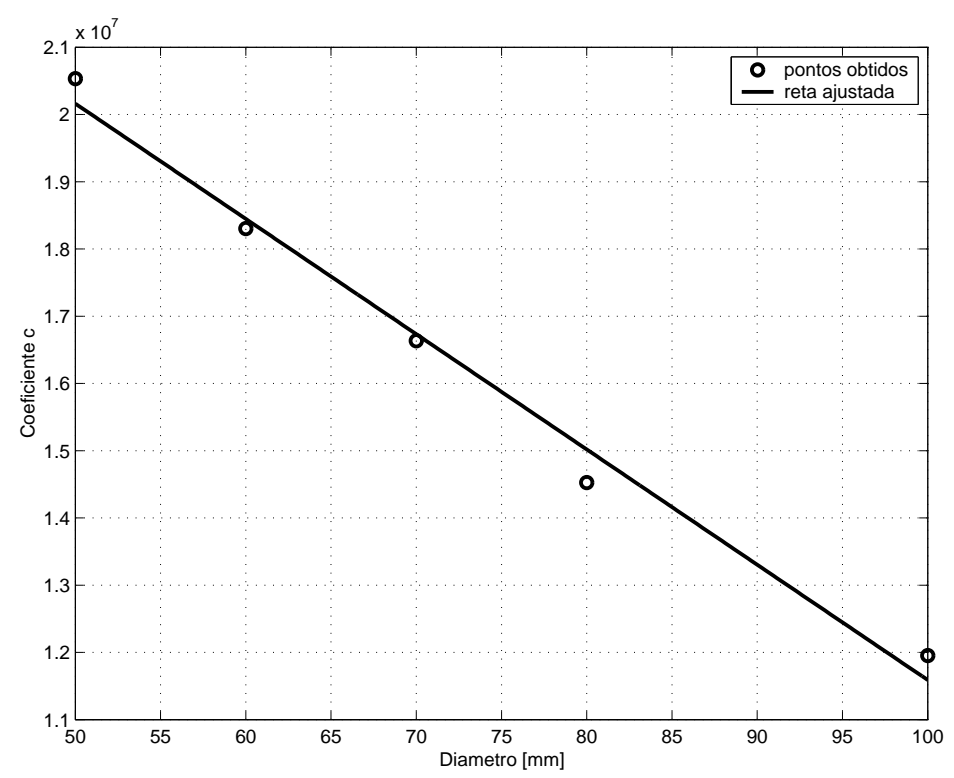

Figura 6.35: Curva ajustada pela regressão linear 


\section{Passo (6) - Solução}

No presente exemplo, para a determinação da tensão admissível, $\sigma_{a d m}$, adotouse um coeficiente de segurança $C S=1.4$ e a tensão perigosa $T P=250[\mathrm{MPa}]$. Desta forma:

$$
\sigma_{a d m}=\frac{T P}{C S} \Rightarrow \sigma_{a d m}=178.57 \quad[\mathrm{MPa}]
$$

Aplicando-se este valor na equação padrão da superfície de tensão máxima, com os coeficientes $a=0.5$ e $b=1.0$ encontra-se:

$$
\sigma_{\max }=c \cdot m^{a} \cdot v^{b} \Rightarrow c=\frac{178.57 \cdot 10^{6}}{1000^{0.5} \cdot 0.3^{1}} \quad \Rightarrow \quad c=18.82 \cdot 10^{6} \quad\left[\mathrm{Kg}^{0.5} / \mathrm{m}^{2} \mathrm{~s}\right]
$$

Finalmente, com o valor do coeficiente $c$ substituído na equação 6.6 tem-se $h=57.82[\mathrm{~mm}]$. Adotando-se então o valor de $\phi_{2}=58[\mathrm{~mm}]$ para a modelagem obteve-se $\sigma_{\max }=179[\mathrm{MPa}]$, ou seja, praticamente o valor esperado de 178.57 [MPa]. A figura abaixo ilustra a distribuição da tensão equivalente na região de interesse e sua a variação ao longo da linha de nós para este caso.

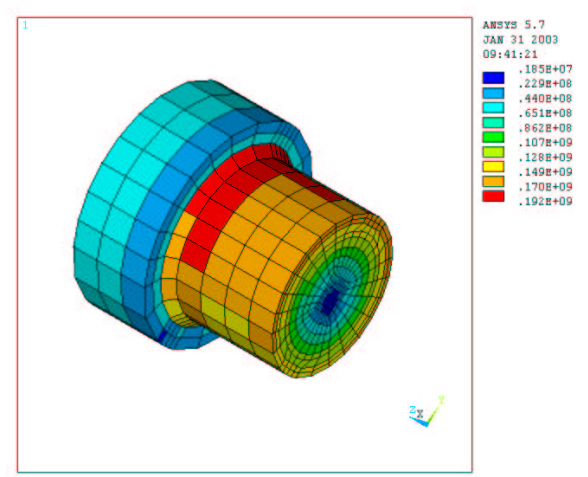

Figura 6.36: Distribuição de tensão na região de interesse $-\phi_{2}=58[\mathrm{~mm}]$

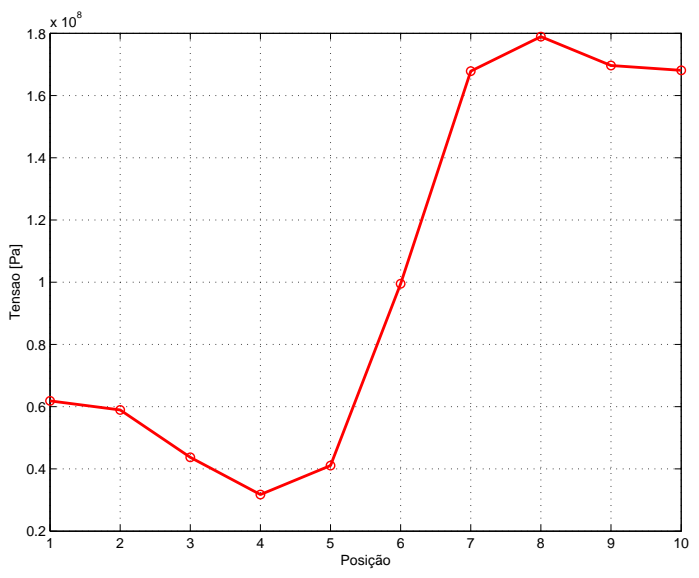

Figura 6.37: Variação da tensão ao longo da linha de nós 


\section{Capítulo 7}

\section{Conclusões}

Os objetivos propostos para o trabalho foram alcançados. A teoria de propagação de ondas de tensão elásticas apresentada no capítulo 2, permitiu um melhor entendimento das simplificações e hipóteses adotadas para o desenvolvimento de expressões da tensão devido ao impacto. Pode-se notar a dificuldade em resolver as equaçõs diferenciais que regem o problema. Mesmo em casos com geometrias definida e condições de contorno simples, como o cilíndro, a solução exata do ponto de vista da teoria da elasticidade foi extremamente complicada, justificando-se a necessidade do uso do Método dos Elementos Finitos no estudo de estruturas mais complexas.

Os principais enfoques para a determinação das tensões em vigas submetidas ao impacto longitudinal, flexional e torcional de massa rígidas, foram apresentados no capítulo 3. No caso do método da energia as expressões das tensões foram obtidas igualando-se a energia cinética do impactador com a energia potencial elástica da viga, considerando-a como uma mola com rigidez dada em função do tipo de solicitação. O método de propagação de ondas baseou-se em simplificações da teoria clássica. Para o impacto longitudinal e torcional, considerou-se a velocidade de propagação da onda constante e para o caso flexional, a solução foi dada a partir da equação de Euller-Bernoulli. 
A solução de problemas dinâmicos, associados ao impacto, pela integração implícita e explícita no tempo foi discutida no capítulo 4. A questão do contato que foi a não linearidade presente nas modelagens também foi comentada.

No capítulo 5 foram realizadas modelagens de impacto em vigas utilizando-se o MEF. Os resultados obtidos para cada caso foram comparados com os fornecidos pelos enfoques discutidos no capítulo 3. Tais resultados demonstraram-se satisfatórios indicando que a solução do problema dinâmico, associado ao impacto, pela integração explícita no tempo foi capaz de reproduzir o fenômeno de propagação de ondas. Também no capítulo 5, apresentou-se as superfícies de tensão máxima, que representam um conjuntos de situações de impacto na qual a massa $m$ e a velocidade $v$ do impactador assumem valores conhecidos dentro de um intervalo. Conforme já constatado em TEIXEIRA (2002), a tensão máxima devido ao impacto nos casos modelados, é aproximadamente proporcional a raiz quadrada da energia cinética do impactador. Com isso tornou-se possível a elaboração de uma forma padrão para as equações da superfície de tensão máxima.

A metodologia de análise de impacto em sistemas elásticos proposta no capítulo 6, foi desenvolvida a partir desta hipótese. Aplicando-se o MEF com a integração explícita no tempo foi possível estimar-se o valor de um certo parâmetro de interesse para que a máxima de tensão devido ao impacto não ultrapasasse um valor desejado $\left(\sigma_{\max } \leq \sigma_{\text {adm }}\right)$. Nos dois exemplos de aplicação apresentados, a metodologia mostrou-se satisfatória. No caso do suporte, foi obtida uma estimativa para a dimensão $h$ do lado da área da secção transversal que forneceu uma diferença de $1.36 \%$ entre a tensão admissível e a máxima tensão. Para o caso do eixo chavetado, foi obtida uma estimativa para o diâmetro $\phi_{2}$ que praticamente não forneceu diferença entre $\sigma_{\max } \mathrm{e} \sigma_{a d m}$.

Como sugestão para trabalhos futuros, pode-se tentar o aprimoramento da equação padrão da superfície de tensão máxima permitindo o melhor entendimento de seus coeficientes. Também pode-se tentar validar a metodologia proposta por meio de dados experimentais além de melhorar os modelos em estudo inserindo parâmetros como o atrito e o amortecimento nas estruturas. 


\section{Capítulo 8}

\section{Referências Bibliográficas}

AALAMI, B. (1973). Waves in prismatic guides of arbitrary cross section. Journal of Applied Mechanics, v.40, p.1067-1072.

ABRATE, S. (1998). Impact on composites structures. 1.ed. Cambridge, Cambridge University Press.

ACHENBACH, J.D. (1975). Wave propagation in elastic solids. 1.ed. Amsterdam, North-Holland.

APARICIO SÁNCHEZ, C.A. (2001). Estudo de impacto usando elementos finitos e análise não linear. São Carlos, 129p. Dissertação (Mestrado) - Escola de Engenharia de São Carlos, Universidade de São Paulo.

BATHE, K.J. (1995). Finite element procedures. 1.ed. Upper Saddle River, Prentice Hall.

BLACK, P.H. (1955). Machine Design. 2.ed. New York, McGraw-Hill.

CHRISTON, M.A. (1999). The influence of the mass matrix on the dispersive nature of the semi-discrete, second order wave equation. Computer Methods in Applied Mechanics and Engineering, v.173, p.147-166.

DAVIES, R.M. (1948). Stress waves in solids. In Cambridge Monographs on Mechanics and Applied Mathematics. p.64-138. 
FARAHANI, K.; MOFID, M.; VAFAI, A. (2000). A solution method for general contact-impact problems. Computer Methods in Applied Mechanics and Engineering, n.1-2, v.187, p.69-77, Jun.

FAIRES, V.M. (1975). Elementos orgânicos de máquinas. 1.ed. Rio de Janeiro, Livros técnicose científicos.

FRASER, W.B. (1969). Stress wave propagation in rectangular bars. International Journal of Solids and Structures, v.5, p.379-397.

GOLDSMITH, W. (1960). Impact: The theory and physical behaviour of colliding solids. 1.ed. London, Edward Arnold.

GRAFF, K.F. (1975). Wave motion in elastic solids. 1.ed. New York, Dover Publications.

HALLQUIST, J.O. (1993). LS-Dyna-3D Theoretical Manual. 2.ed. Livermore, USA. Livermore Software.

HEINSTEIN, M.W. et al. (2000). Contact-impact modeling in explicit transient dynamics. Computer Methods in Applied Mechanics and Engineering, v.187, p.621640.

HUEBNER, K.H.; THORNTON, E.A.; BYROM, T.G. (1994). The finite element method for engineers. 3.ed. New York, John Wiley.

JOHNSON, W. (1972). Impact strength of materials. 1.ed. Londres, Edward Arnold.

JONES, N.L. (1997). Structural Impact. 1.ed. Cambridge, Cambridge University Press.

KARAGIOZOVA, D.; ALVES, M.; NORMAN, J. (2000). Inertia effects in axisymmetrically deformed cylindrical shells under axial impact. International Journal of Impact Engineering, v.24, p.1083-1115.

KOLSKY, H. (1963). Stress Waves in Solids. 1.ed New York, Dover Publications. 


\section{CAPÍTULO 8. REFERÊNCIAS BIBLIOGRÁFICAS 107}

KRENK, S. (2001). Dispersion-corrected explicit integration of the wave equation. Computer Methods in Applied Mechanics and Engineering, v.191, p.975-987.

LIRANI, J. (2002). Notas de aula do curso de pós graduação SEM-754 Elementos Finitos II, Departamento de Engenharia Mecânica, EESC-USP.

LIU, K.; LI, B. (2000). Torsional stress wave propagation in orthotropic bar of rectangular cross section. Computer Methods in Applied Mechanics and Engineering, v.190, p.1187-1196.

LOVE, A.E.H. (1934). On treatise on the mathematical theory of elasticity. 4.ed. Cambridge, Cambridge University Press.

MACDONALD, B.J. (2002). A computacional and experimental analysis of high energy impact to sheet metal aircraft structures. Journal of Materials Processing Technology, v.124, p.92-98.

MINDLIN, R.D.; FOX, E.A. (1960). Vibrations and wave in elastic bars of rectangular cross section. Journal of Applied Mechanics, v.27, p.152-158.

MORSE, R.W. (1950). The velocity of compressional waves in rods of rectangular cross section. The Journal of the Acoustical Society of America, v.22, p.219-223.

MOTTERSHEAD, J.E.; PASCOE, S.K.; ENGLISH, R.G. (1992). A general finite element approach for contact stress analysis. International Journal for Numerical Methods in Engineering, v.33, p.765-779.

NAYFEH, A.H.; ABDELRAHMAN, W.G. (2000). An approximate model for wave propagation in rectangular rods and their geometric limits. Journal of Vibration and Control, v.6, p.3-17.

NIGRO, N.J. (1966). Steady state wave propagation in infinite bars of noncircular cross section. The Journal of the Acoustical Society of America, v.40, p.15011508. 
OWEN, D.R.J.; HINTON, E. (1980). Finite elements in plasticity: Theory and Practice. 2.ed. Swansea, Pineridge Press.

SCHREYER, H.L. (1983). Dispersion of semidiscretized and fully discretized systems. In Computational Methods for Transient Analysis. Amsterdam, NorthHolland. Cap. 6, p.267-299.

SERON, F.J. et al. (1990). Finite element method for elastic wave propagation. Communications in Applied Numerical Methods, v.6, p.359-368.

SHIGLEY, J.E. (1980). Theory of machines and mechanisms. 1.ed. London, MacGraw-Hill.

SPOTTS, M.F.; SHOUP, T.E. (1998). Design of machine elements. 7.ed. New Jersey, Prentice Hall.

STRONGE, W.J. (2000). Impact Mechanics. 1.ed. Cambridge, Cambridge University Press.

TEIXEIRA, G. M. (2002). Análise de impacto em vigas usando-se o método de integração explícita no tempo. São Carlos, 142p. Dissertação (Mestrado)-Escola de Engenharia de São Carlos, Universidade de São Paulo.

TIMOSHENKO, S.P.; GOODIER, J.N. (1980). Teoria da Elasticidade. 3.ed. Rio de Janeiro, Guanabara Dois.

TITA, V. CARVALHO, J. (2001). Impact study on composite materials using Finite Element Method. (CD Rom) In: XIII INTERNATIONAL CONFERENCE ON COMPOSITE MATERIALS (ICCM 2001), Bejing, 2001. Anais. China.

WRIGHT, J.P. (1998). Numerical instability due to varying time steps in explicit wave propagation and mechanics calculations. Journal of Computacional Physics, v.140, p.421-431.

ZIENKIEWICZ, O.C.; TAYLOR, R.L. (2000). The finite element method Solids Mechanics. 5.ed. Boston, Butterworth-Heinemann. 